\title{
Efficient Synthesis of Potential Impurities in Levonadifloxacin (WCK 771)
}

Jaydeo T. Kilbile, Yasinalli Tamboli, Mohammad Rafeeq, Ram Prasad Yadav, Vipul

P. Rane, Vijay S. Bhamare, and Arvind Y. Merwade ${ }^{1 *}$

1. Wockhardt Research Centre, D-4, MIDC, Chikalthana, Aurangabad-431 006, India 


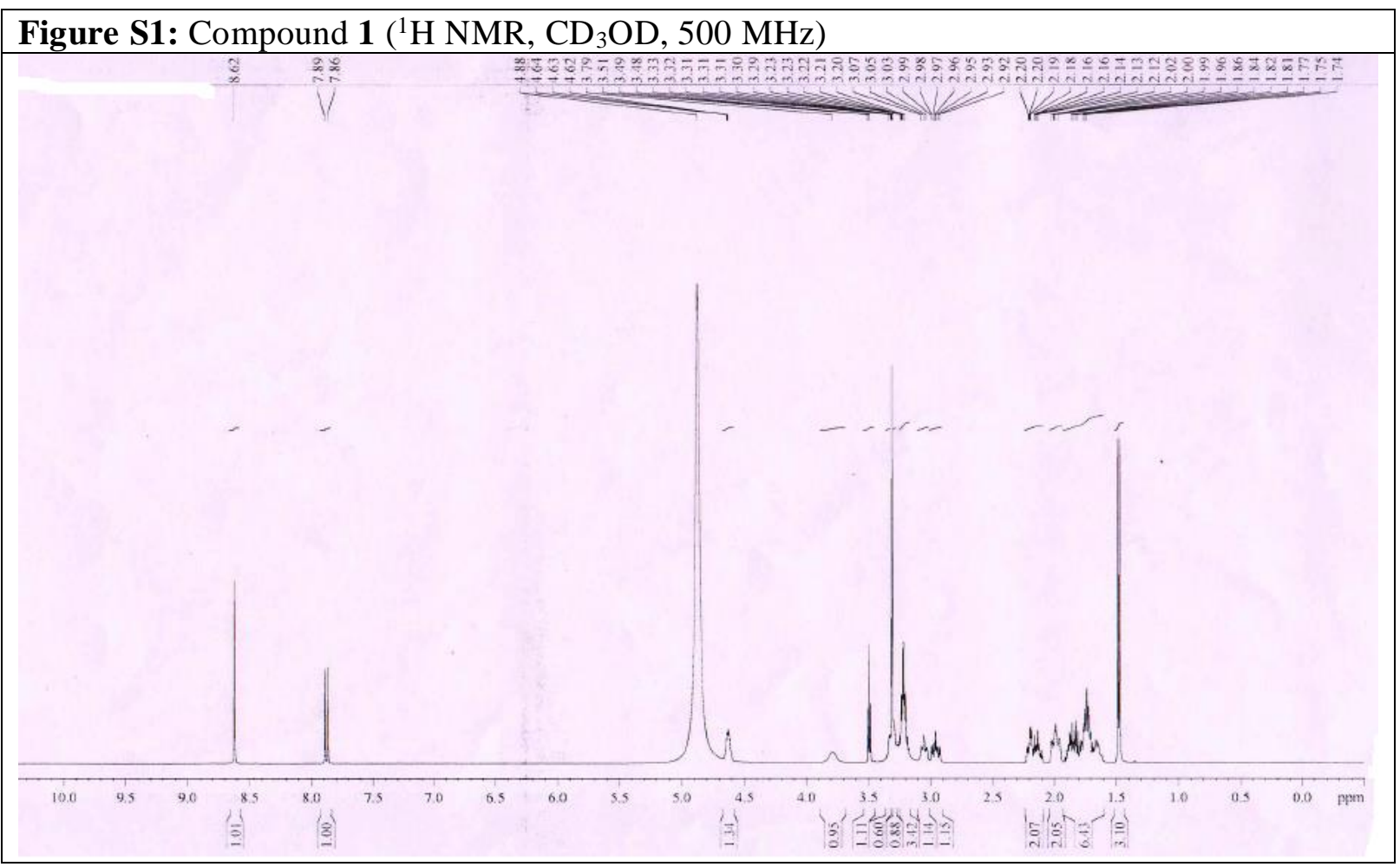

Figure S2: Compound $1\left({ }^{19} \mathrm{~F}\right.$ NMR, $\left.\mathrm{CD}_{3} \mathrm{OD}, 376 \mathrm{MHz}\right)$

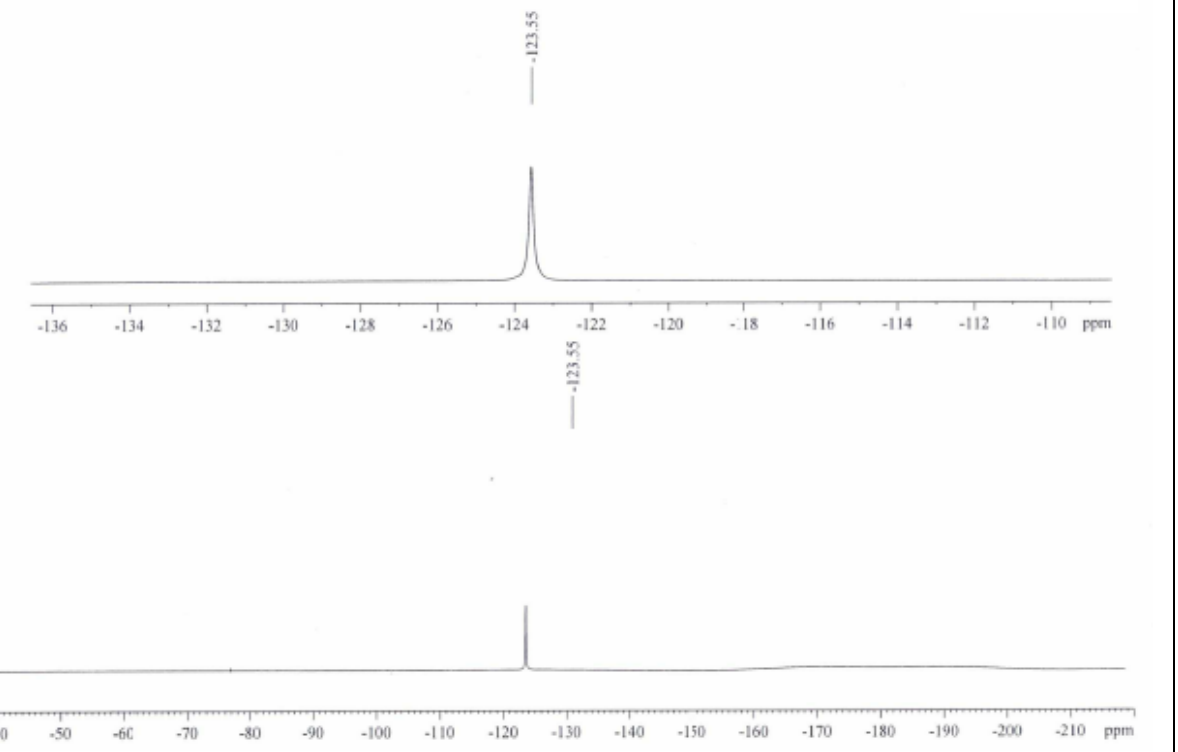

SQ 
Figure S3: Compound $1\left({ }^{13} \mathrm{C}\right.$ NMR, $\left.\mathrm{CD}_{3} \mathrm{OD}, 125 \mathrm{MHz}\right)$

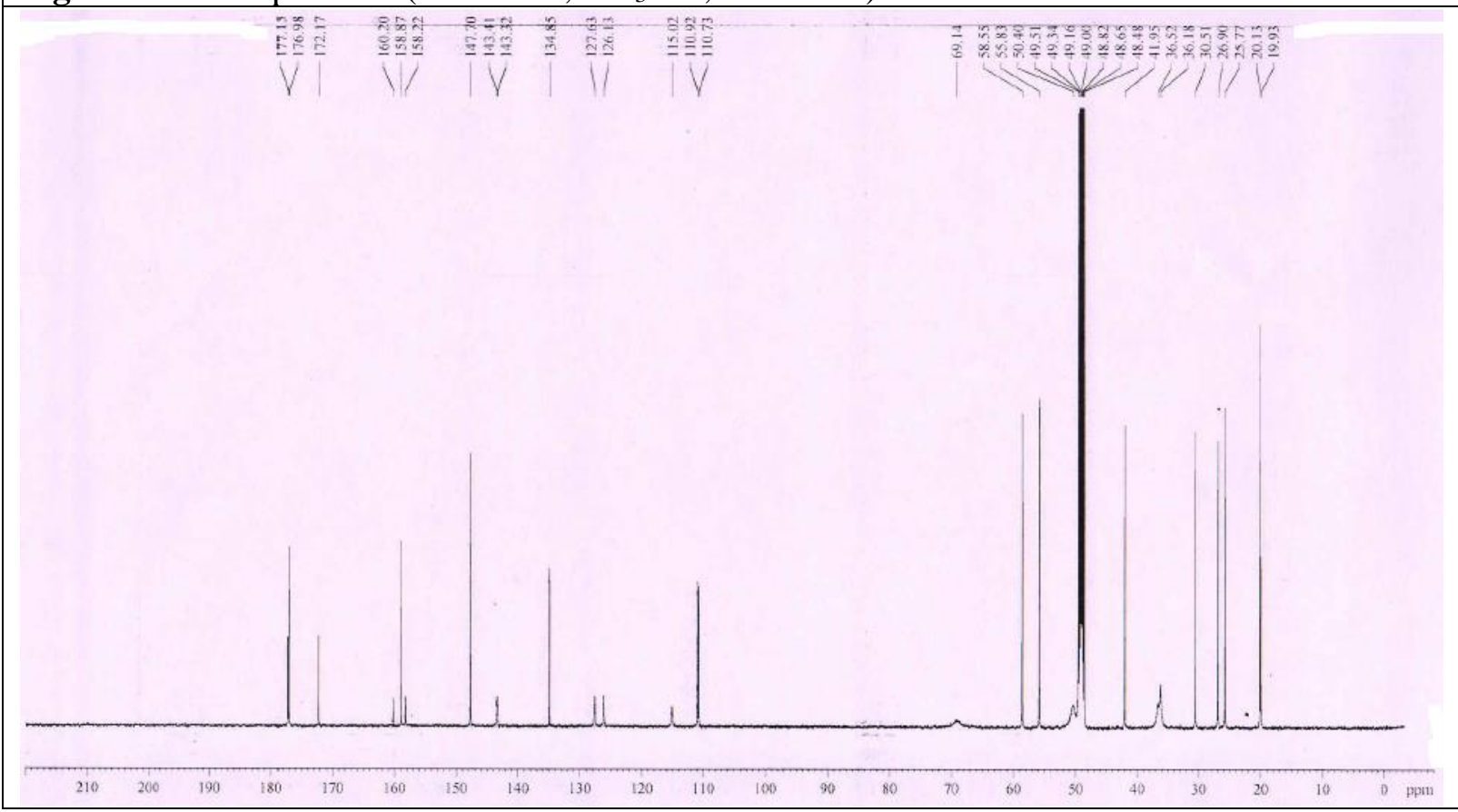

Figure S4: Compound $1\left({ }^{13} \mathrm{C}\right.$ NMR DEPT, $\left.\mathrm{CD}_{3} \mathrm{OD}, 125 \mathrm{MHz}\right)$

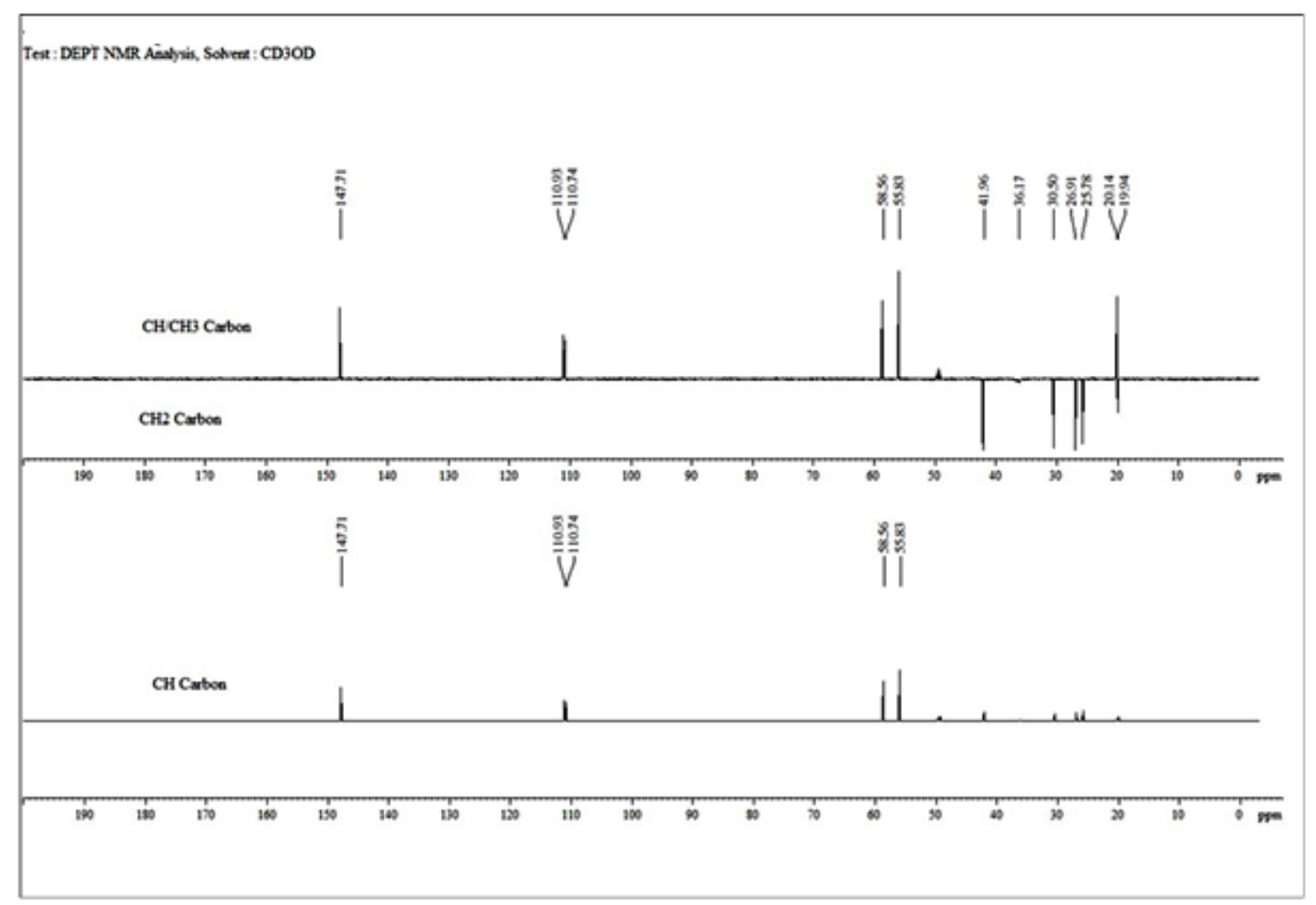


Figure S5: Compound 1 (COSY NMR, $\mathrm{CD}_{3} \mathrm{OD}$ )

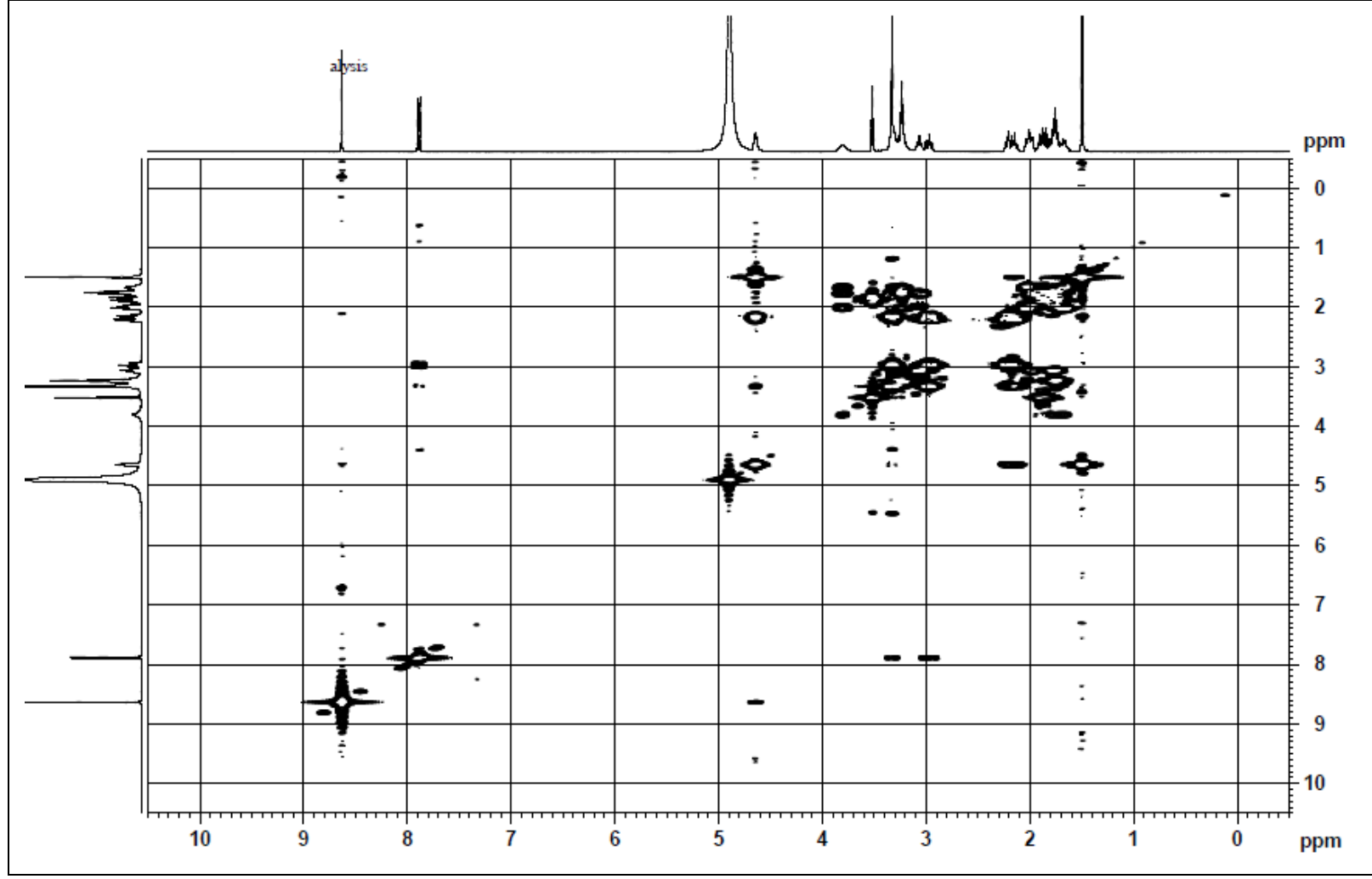

Figure S6: Compound 1 (HSQC NMR, $\mathrm{CD}_{3} \mathrm{OD}$ )

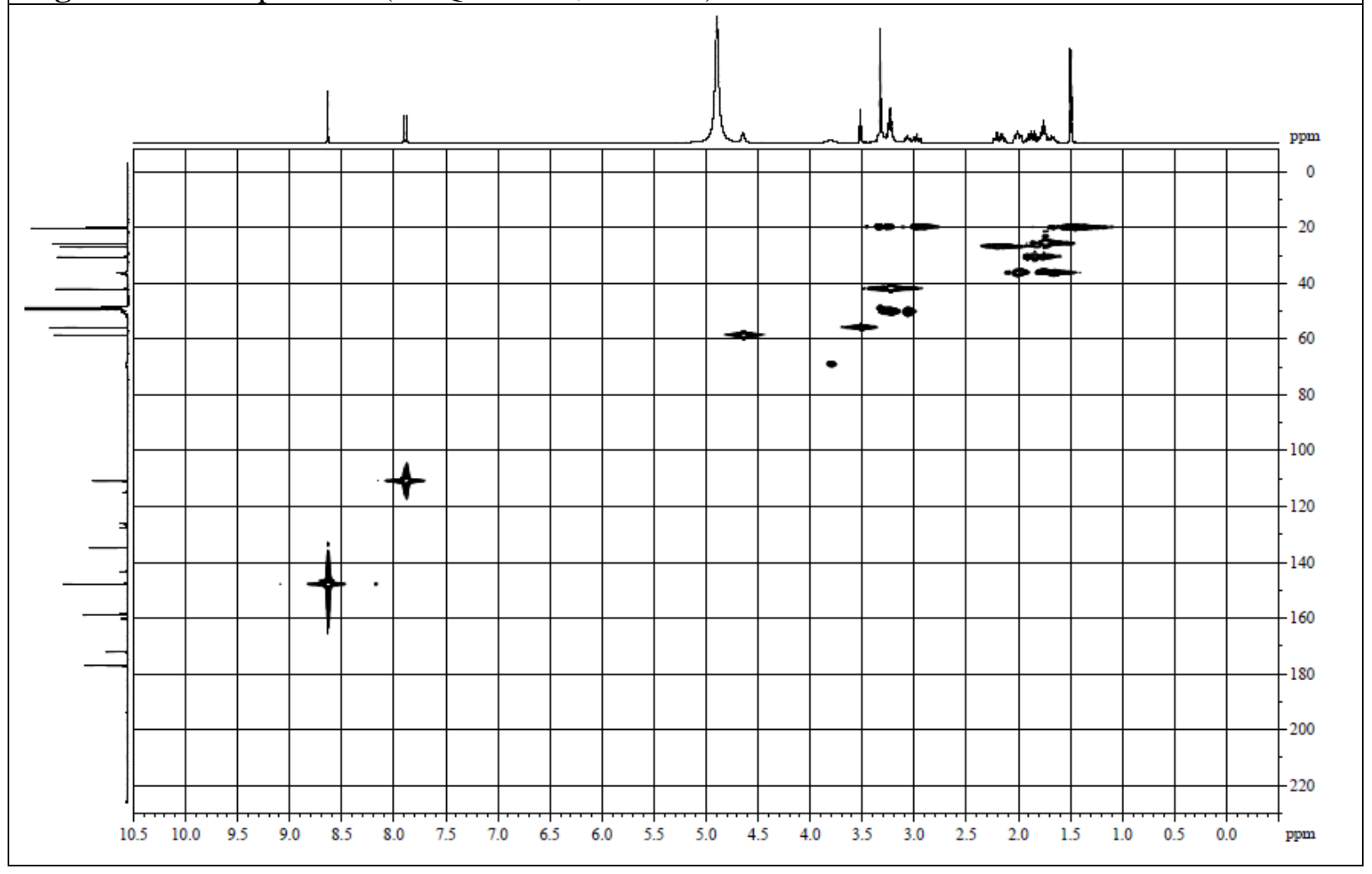




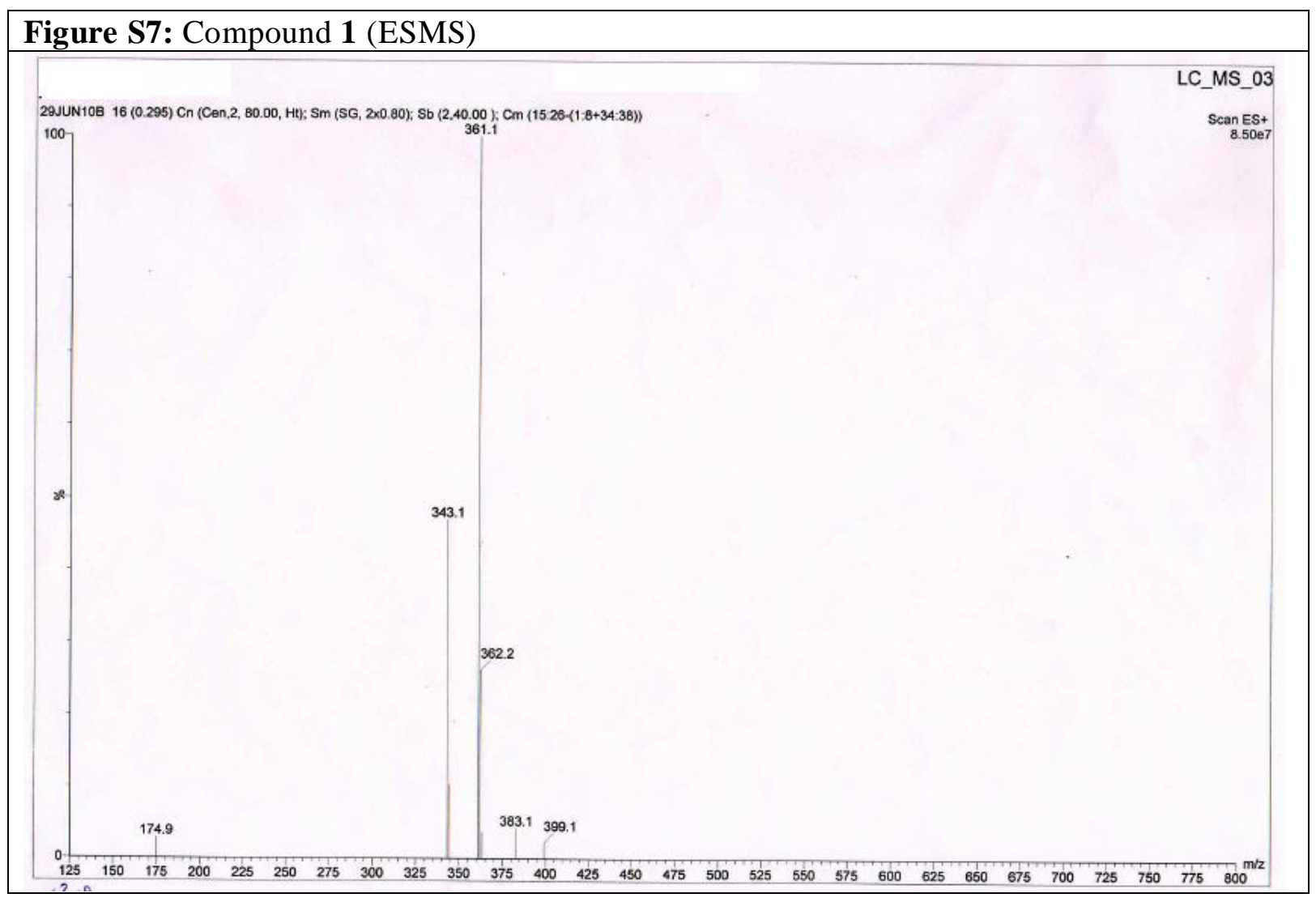

Figure S8: Compound 1 ( IR)

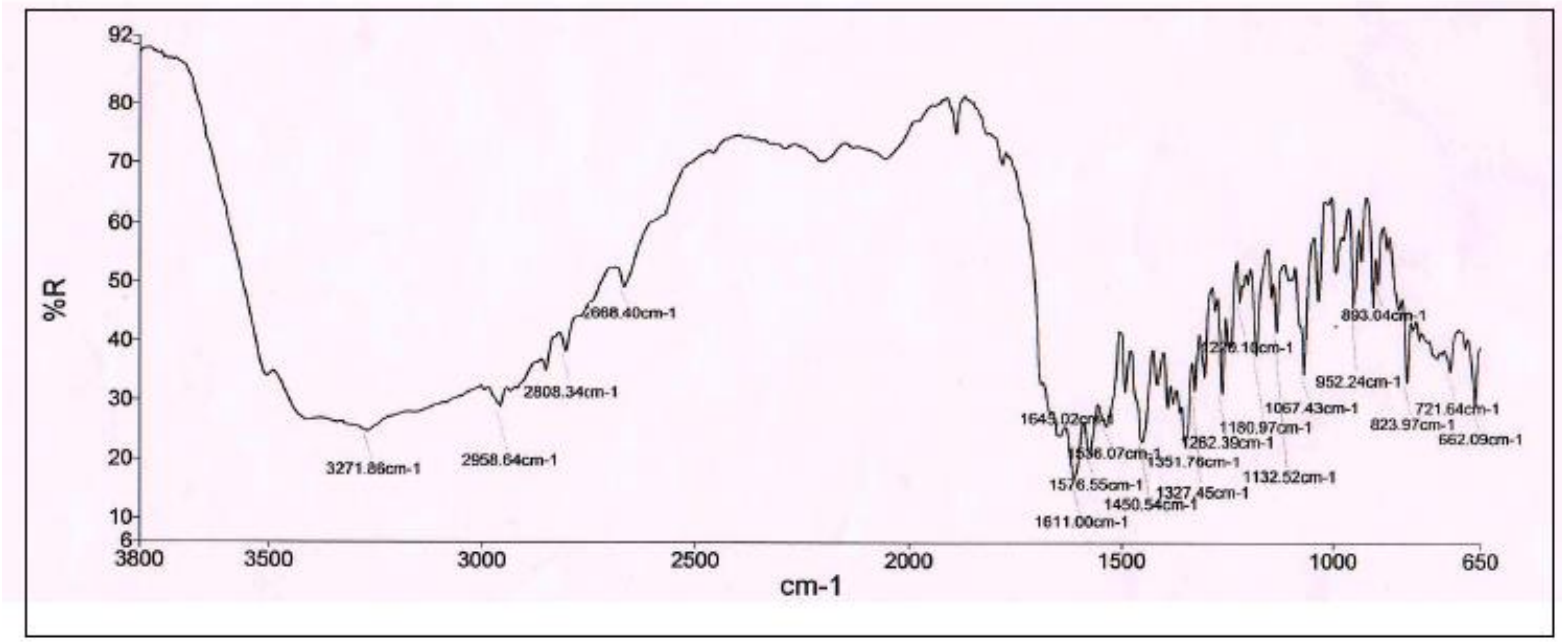




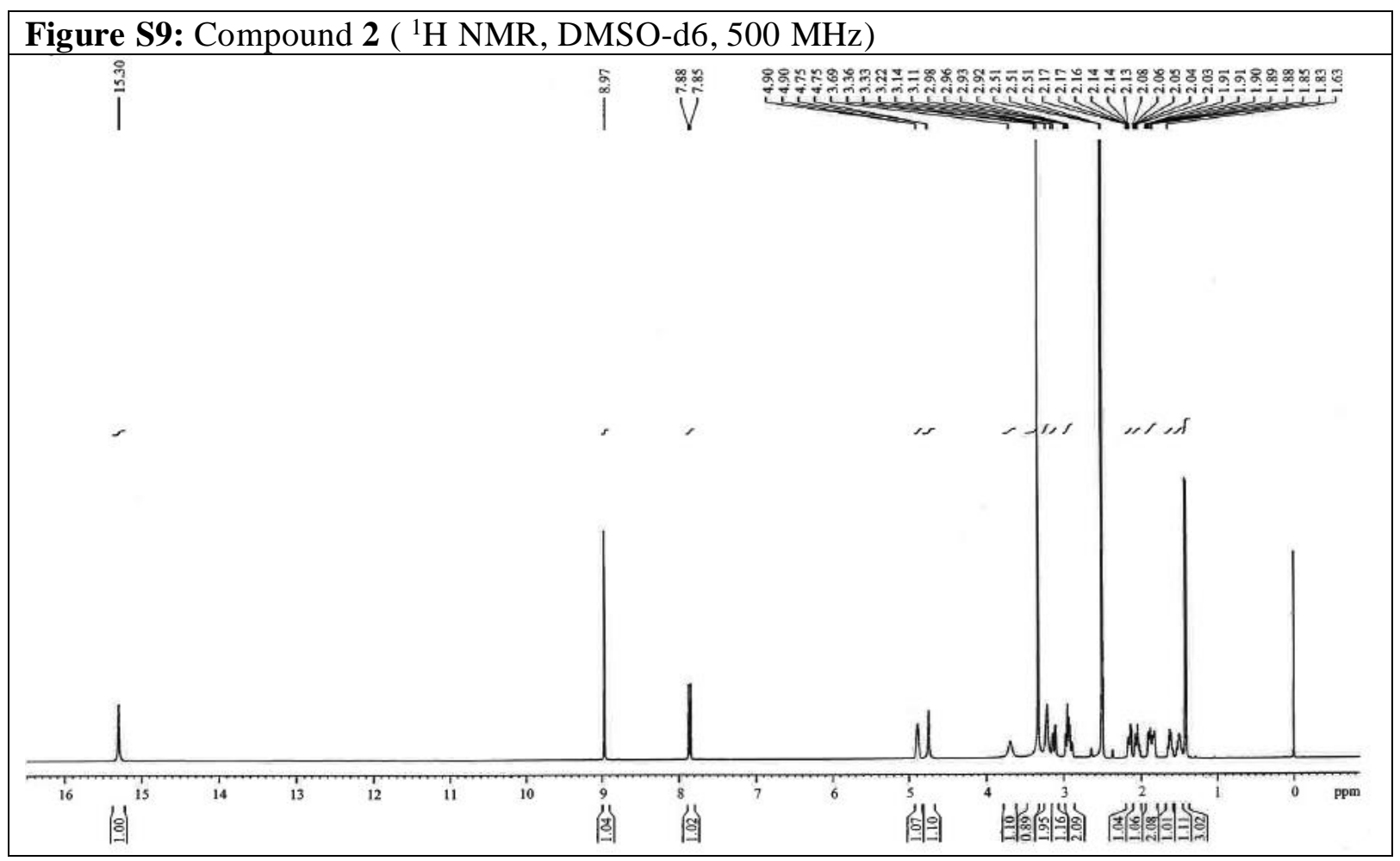

Figure S10: Compound 2 ( ${ }^{19} \mathrm{~F}$ NMR, DMSO-d6, $376 \mathrm{MHz}$ )

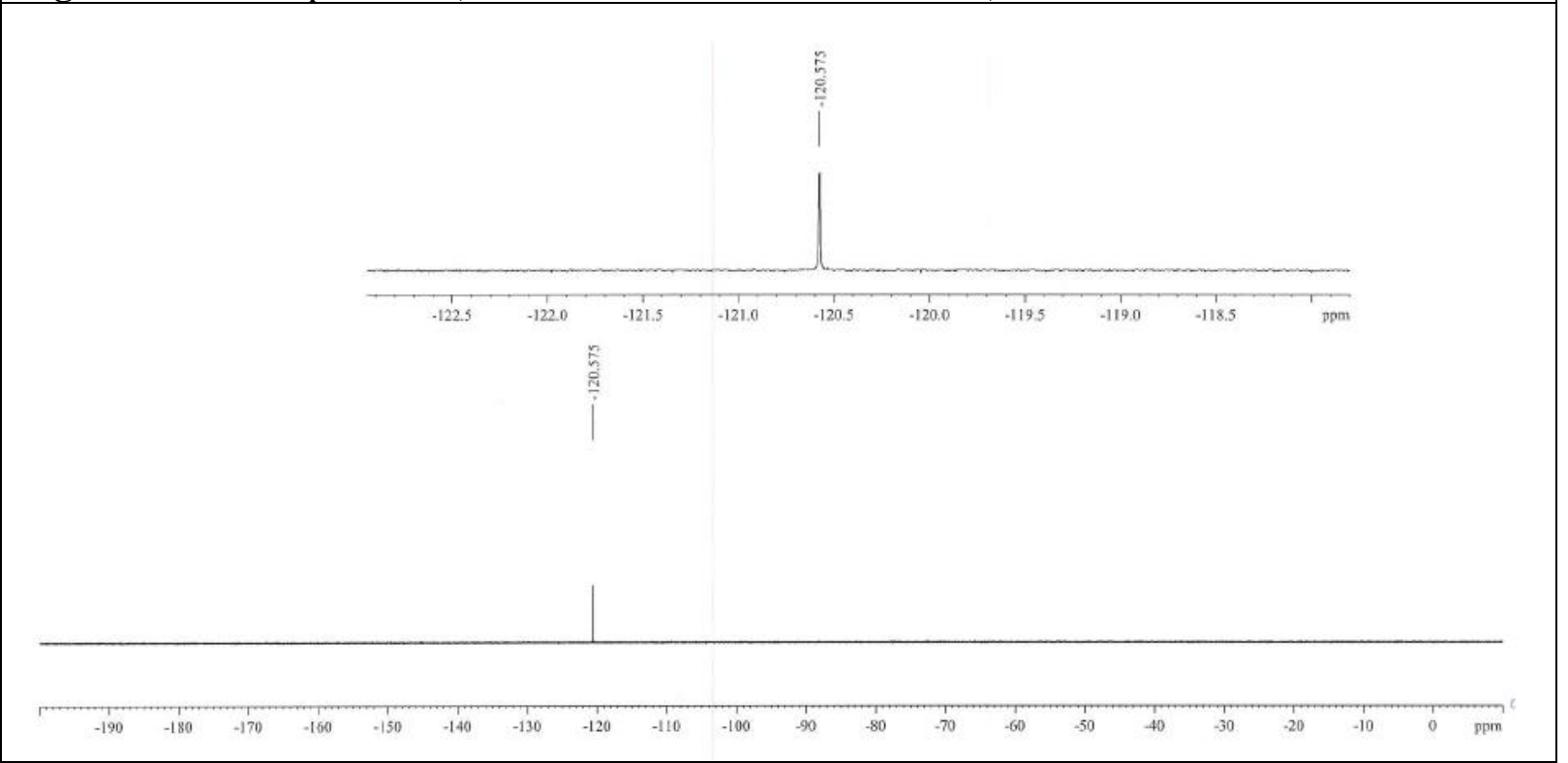




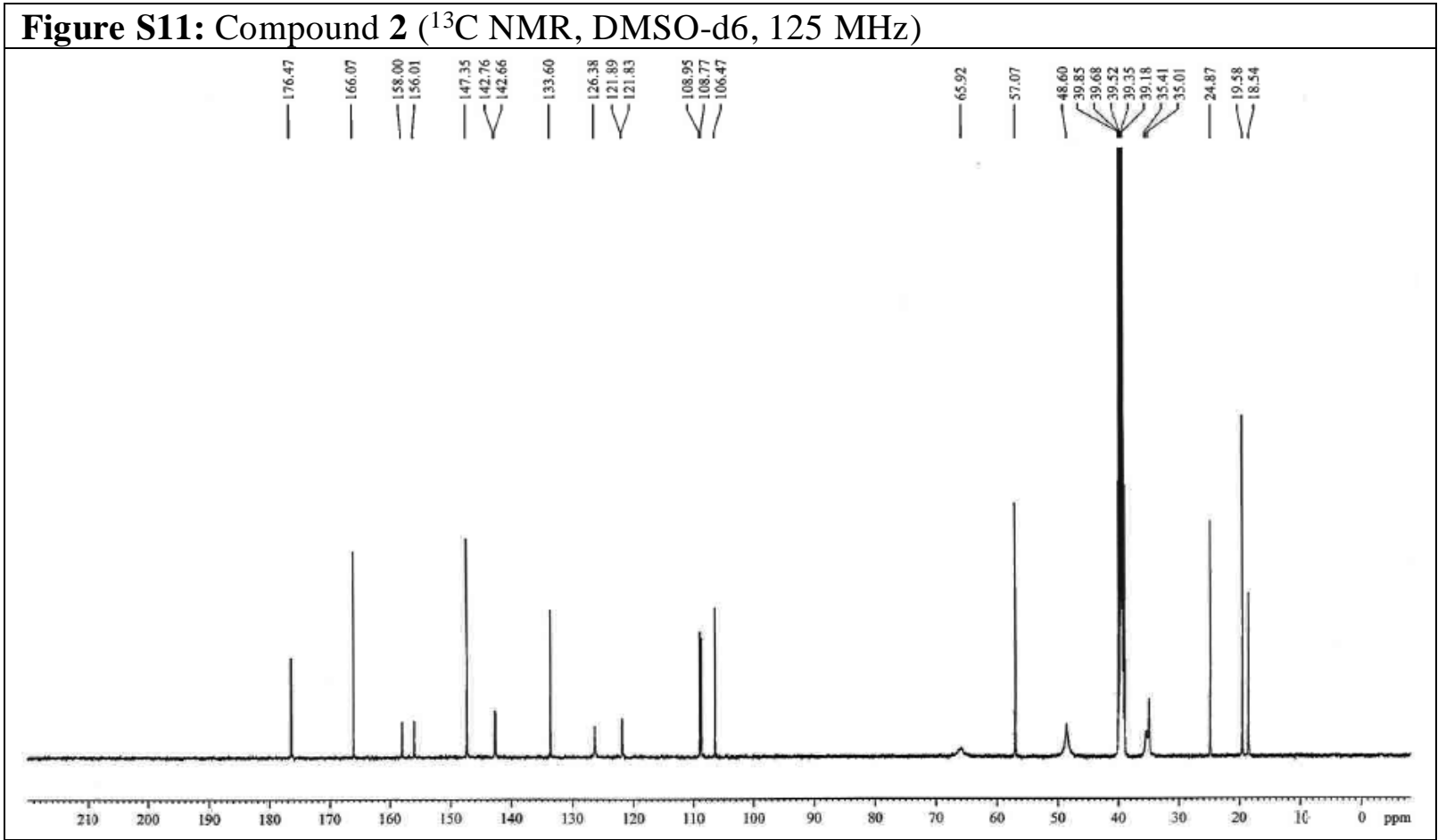

Figure S12: Compound 2 ( ${ }^{13} \mathrm{C}$ NMR DEPT, DMSO-d6, $125 \mathrm{MHz}$ )

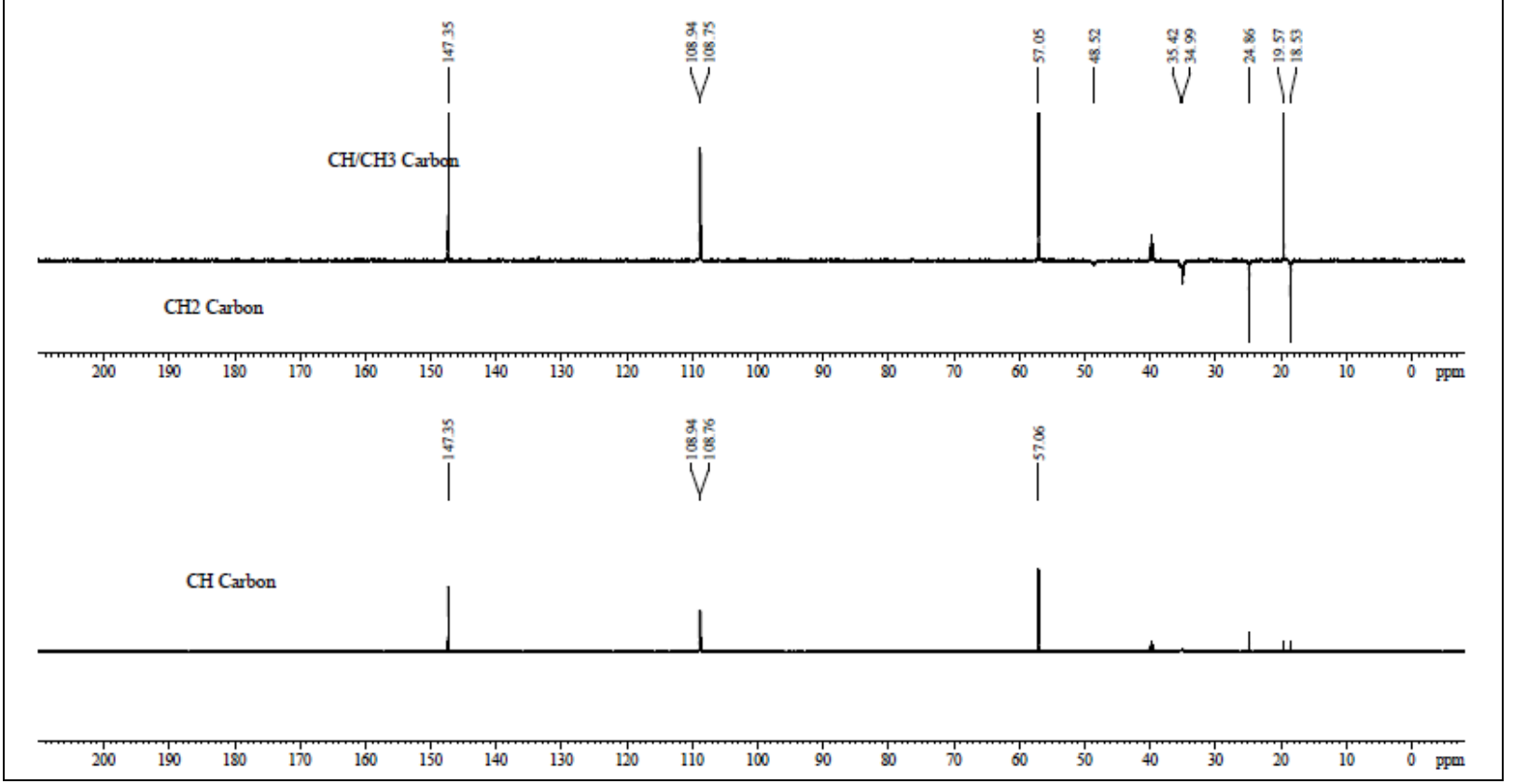




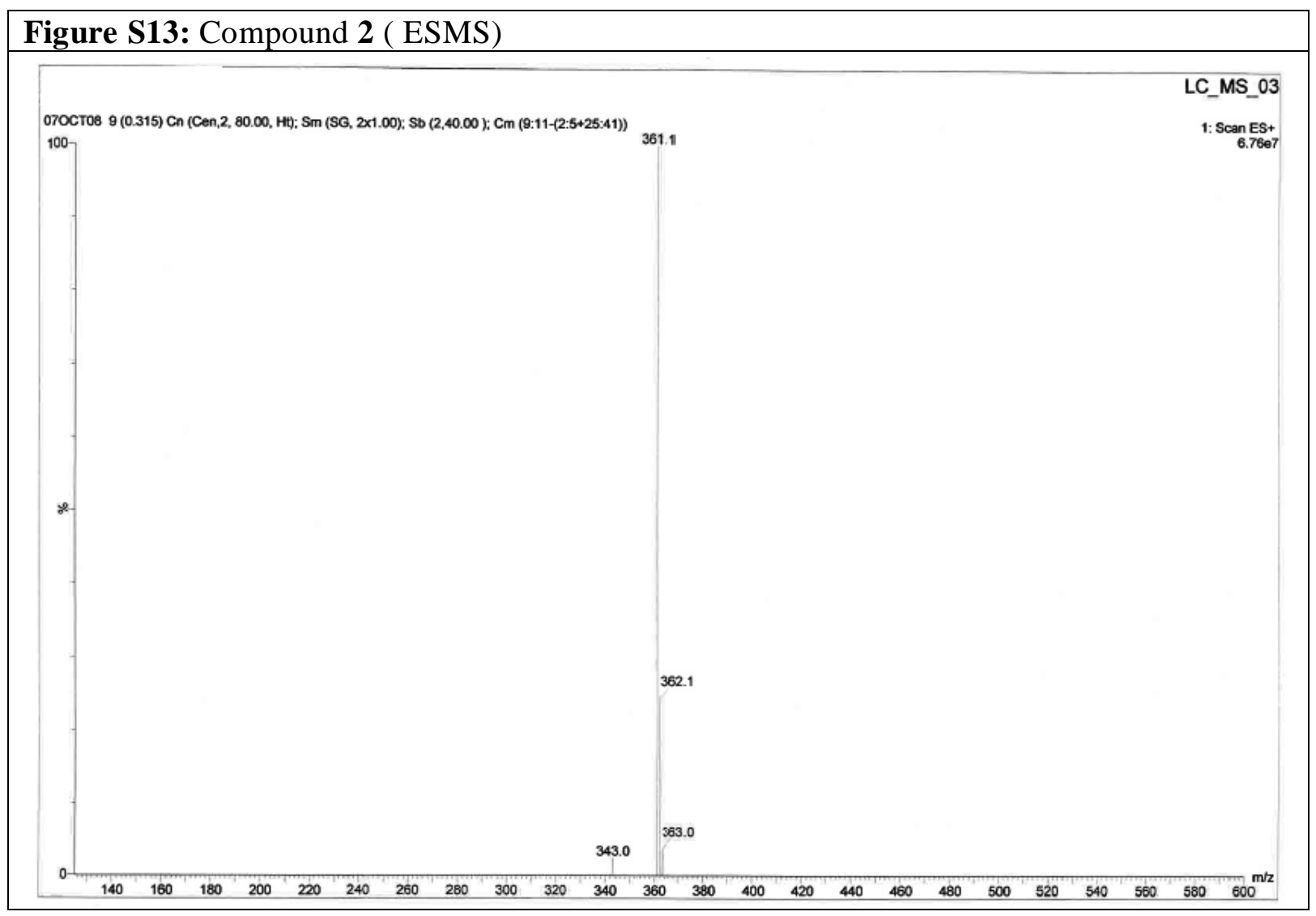

Figure S14: Compound 2 ( IR)

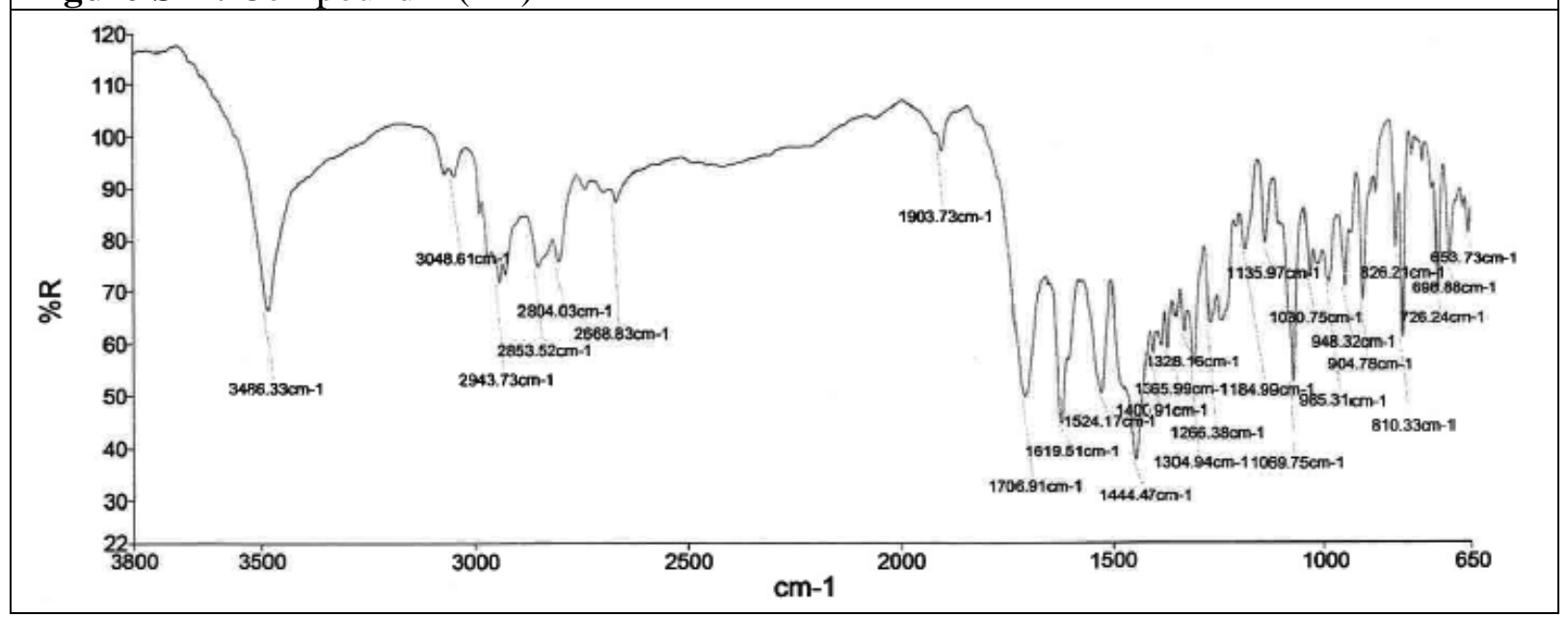


Figure S15: Compound $6\left({ }^{1} \mathrm{H}\right.$ NMR, DMSO-d6, $\left.500 \mathrm{MHz}\right)$

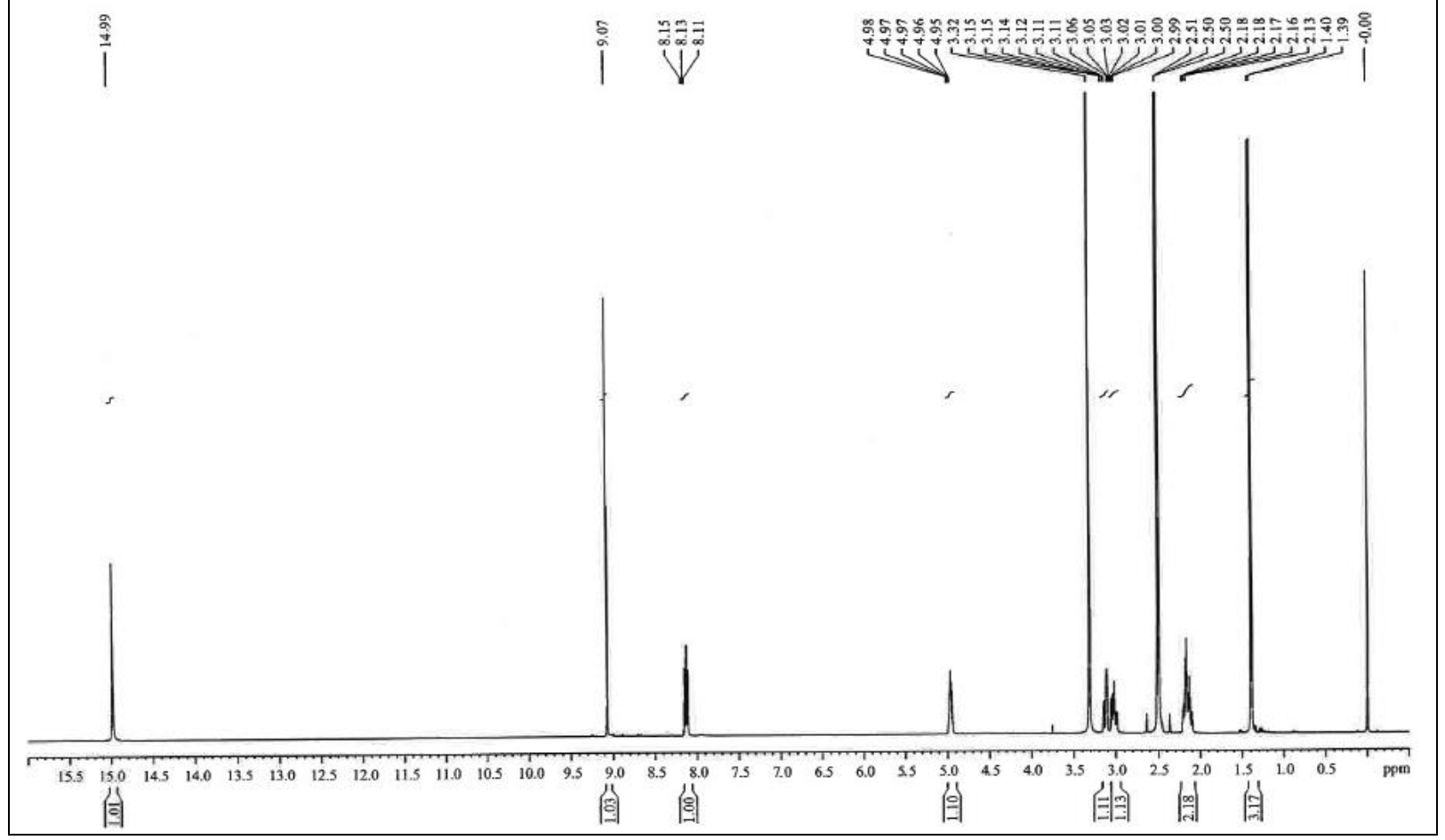

Figure S16: Compound $6\left({ }^{19} \mathrm{~F}\right.$ NMR, DMSO-d6, $\left.376 \mathrm{MHz}\right)$

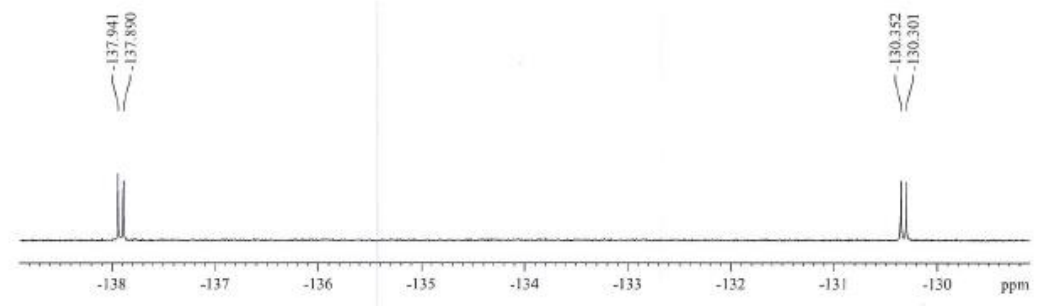

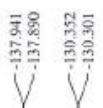

$\begin{array}{ccc}-170 & -160 & -150 \\ -150 & 0\end{array}$

$\begin{array}{llllll}-140 & -130 & -120 & -110 & -100 & -90\end{array}$ 
Figure S17: Compound $6\left({ }^{13} \mathrm{C}\right.$ NMR, DMSO-d6, $\left.125 \mathrm{MHz}\right)$

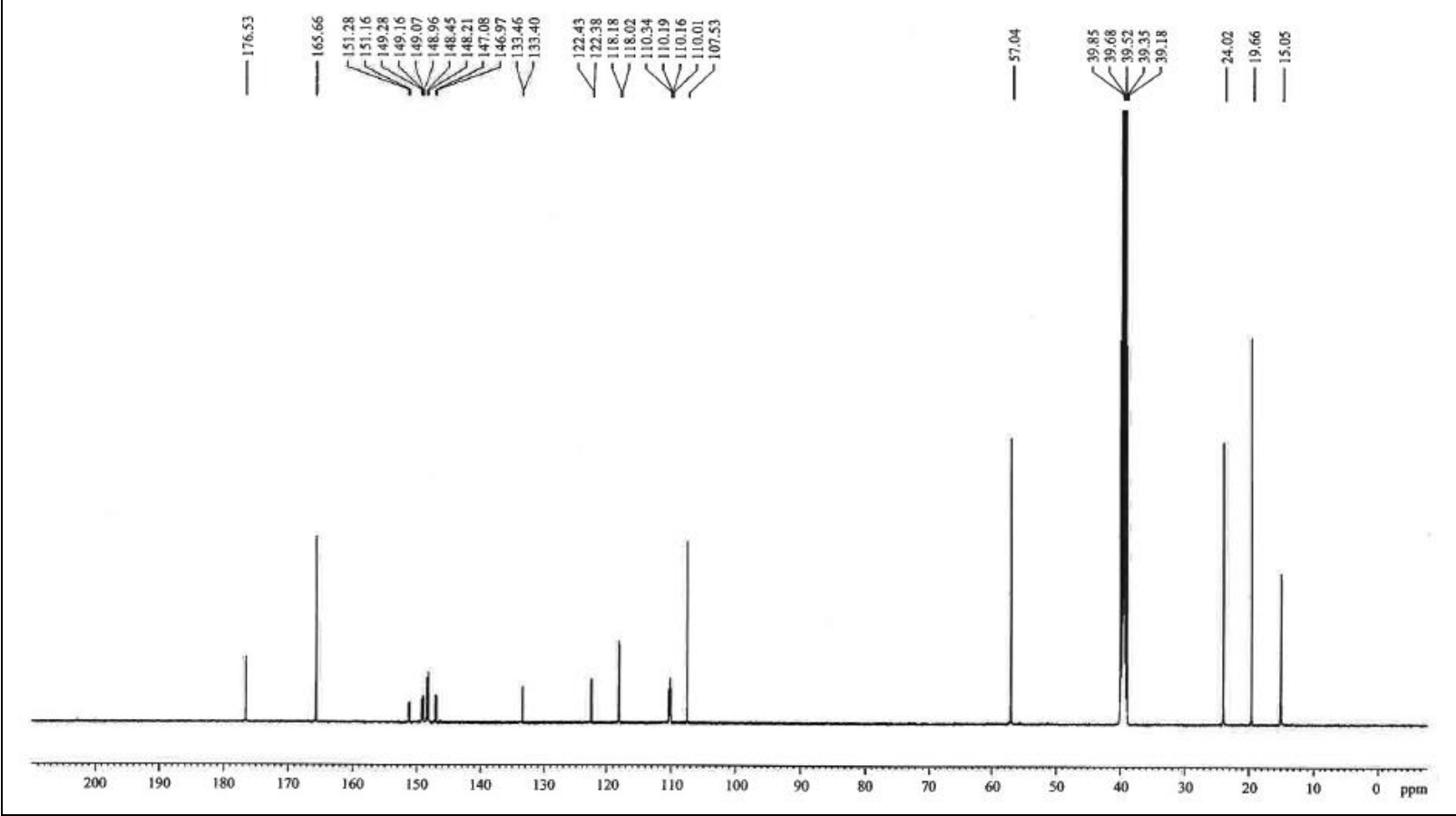

Figure S18: Compound $6\left({ }^{13} \mathrm{C}\right.$ NMR DEPT, DMSO-d6, $\left.125 \mathrm{MHz}\right)$

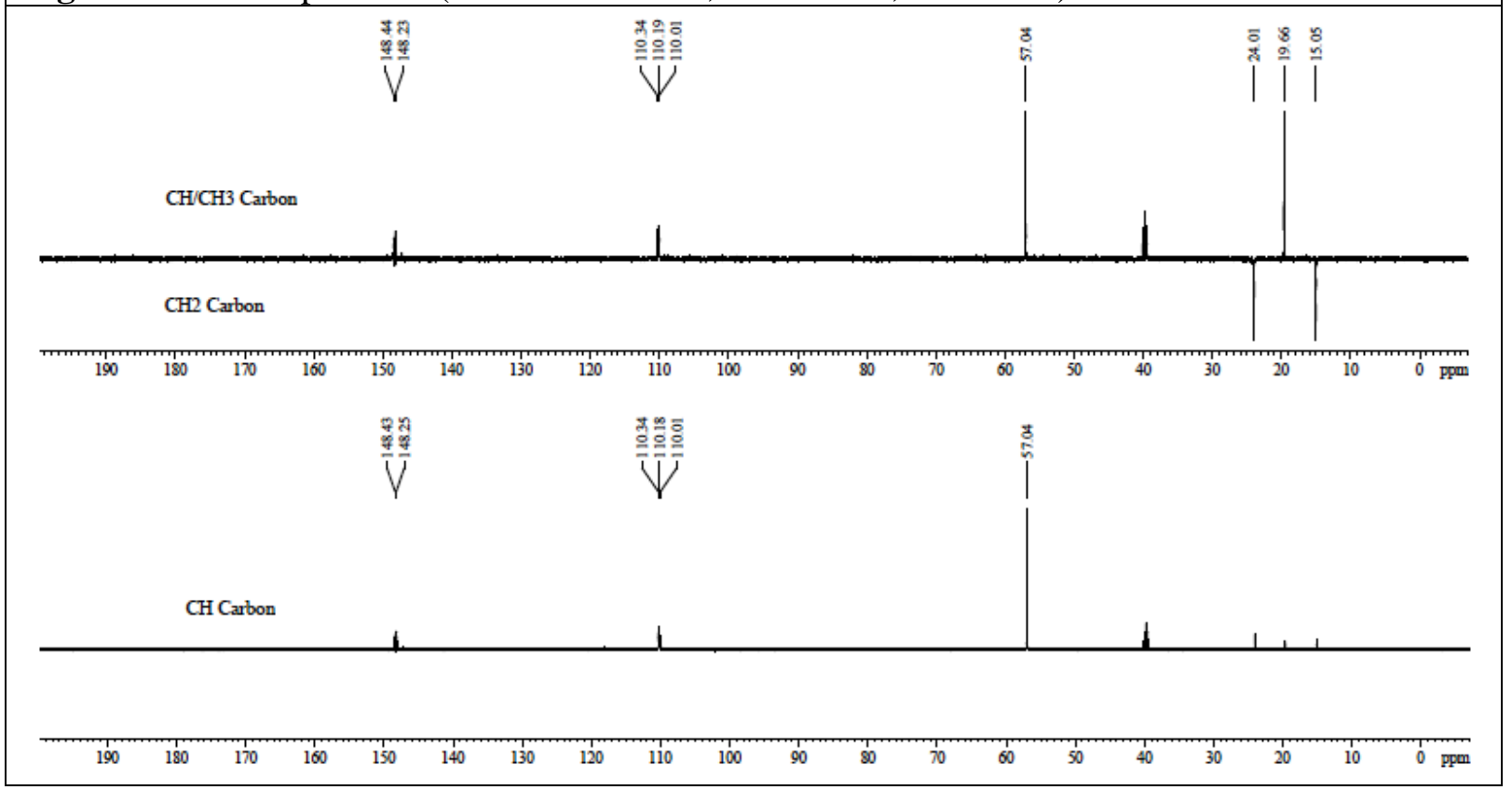



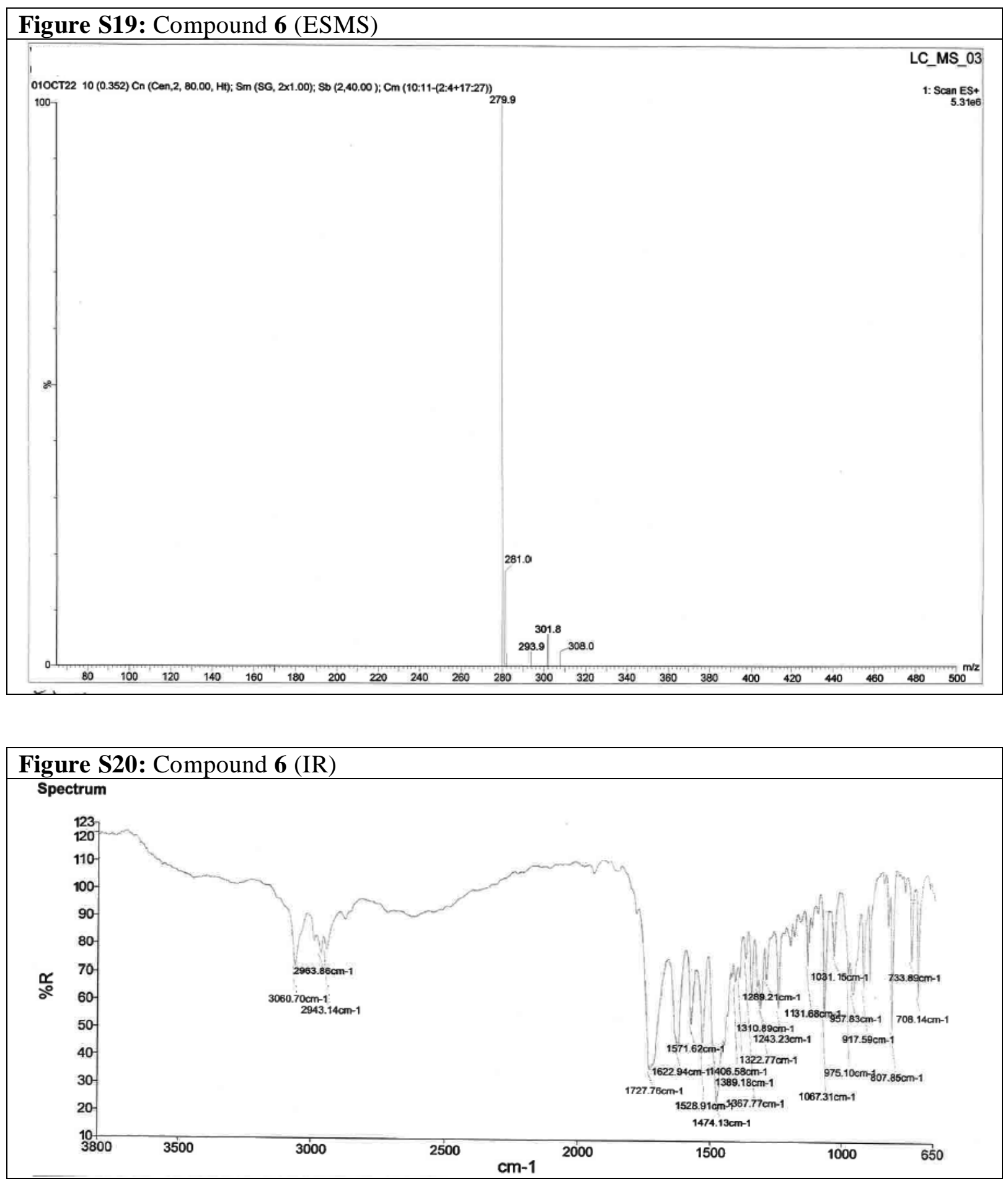


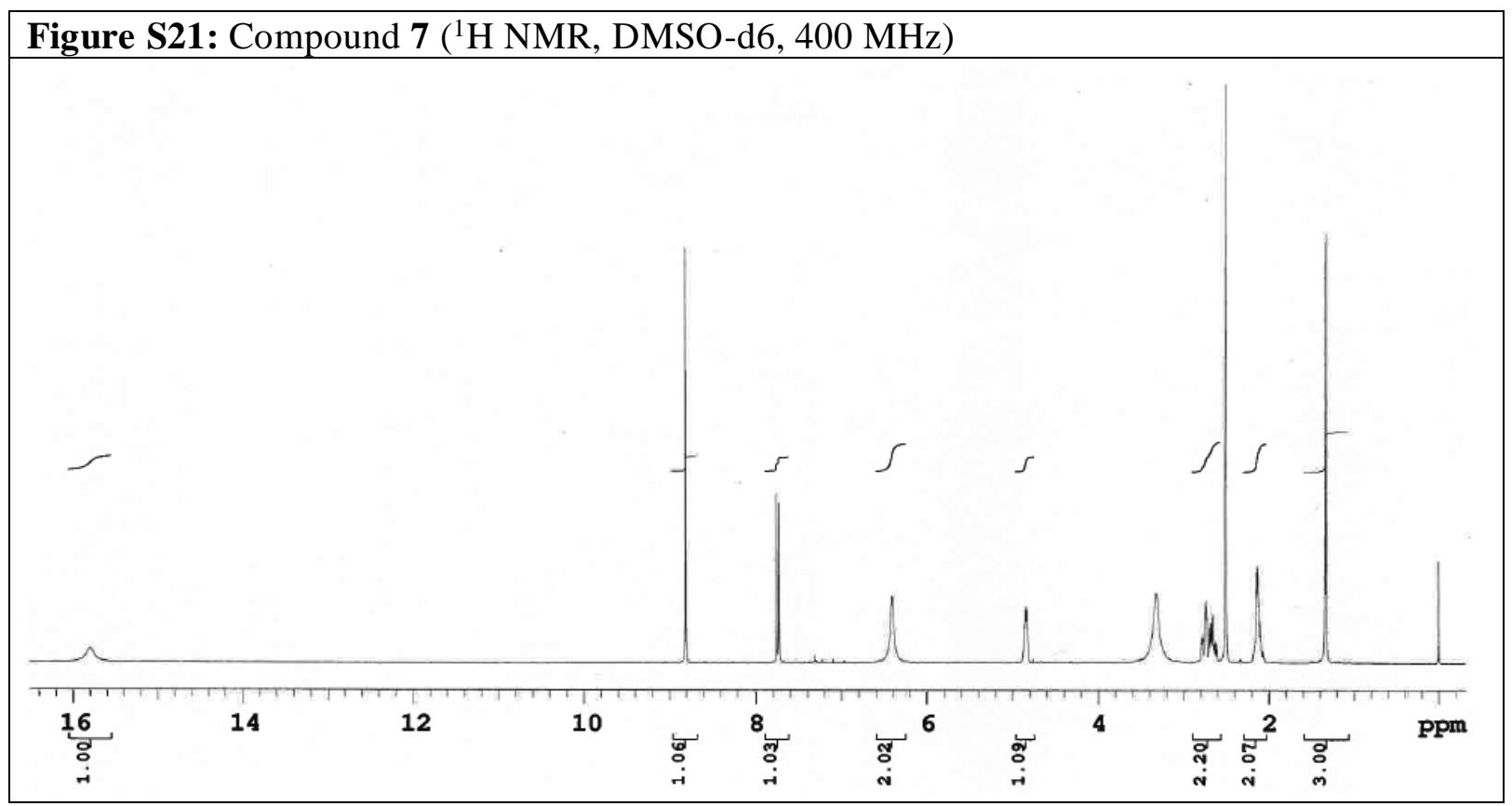

Figure S22: Compound $7\left({ }^{19} \mathrm{~F}\right.$ NMR, DMSO-d6, $\left.376 \mathrm{MHz}\right)$

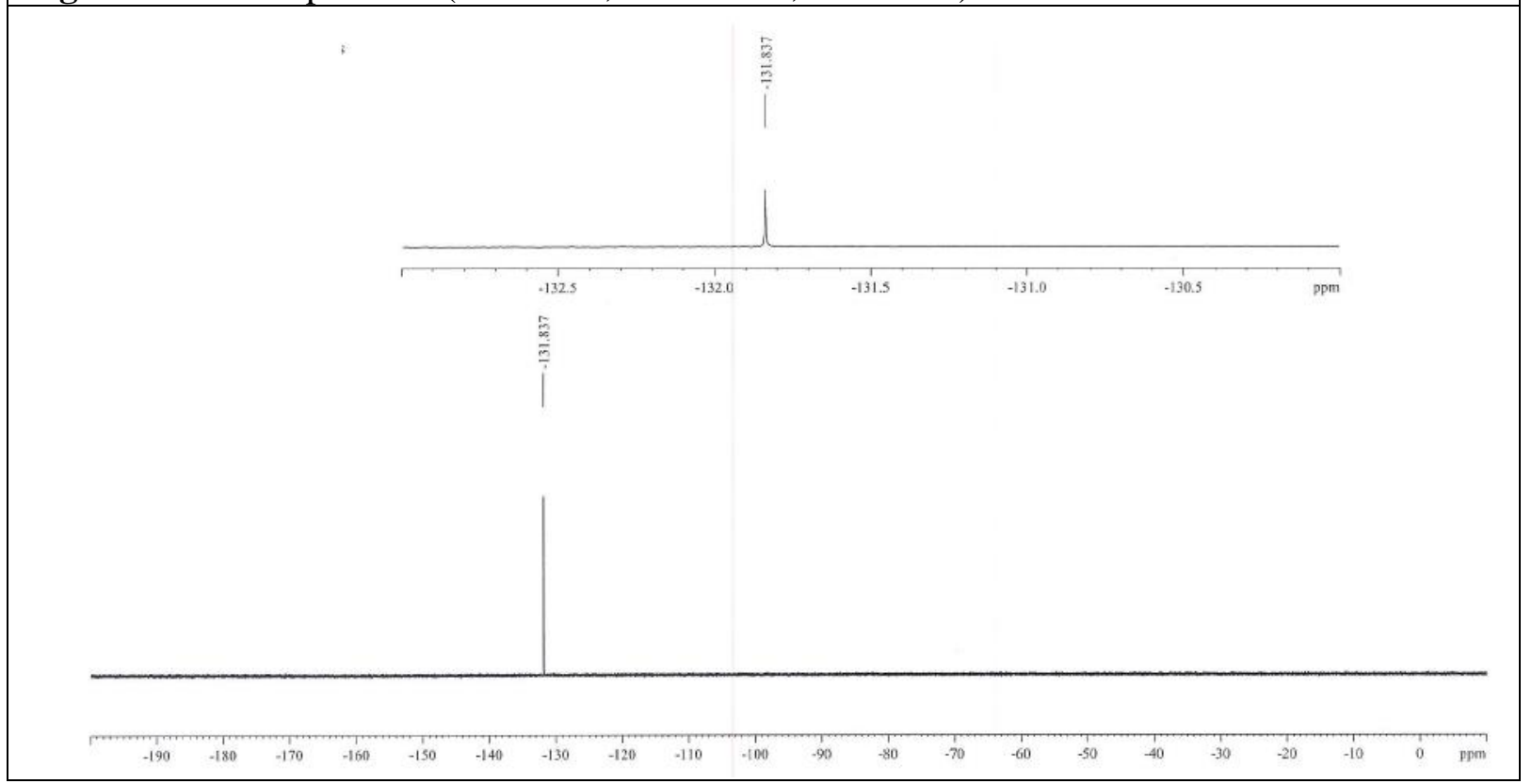


Figure S23: Compound $7\left({ }^{13} \mathrm{C}\right.$ NMR, DMSO-d6, $\left.100 \mathrm{MHz}\right)$

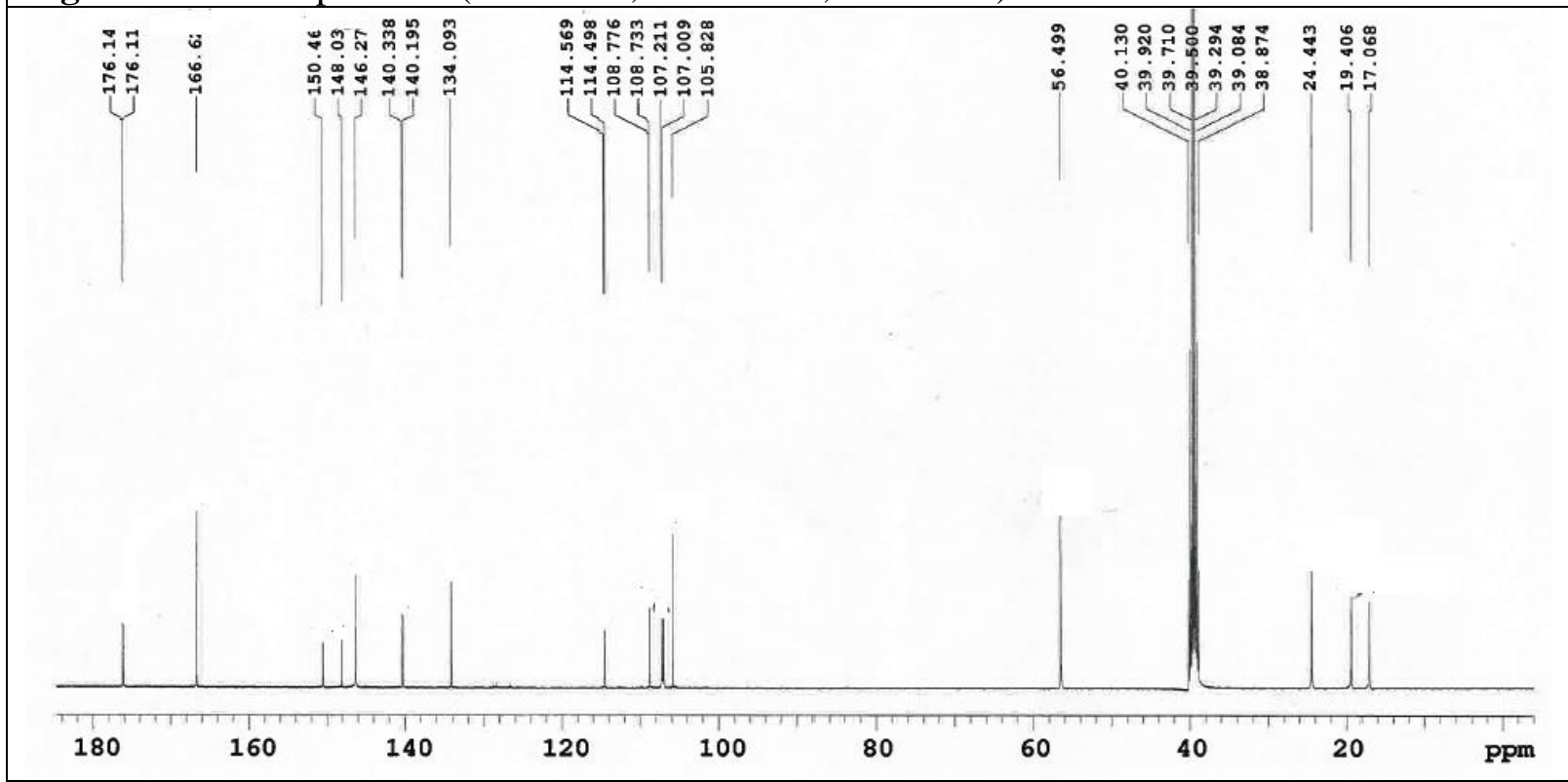

Figure S24: Compound $7\left({ }^{13} \mathrm{C}\right.$ NMR DEPT, DMSO-d6, $\left.100 \mathrm{MHz}\right)$

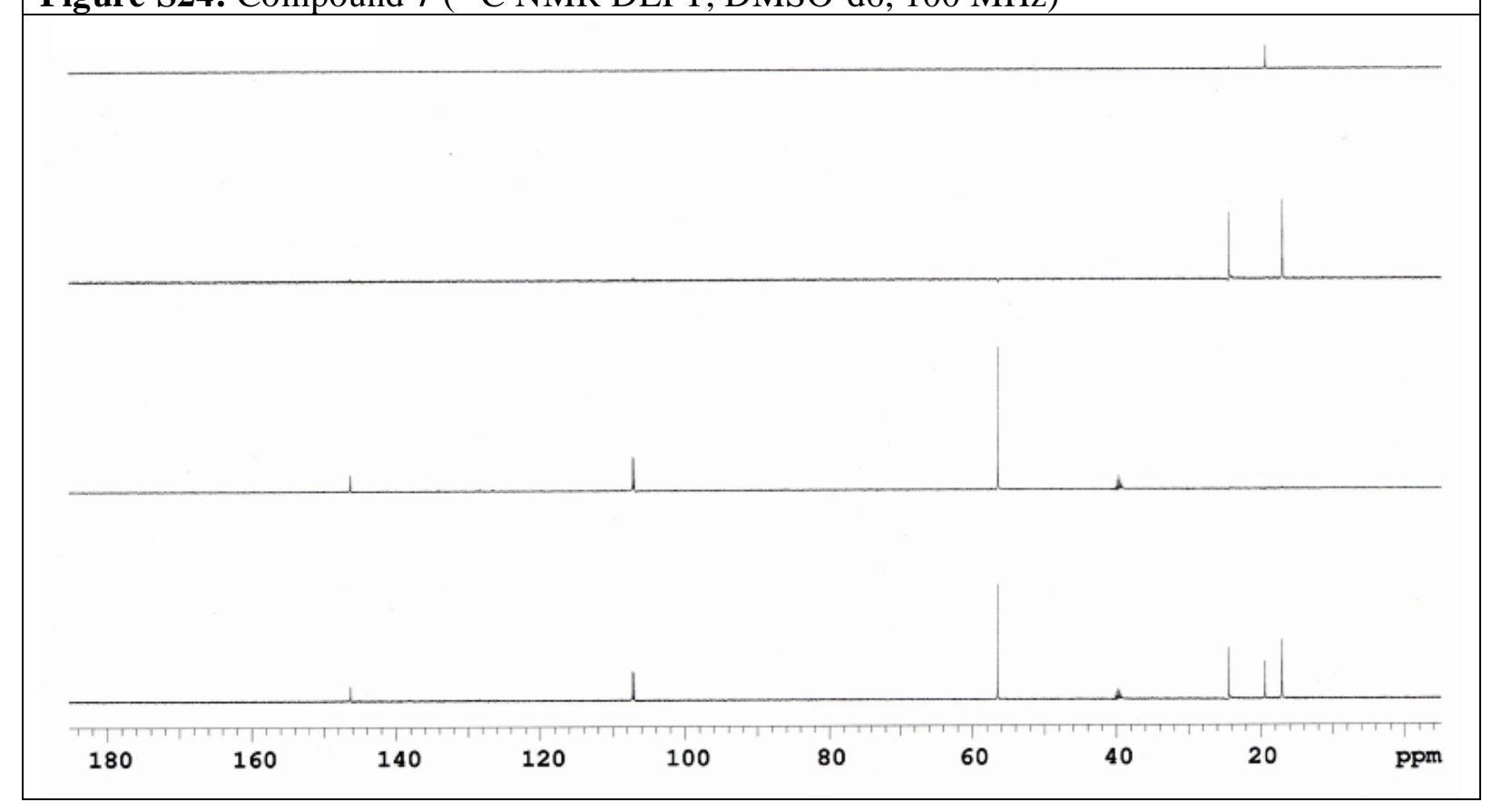



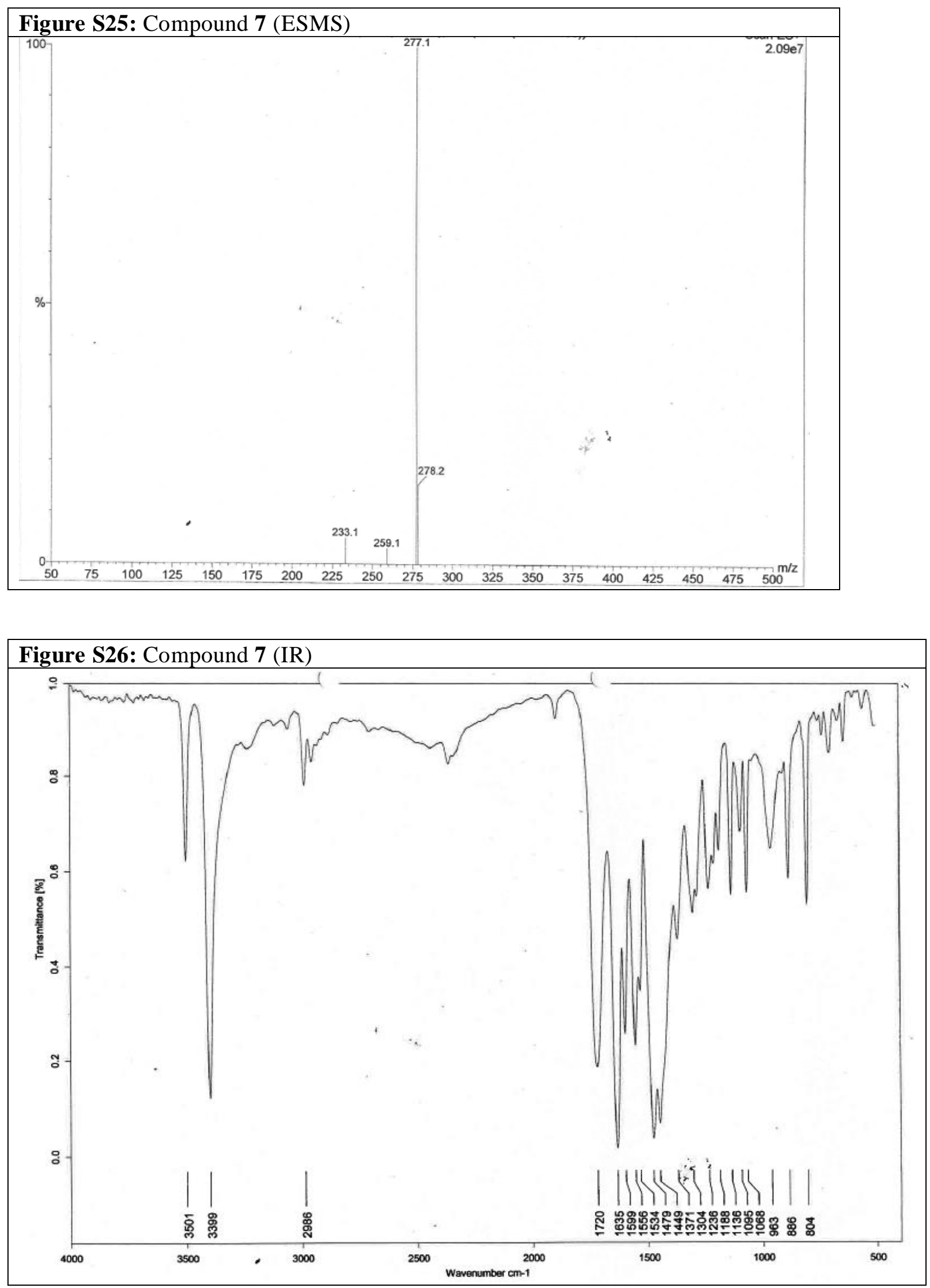

S14 
Figure S27: Compound $3\left({ }^{1} \mathrm{H}\right.$ NMR, DMSO-d6, $\left.400 \mathrm{MHz}\right)$

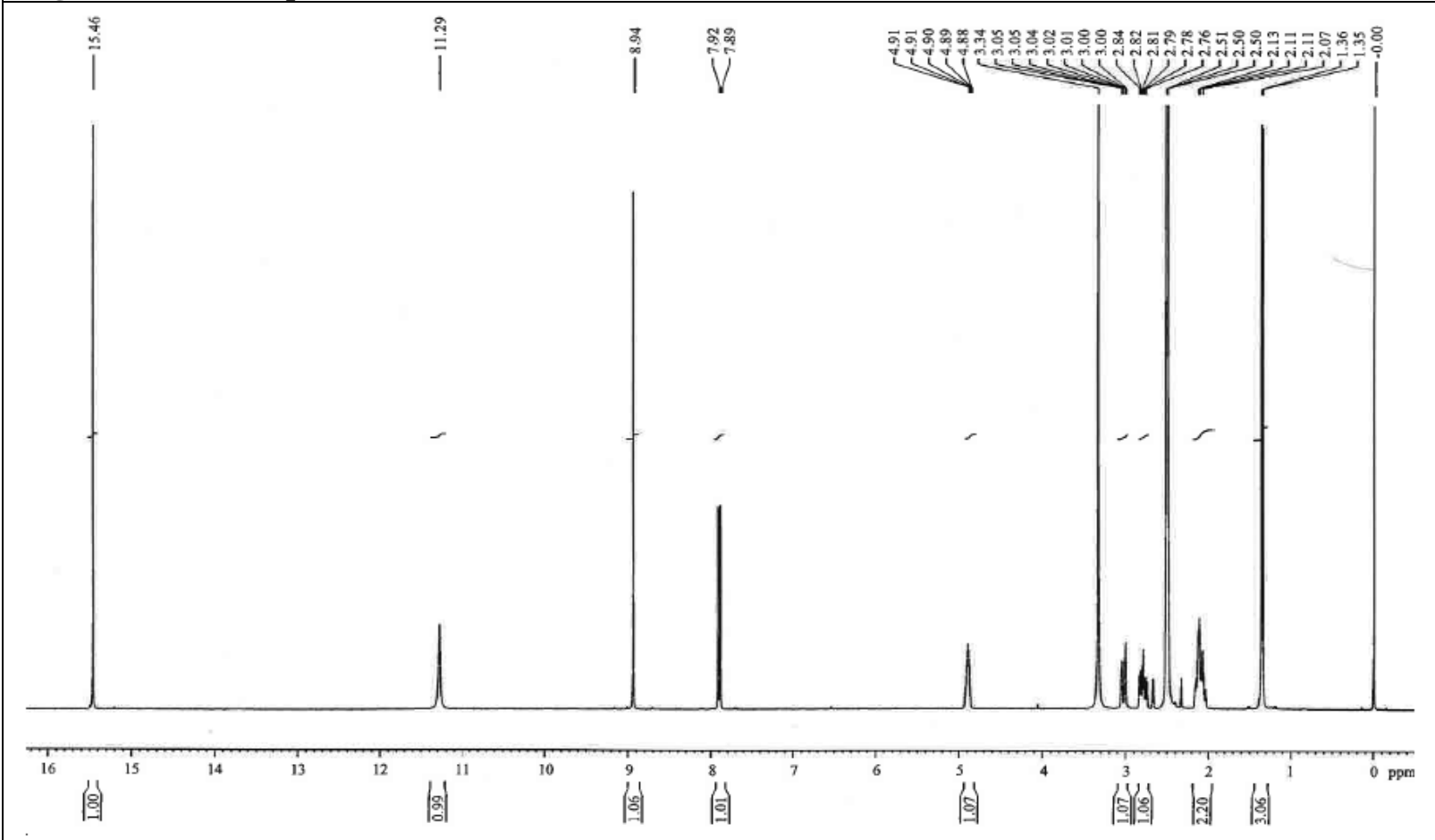

Figure S28: Compound $3\left({ }^{19} \mathrm{~F}\right.$ NMR, DMSO-d6, $\left.376 \mathrm{MHz}\right)$

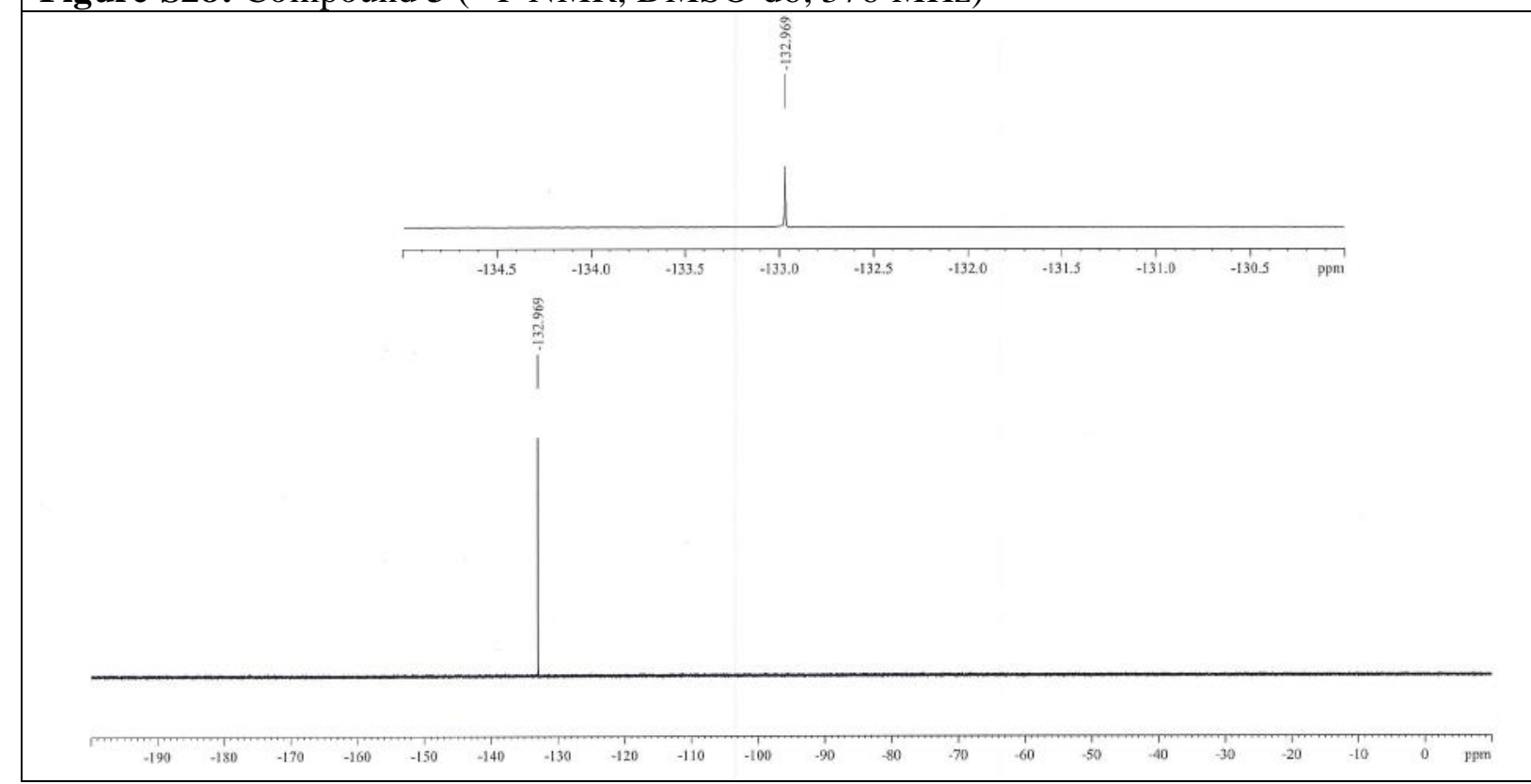




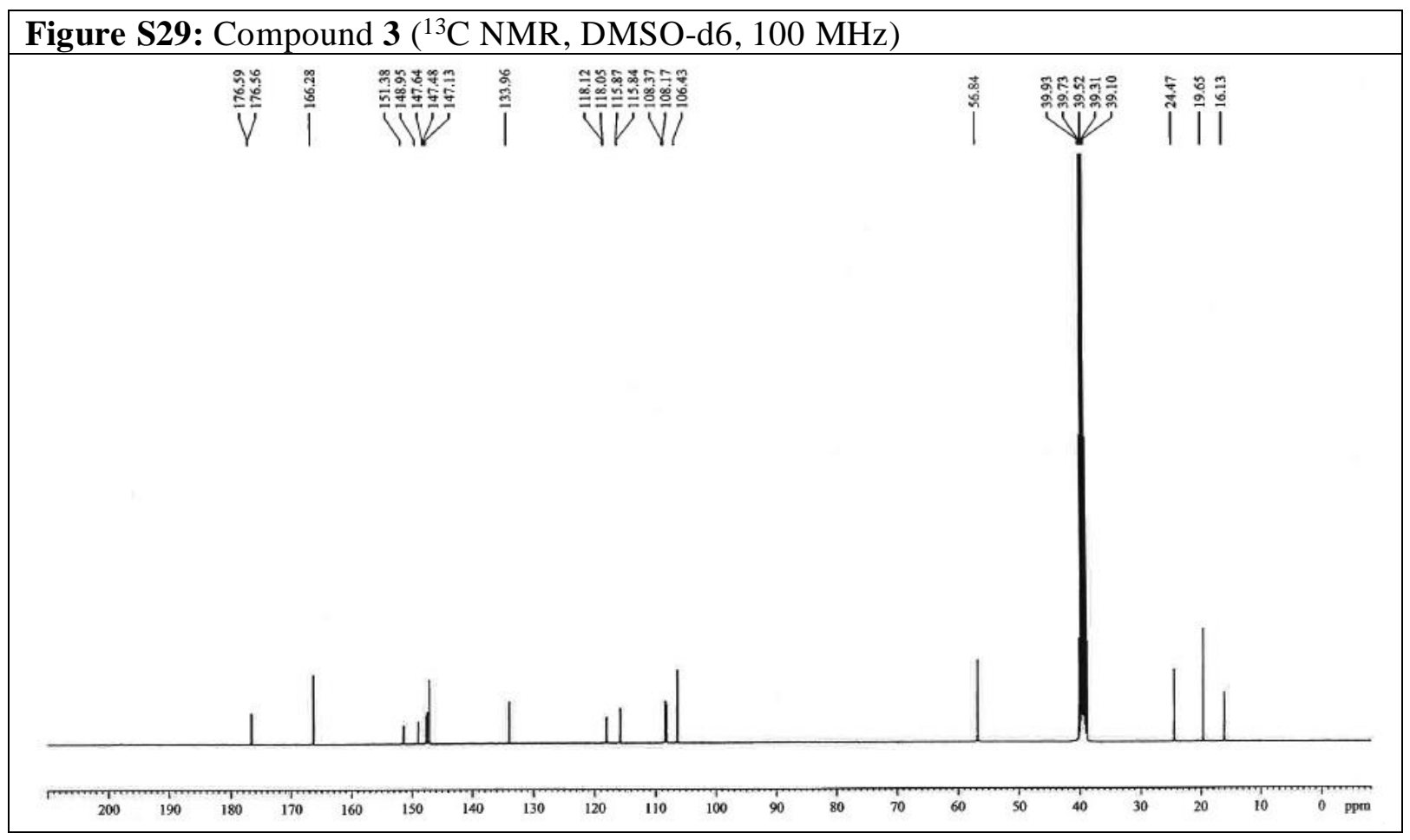

Figure S30: Compound $3\left({ }^{13} \mathrm{C}\right.$ NMR DEPT, DMSO-d6, $\left.100 \mathrm{MHz}\right)$

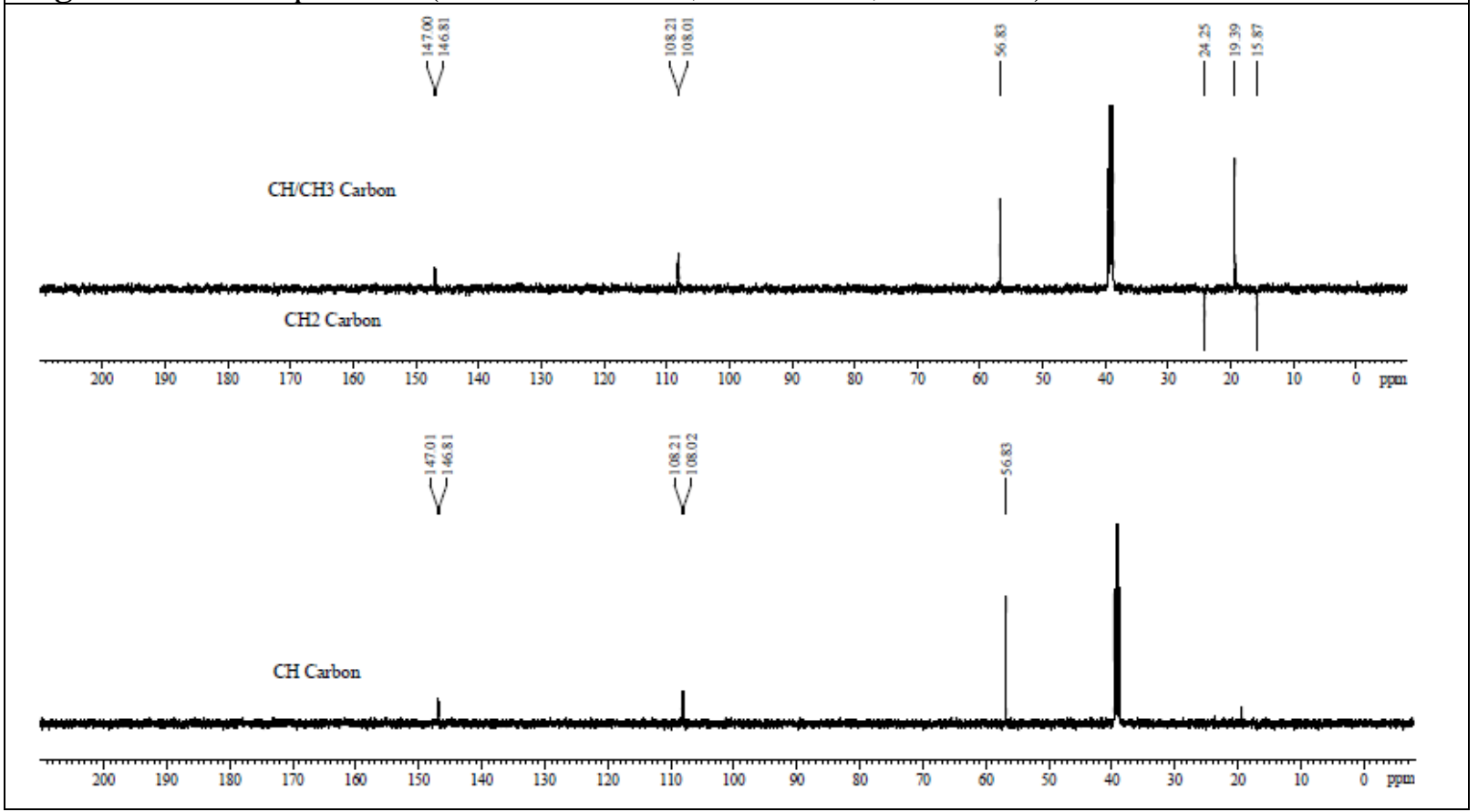


Figure S31: Compound 3 (ESMS)

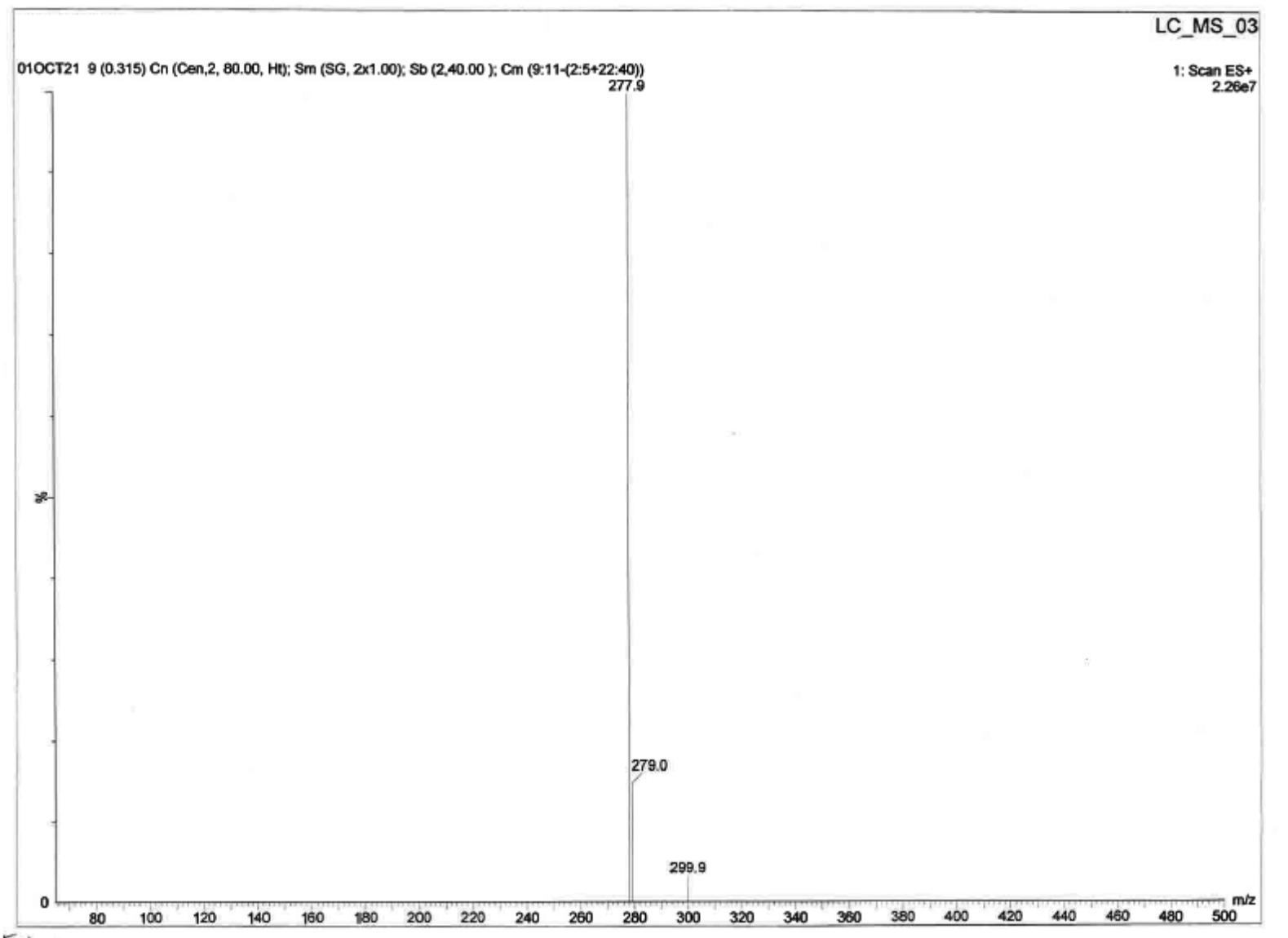

Figure S32: Compound 3 (IR) Spectrum

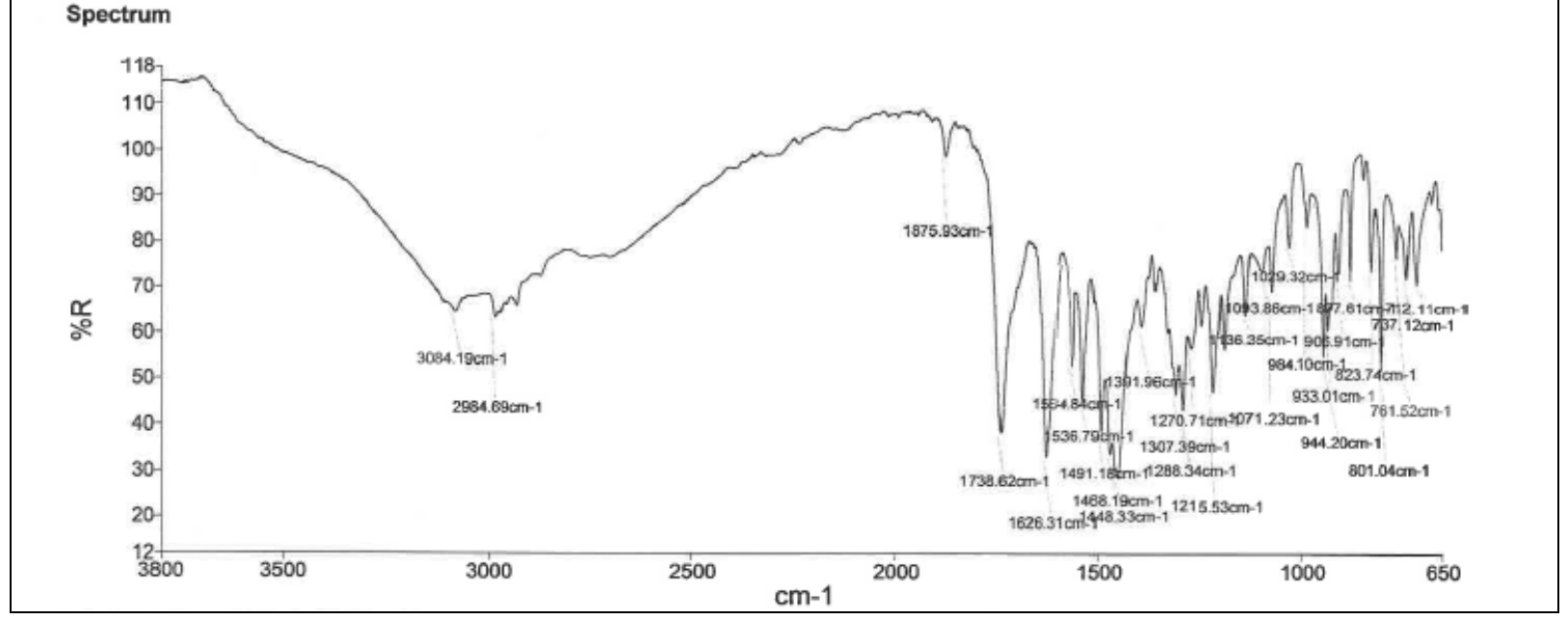




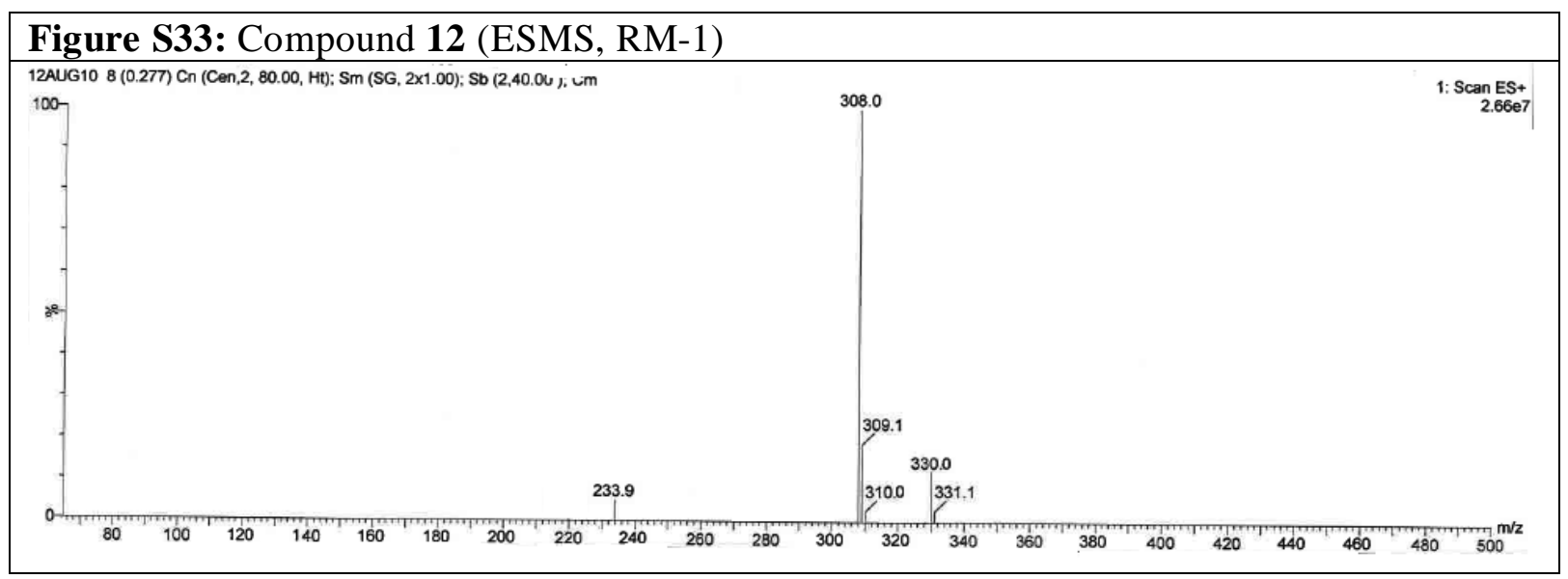

Figure S34: Compound $12\left({ }^{1} \mathrm{H} \mathrm{NMR}, \mathrm{CDCl}_{3}, 400 \mathrm{MHz}\right)$

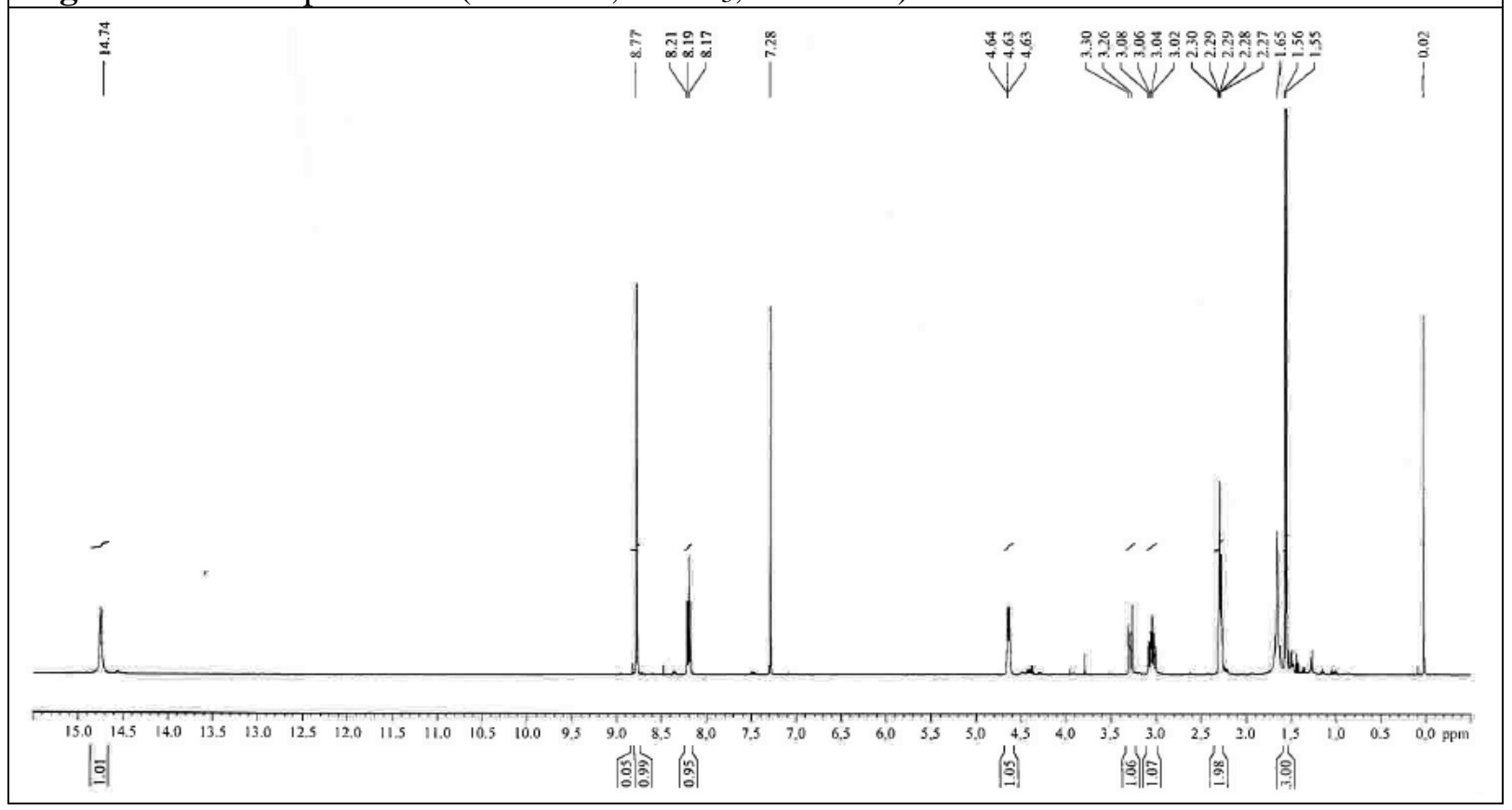



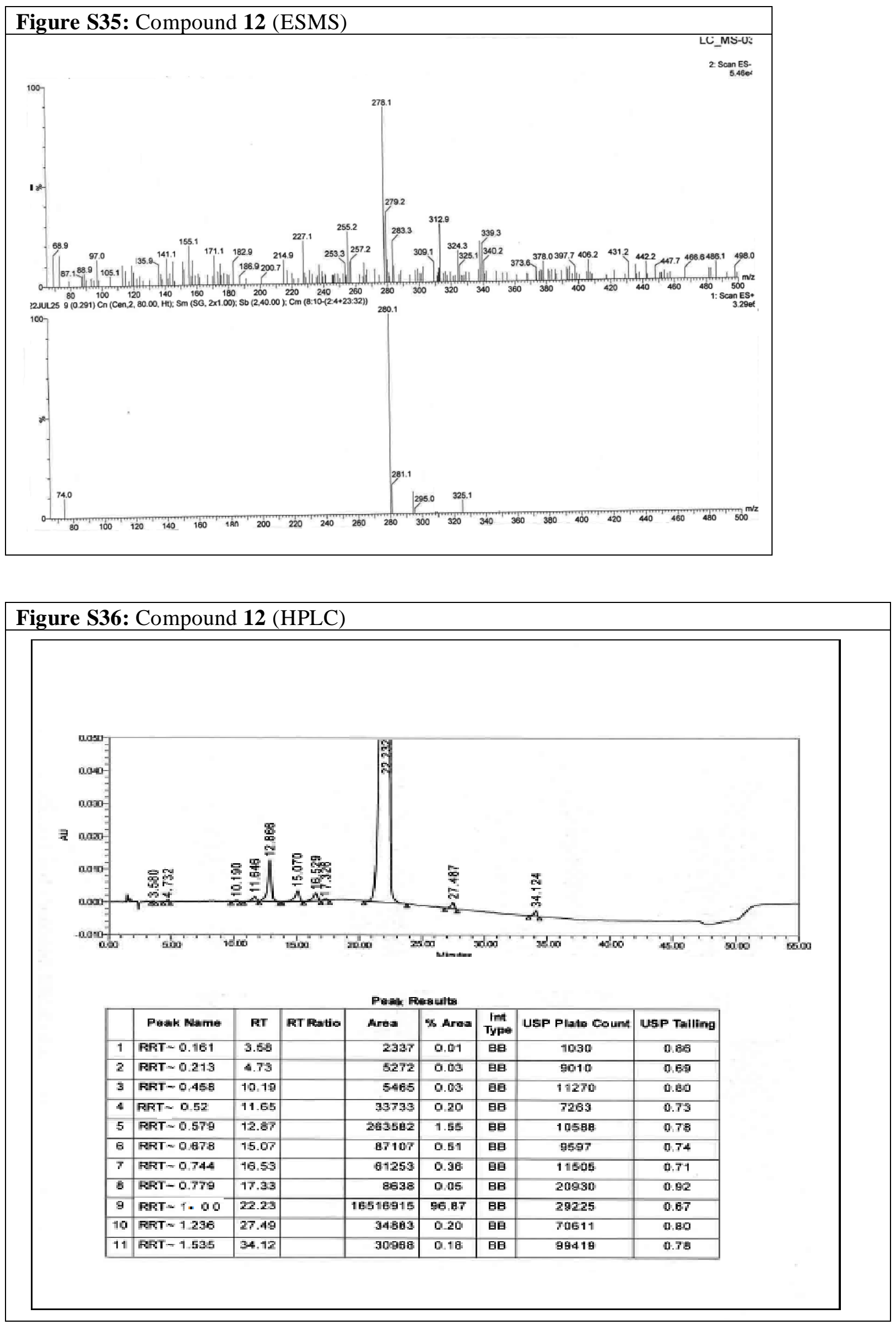
Figure S37: Compound 4 (HPLC RM-1)

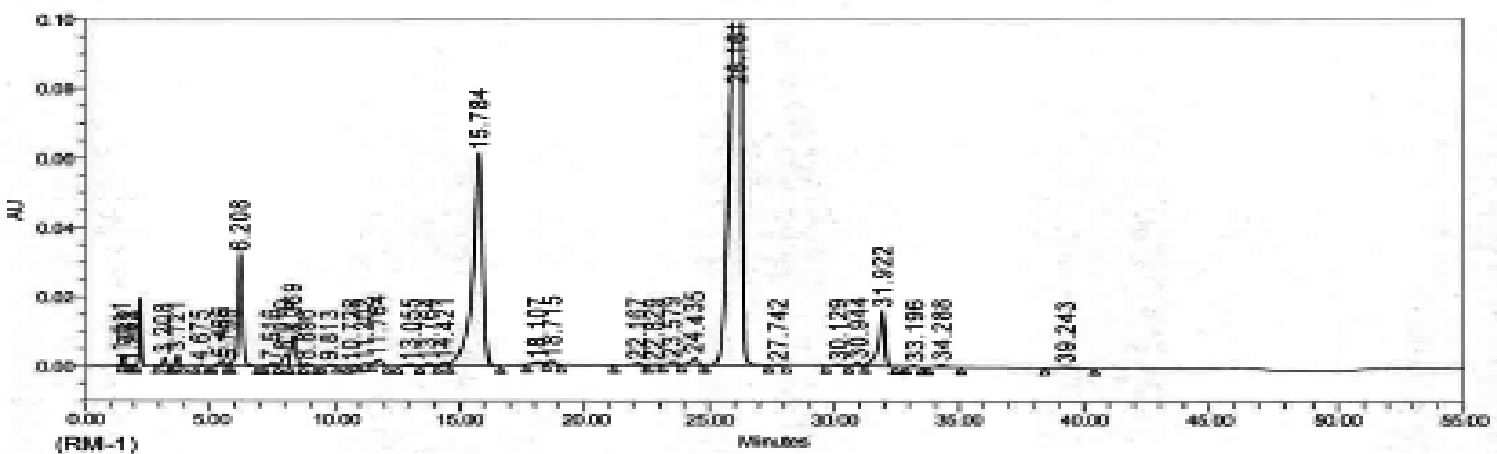

\begin{tabular}{|r|r|r|r|r|c|}
\hline & Peak Name & RT & \multicolumn{1}{c|}{ Area } & \% Area & $\begin{array}{c}\text { Int } \\
\text { Typo }\end{array}$ \\
\hline 1 & & 1.51 & 13997 & 0.13 & BB \\
\hline 2 & & 1.76 & 714 & 0.01 & BB \\
\hline 3 & & 1.94 & 1068 & 0.01 & BB \\
\hline 4 & & 3.21 & 18104 & 0.17 & BB \\
\hline 5 & & 3.72 & 25620 & 0.24 & BB \\
\hline 6 & & 4.68 & 3843 & 0.04 & BB \\
\hline 7 & & 5.49 & 21006 & 0.20 & BV \\
\hline 8 & & 5.80 & 6473 & 0.06 & V \\
\hline 9 & & 6.21 & 425776 & 3.95 & VV \\
\hline 10 & & 7.52 & 13041 & 0.12 & VV \\
\hline 11 & & 8.02 & 58098 & 0.54 & VV \\
\hline 12 & & 8.37 & 123176 & 1.14 & VV \\
\hline 13 & & 8.90 & 10871 & 0.10 & VB \\
\hline 14 & & 9.81 & 4877 & 0.05 & BB \\
\hline
\end{tabular}

\begin{tabular}{|r|r|r|r|r|c|}
\hline & Peak Name & RT & \multicolumn{1}{c|}{ Area } & \% Area & $\begin{array}{c}\text { Int } \\
\text { Type }\end{array}$ \\
\hline 15 & & 10.73 & 2068 & 0.02 & BB \\
\hline 16 & & 11.20 & 3575 & 0.03 & BB \\
\hline 17 & & 11.76 & 23198 & 0.22 & BB \\
\hline 18 & & 13.06 & 13715 & 0.13 & BV \\
\hline 19 & & 13.76 & 16033 & 0.15 & W \\
\hline 20 & & 14.42 & 19100 & 0.18 & W \\
\hline 21 & & 15.78 & 1770374 & 16.44 & VB \\
\hline 22 & & 18.11 & 10368 & 0.10 & BB \\
\hline 23 & & 18.71 & 15188 & 0.14 & BB \\
\hline 24 & SMC & 22.17 & 11992 & 0.11 & BB \\
\hline 25 & & 22.83 & 2971 & 0.03 & BB \\
\hline 26 & & 23.58 & 13558 & 0.13 & BB \\
\hline 27 & & 24.43 & 37271 & 0.35 & BB \\
\hline 25 & S-nadifloracin & 26.16 & 7768370 & 72.14 & BB \\
\hline 29 & & 27.74 & 4576 & 0.04 & BB \\
\hline 30 & & 30.13 & 7191 & 0.07 & BB \\
\hline 31 & & 30.94 & 13358 & 0.12 & BB \\
\hline 32 & & 31.92 & 268777 & 2.50 & BB \\
\hline 33 & & 33.20 & 6587 & 0.06 & BB \\
\hline 34 & & 34.29 & 15144 & 0.14 & BB \\
\hline 35 & & 39.24 & 18118 & 0.17 & BB \\
\hline
\end{tabular}




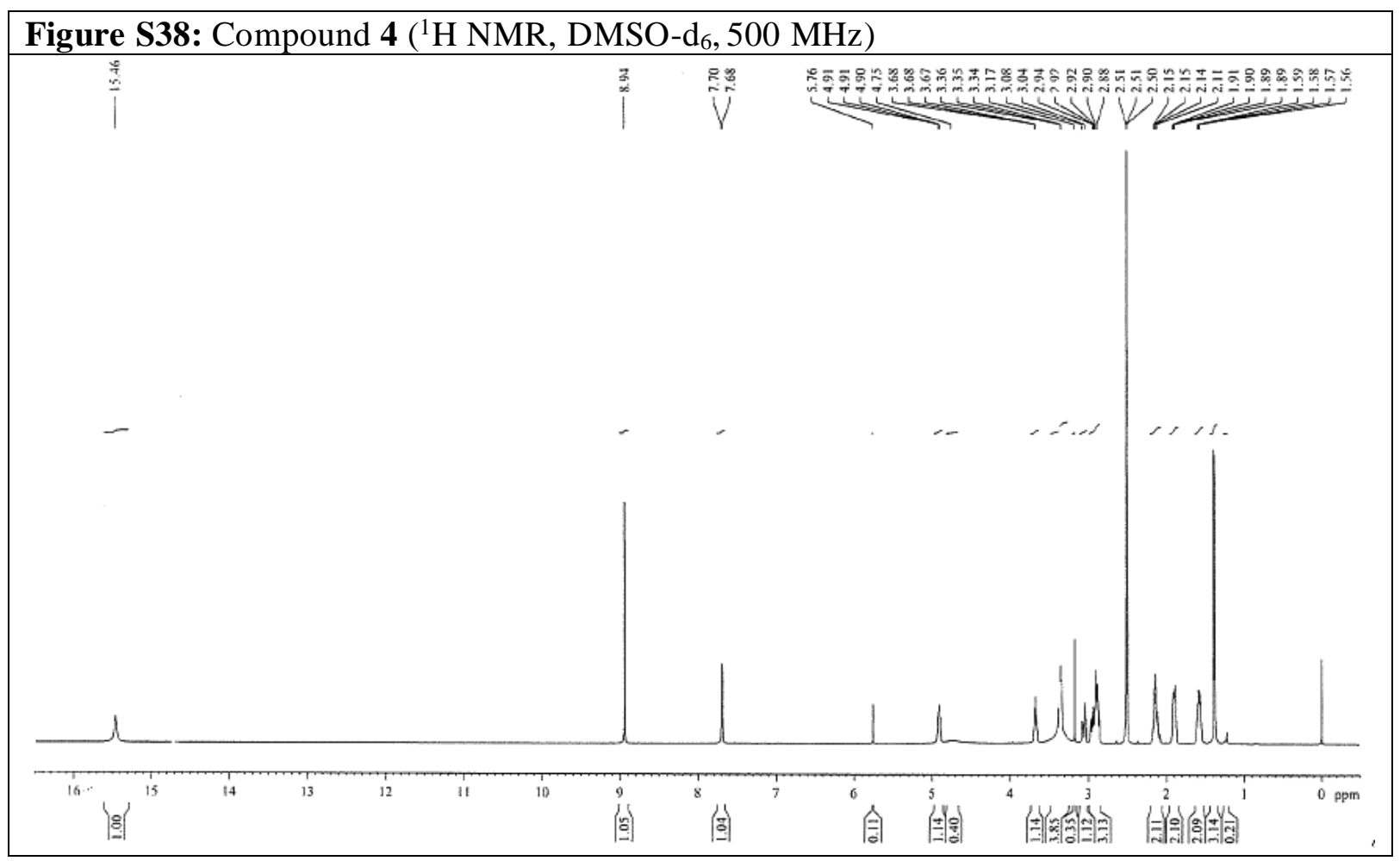

Figure S39: Compound $4\left({ }^{19} \mathrm{~F}\right.$ NMR, DMSO-d 6 , $\left.376 \mathrm{MHz}\right)$

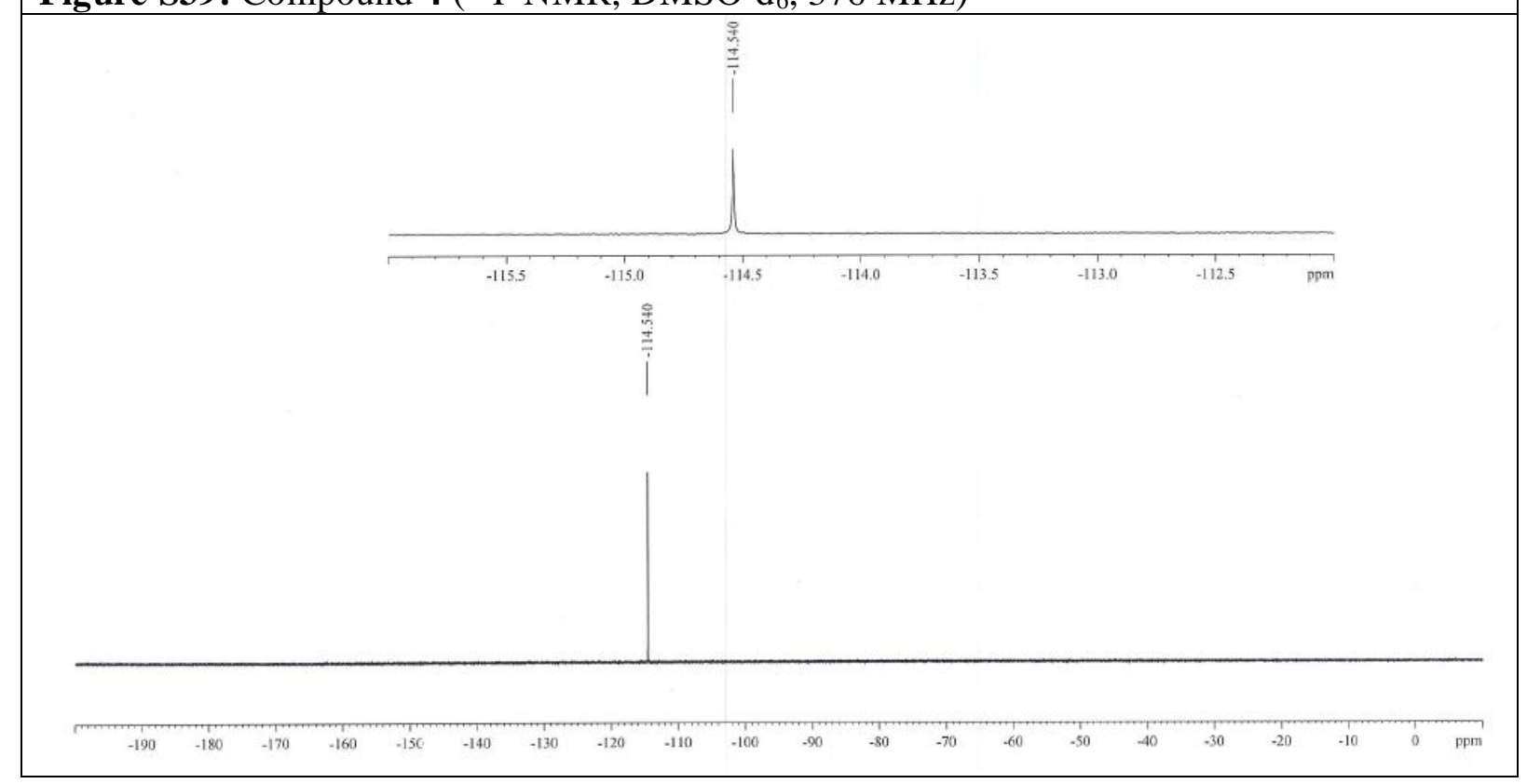


Figure S40: Compound $4\left({ }^{13} \mathrm{C}\right.$ NMR, DMSO-d $\left.6,125 \mathrm{MHz}\right)$

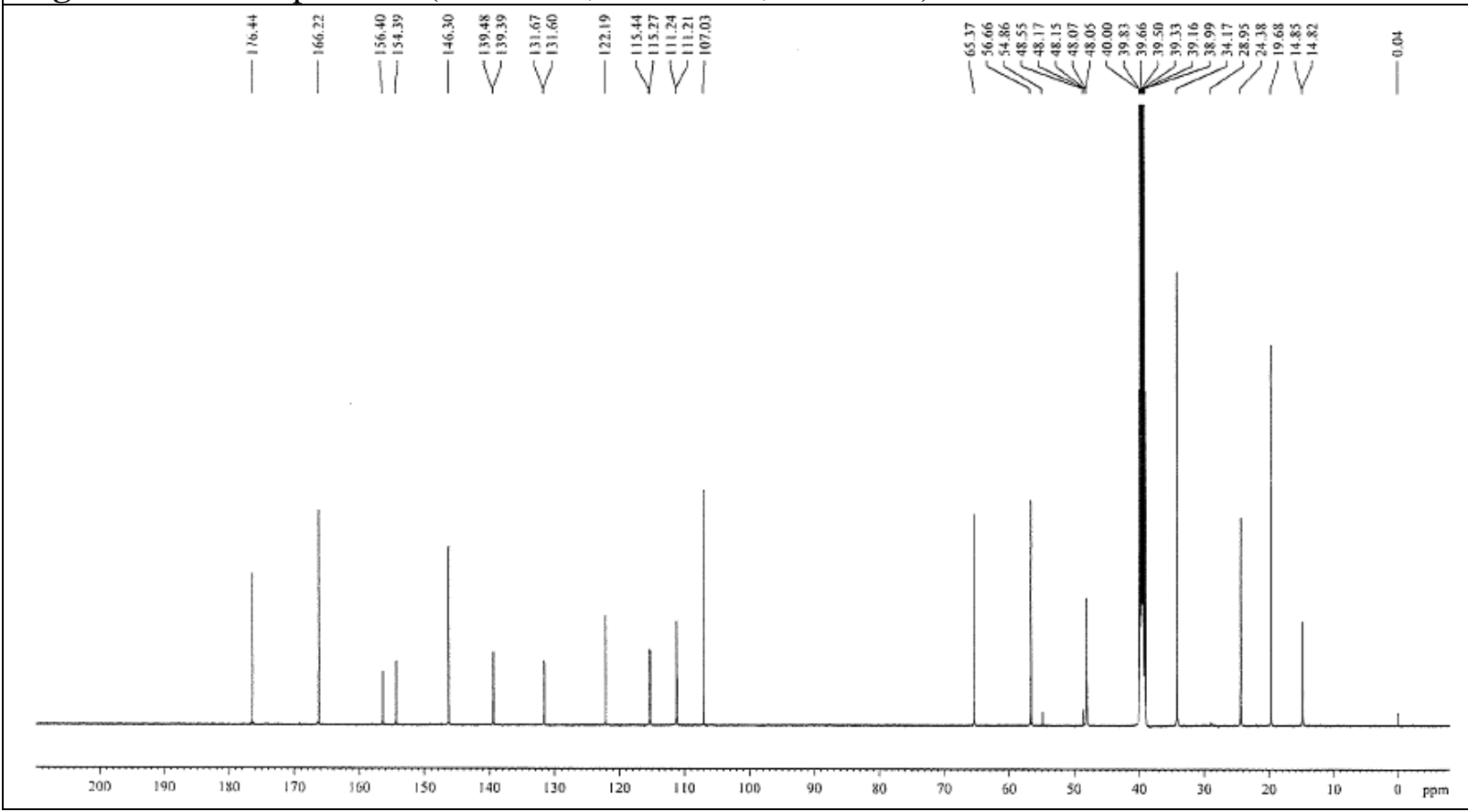

Figure S41: Compound $4\left({ }^{13} \mathrm{C}\right.$ NMR DEPT, $\left.\mathrm{CDCl}_{3}, 100 \mathrm{MHz}\right)$

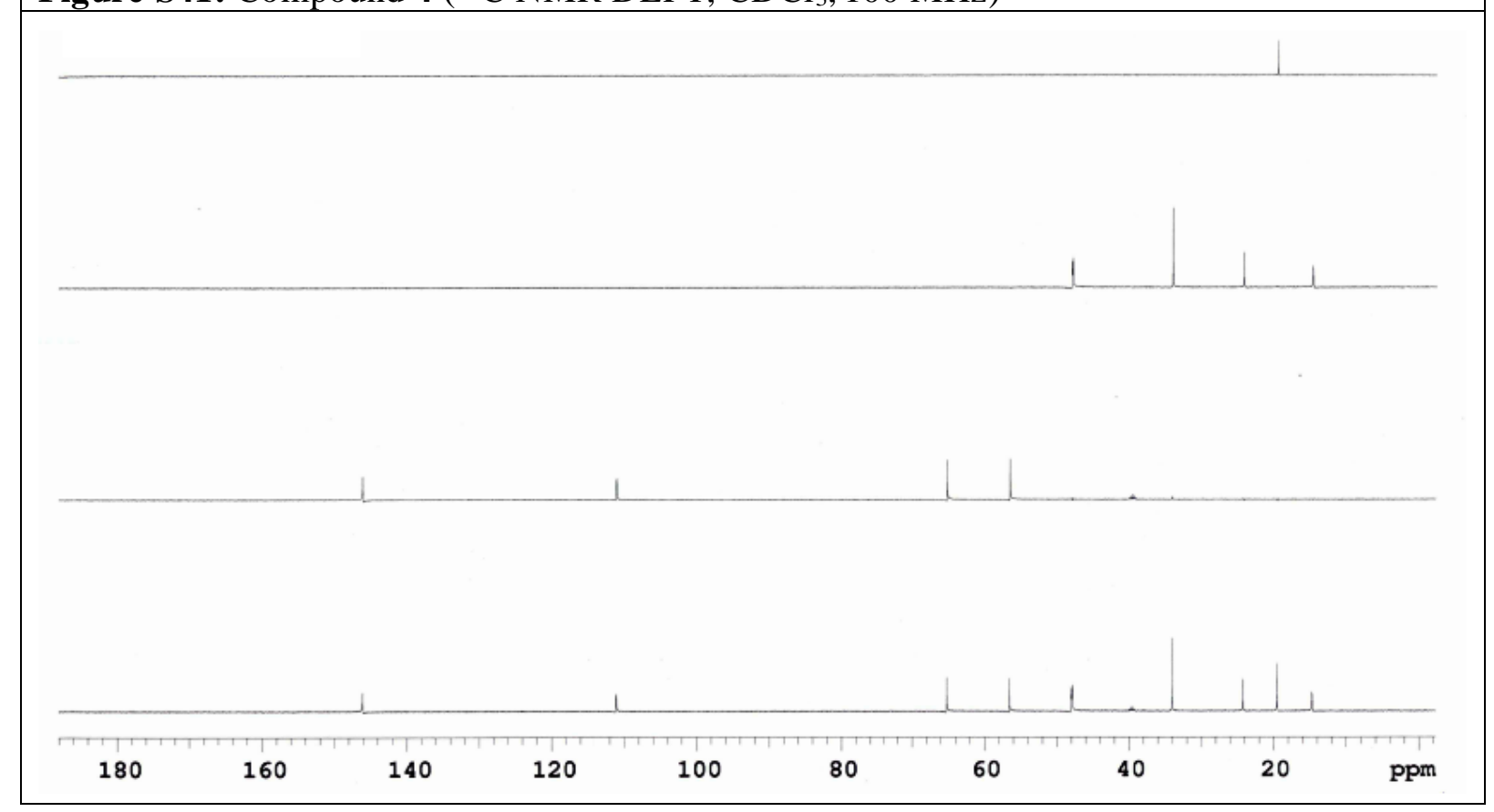




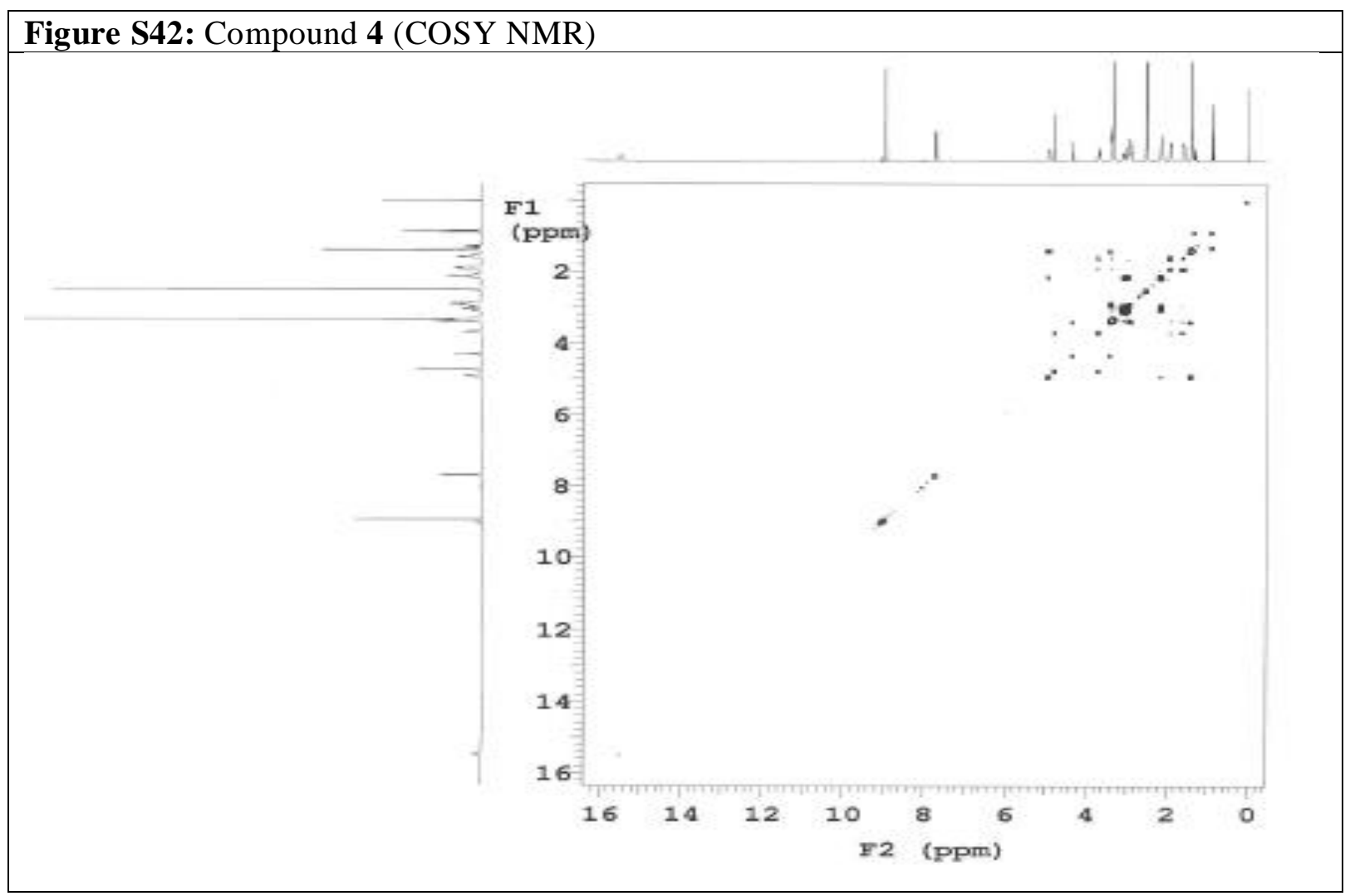

Figure S43: Compound 4 (HSQC NMR)

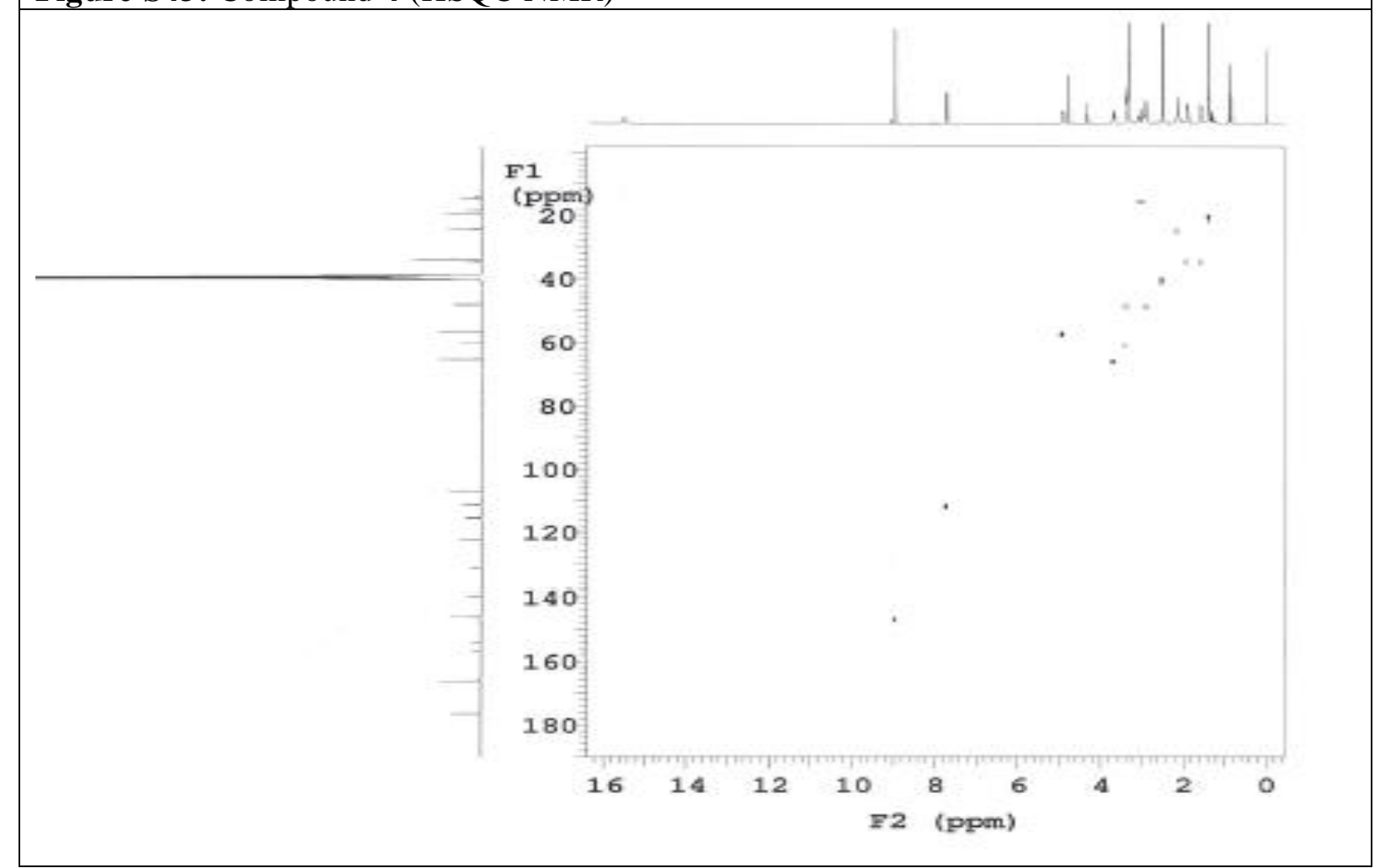




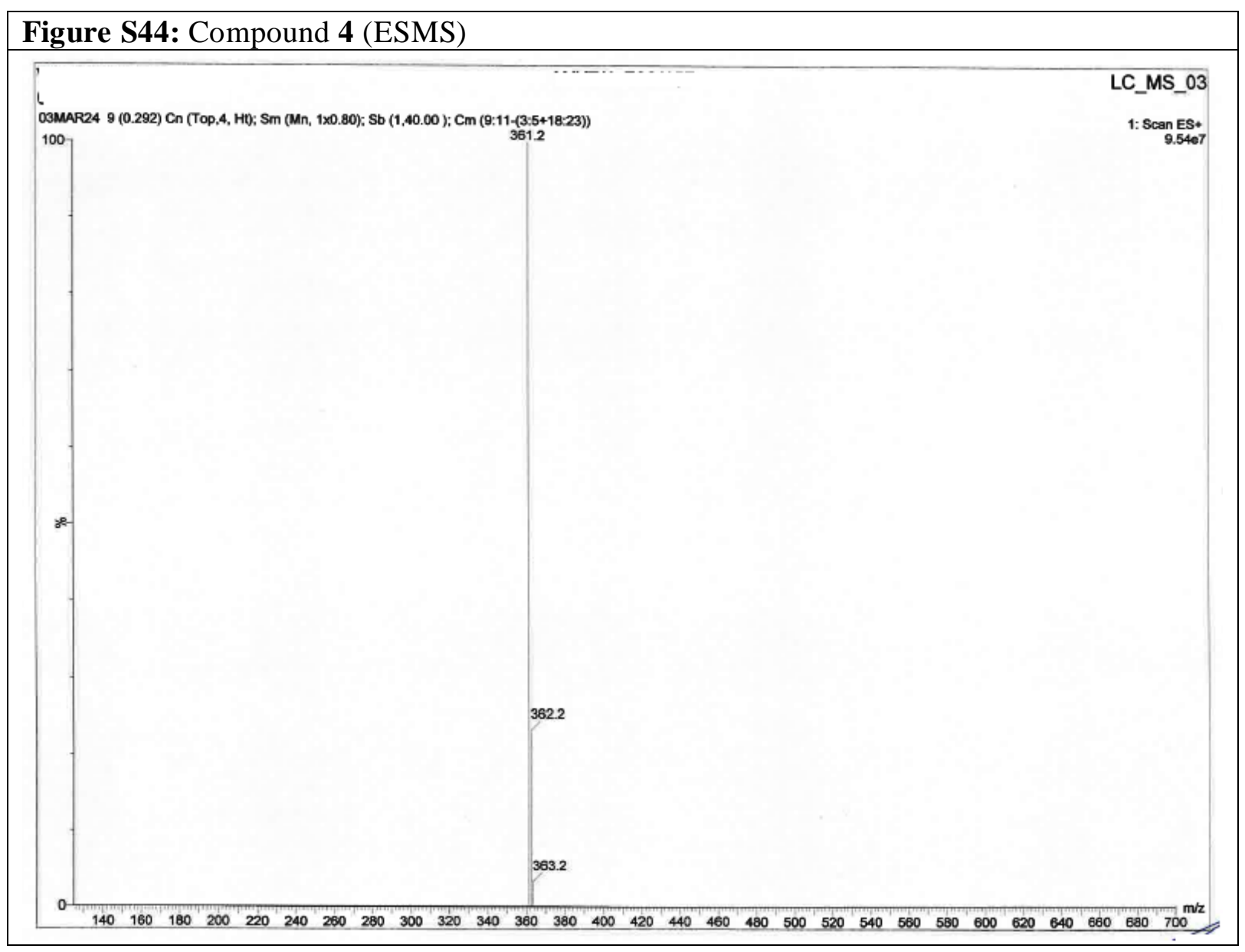

Figure S45: Compound 4 (IR)

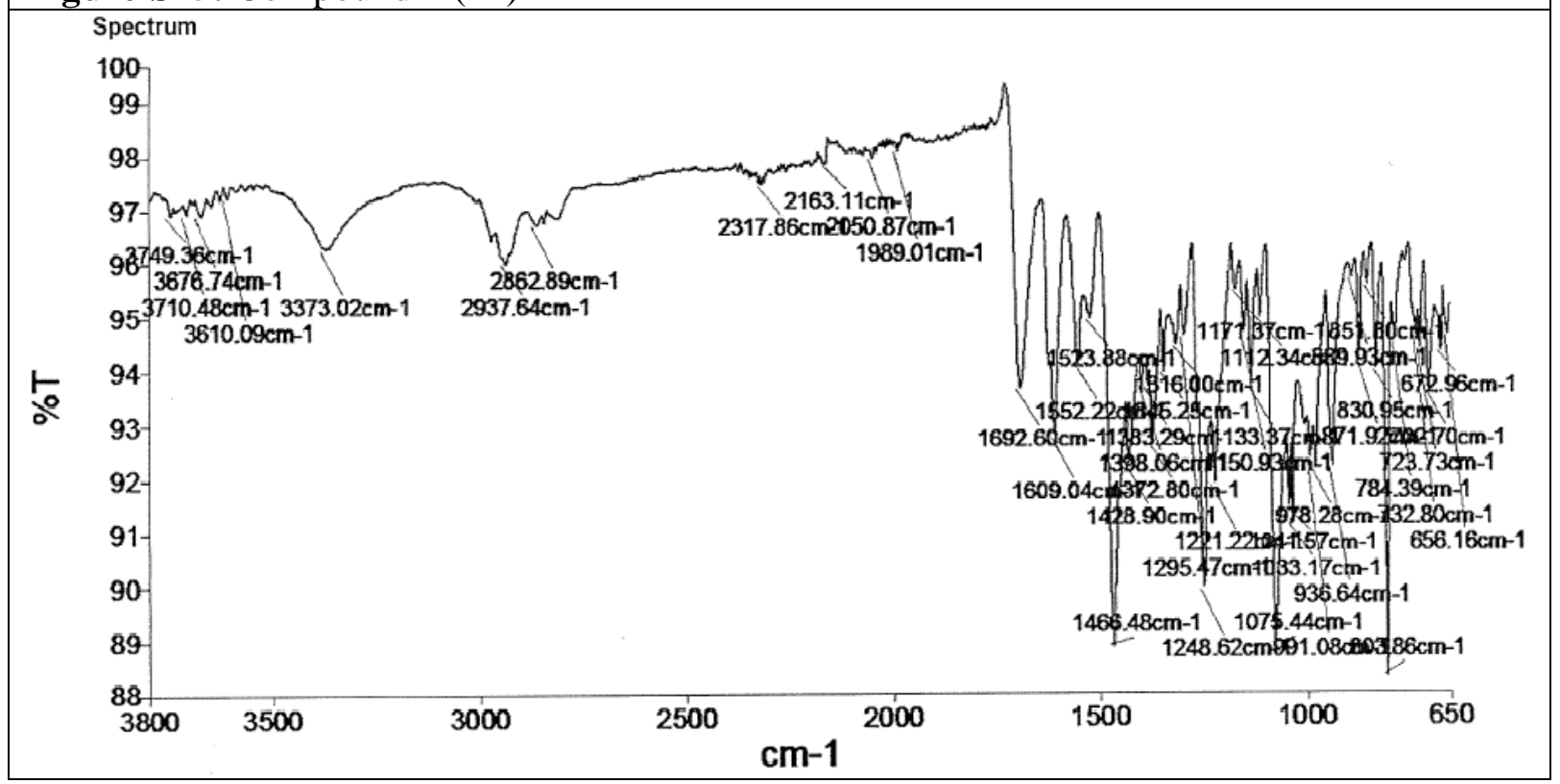




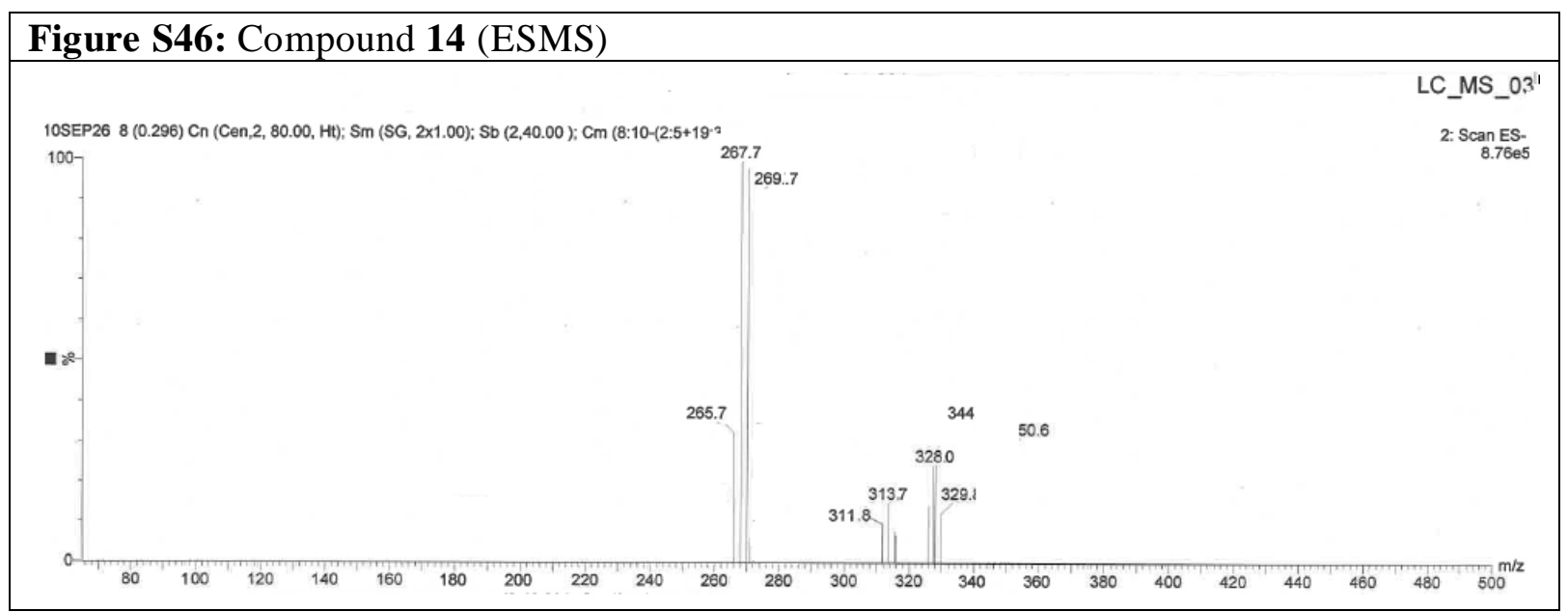

Figure S47: Compound $15\left({ }^{1} \mathrm{H} \mathrm{NMR}, \mathrm{CDCl}_{3}, 400 \mathrm{MHz}\right)$

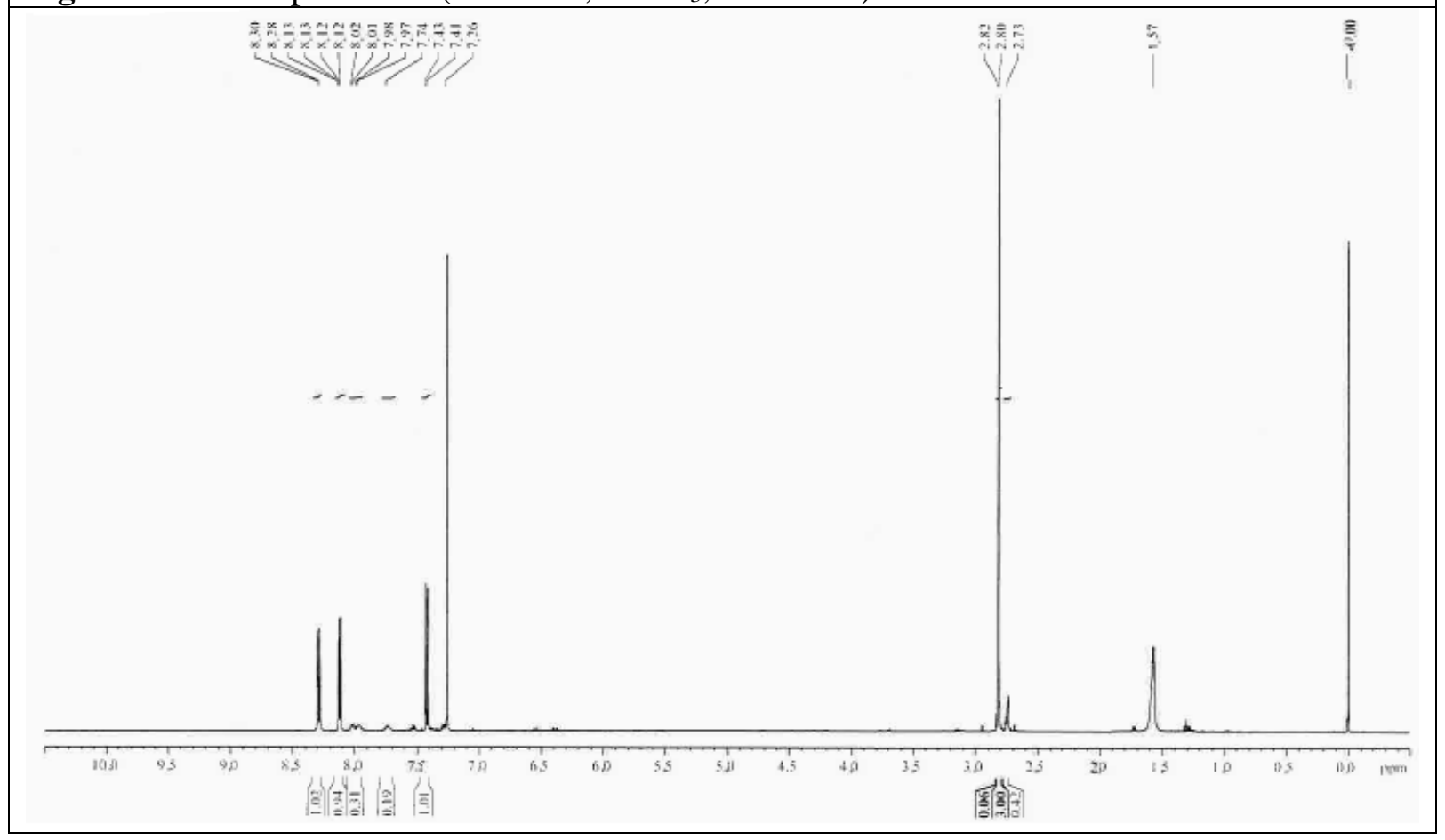



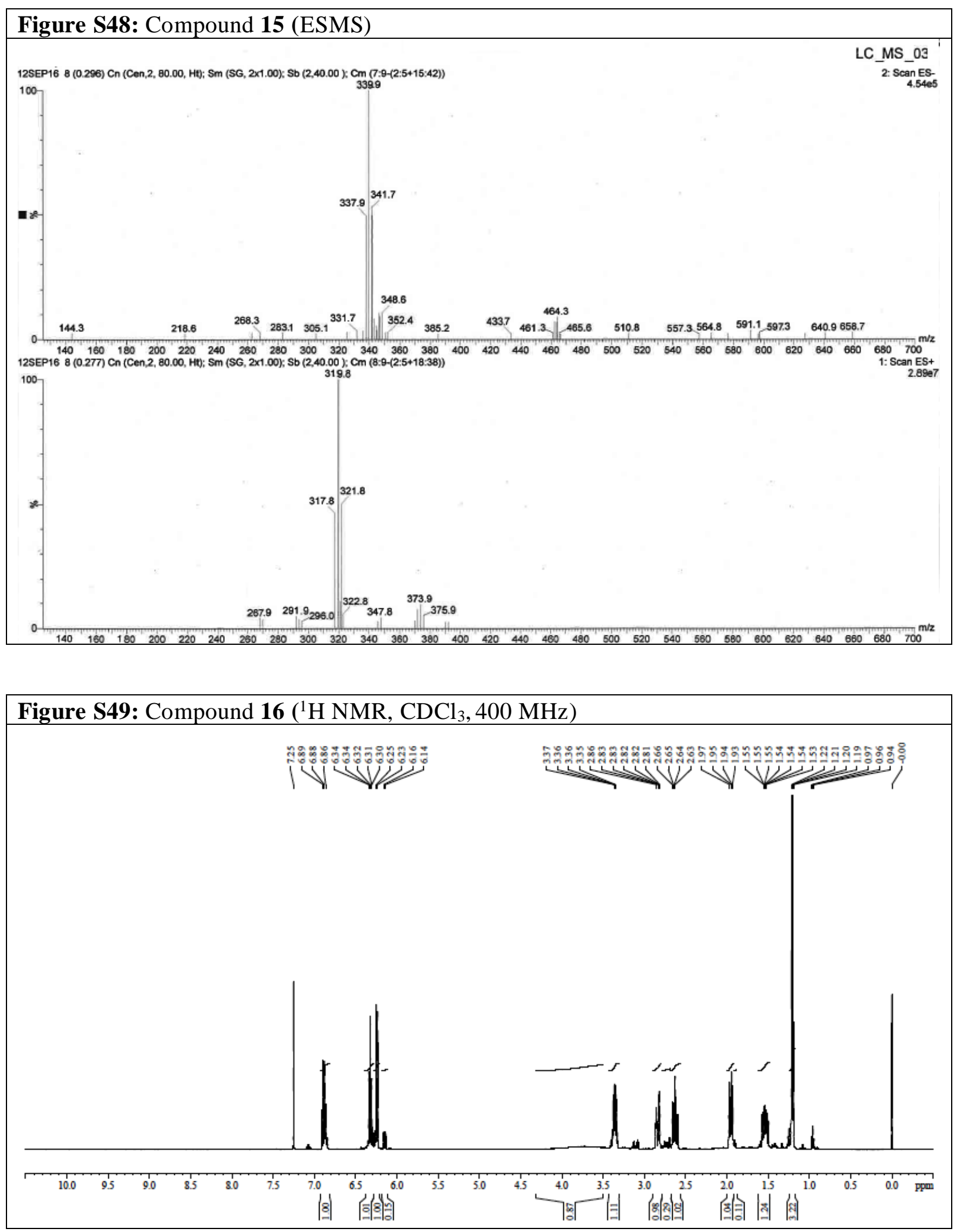

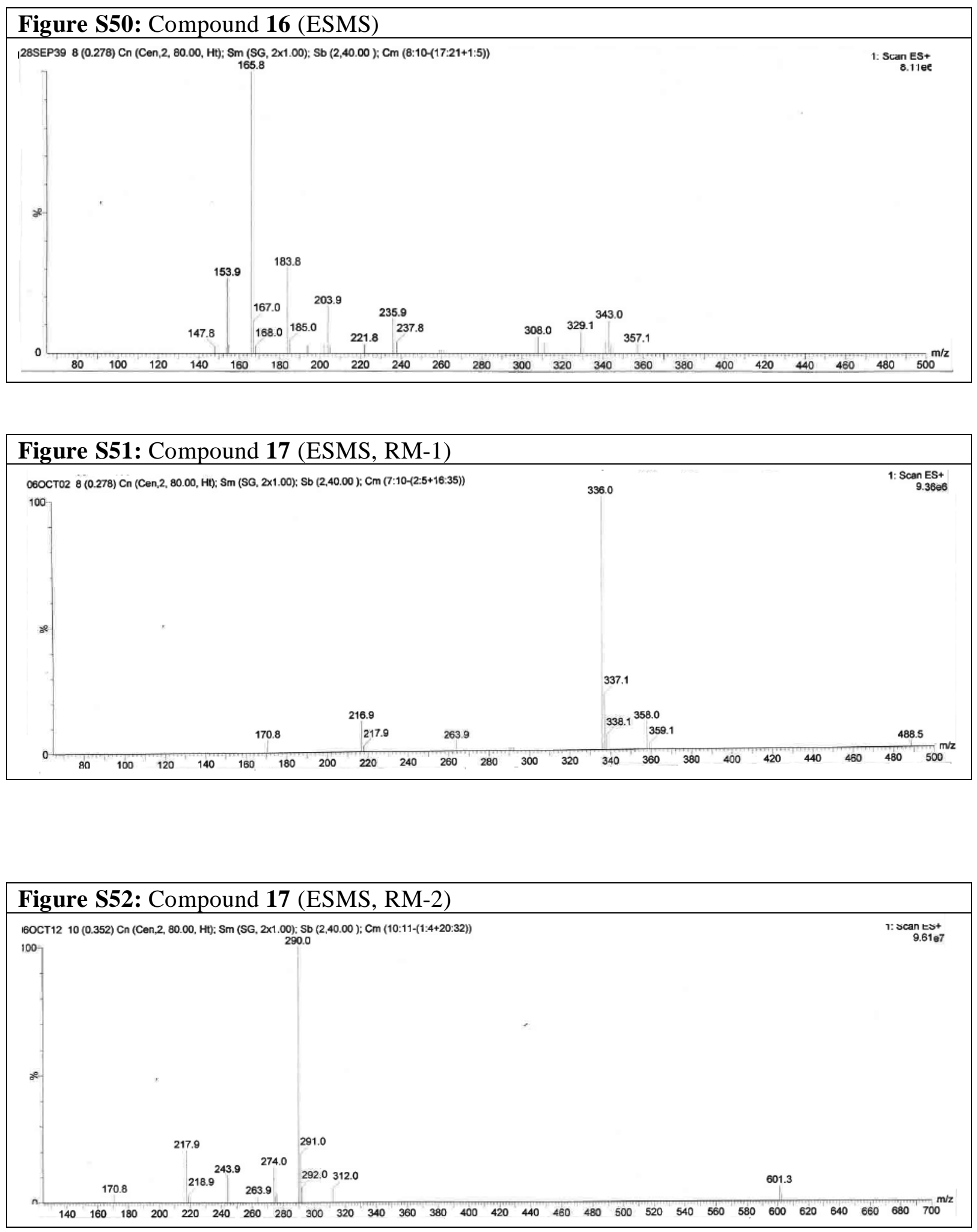

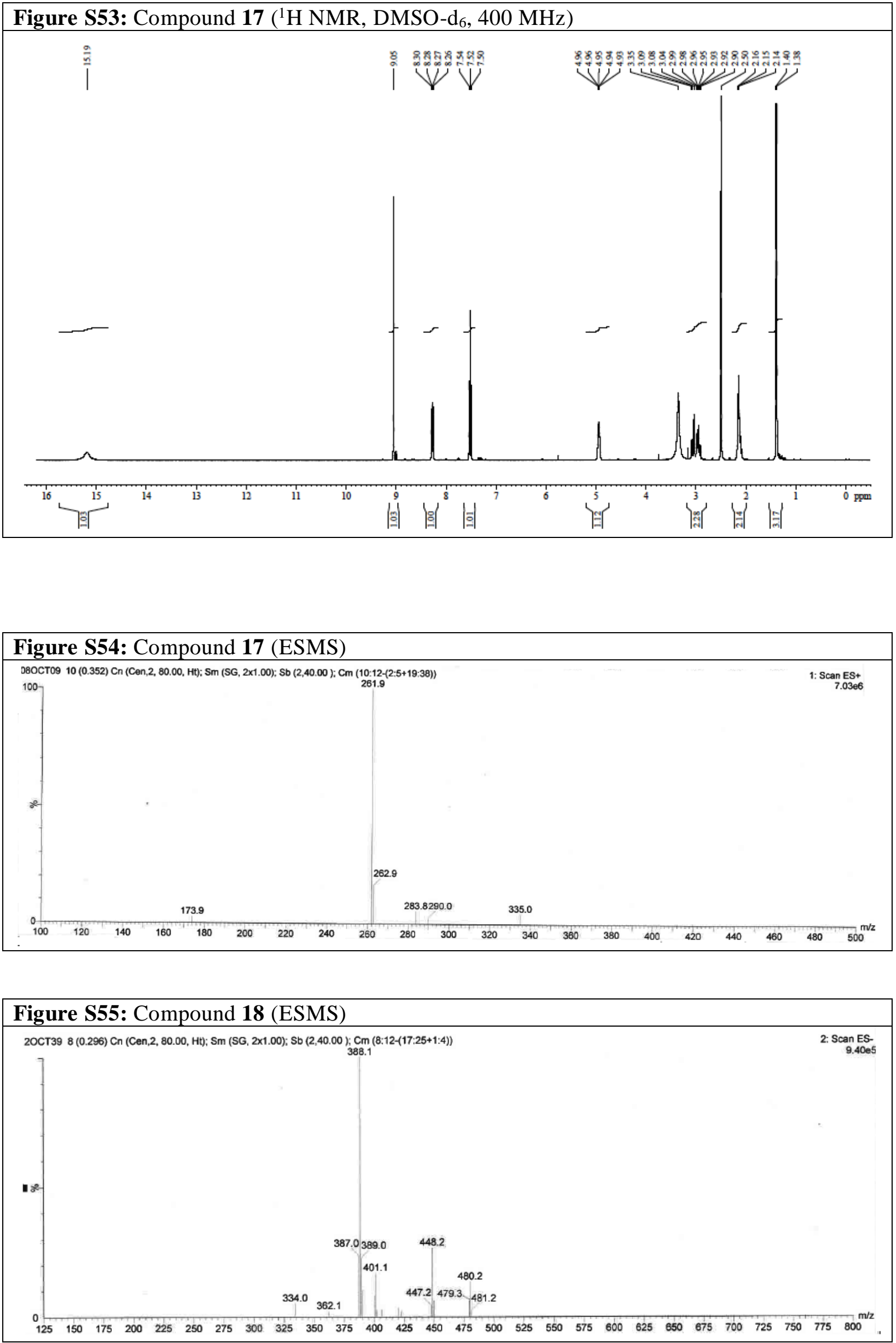


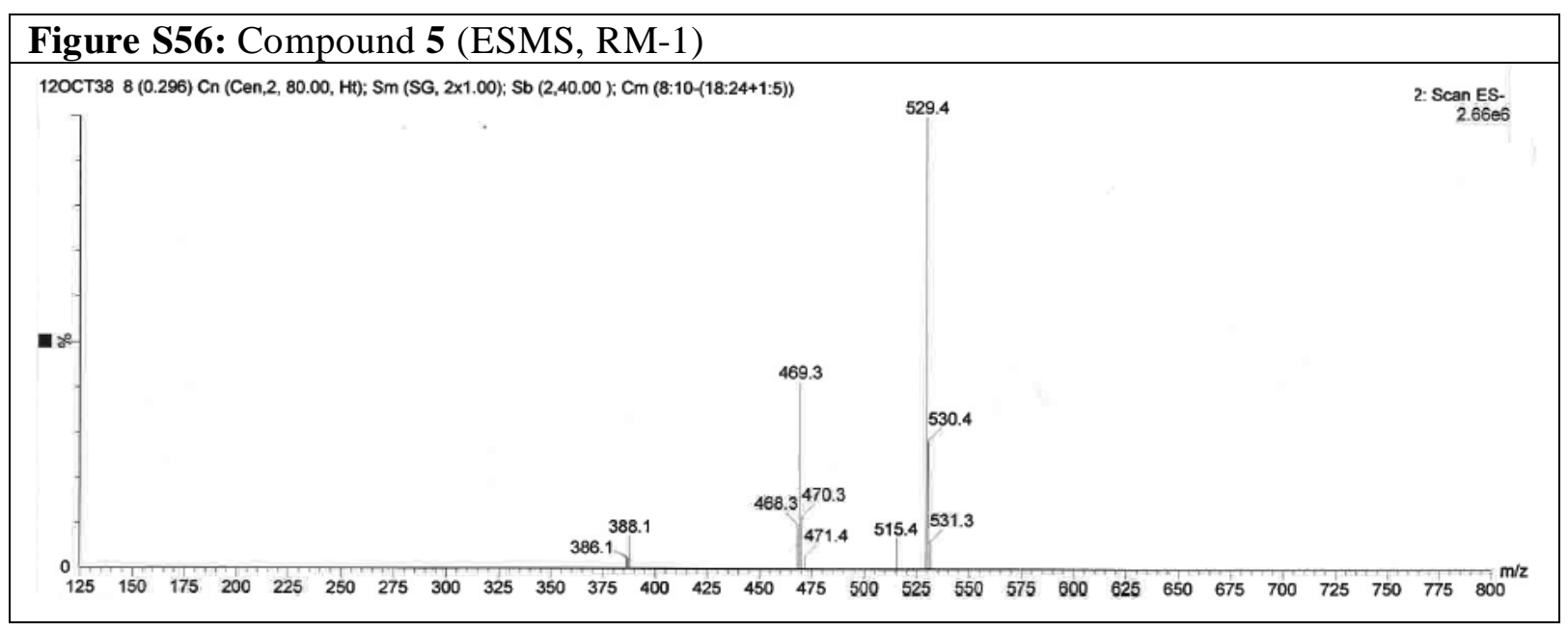

Figure S57: Compound $5\left({ }^{1} \mathrm{H}\right.$ NMR, DMSO-d6, $\left.400 \mathrm{MHz}\right)$

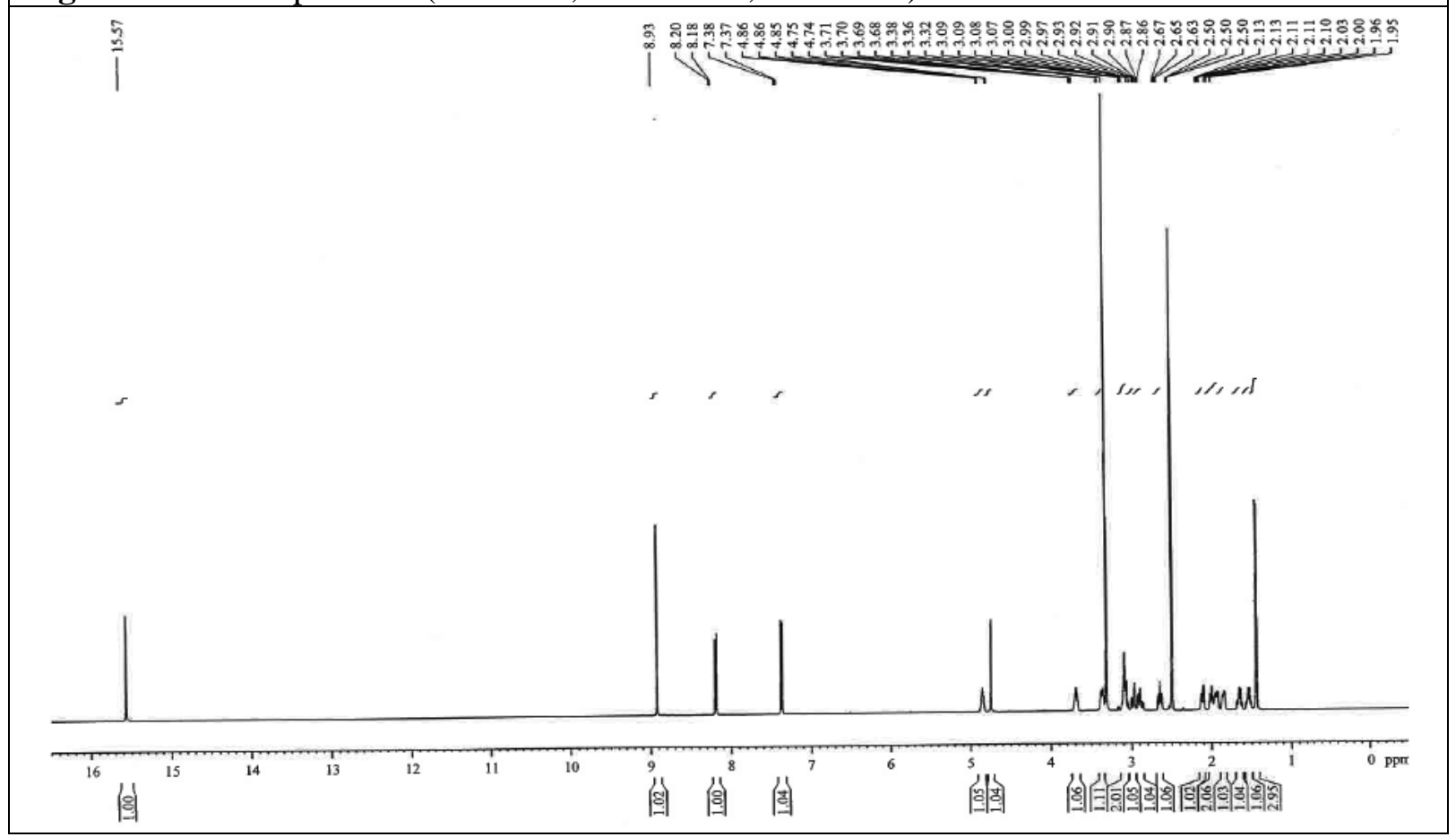

Figure S58: Compound $5\left({ }^{19} \mathrm{~F}\right.$ NMR, DMSO-d6, $\left.376 \mathrm{MHz}\right)$

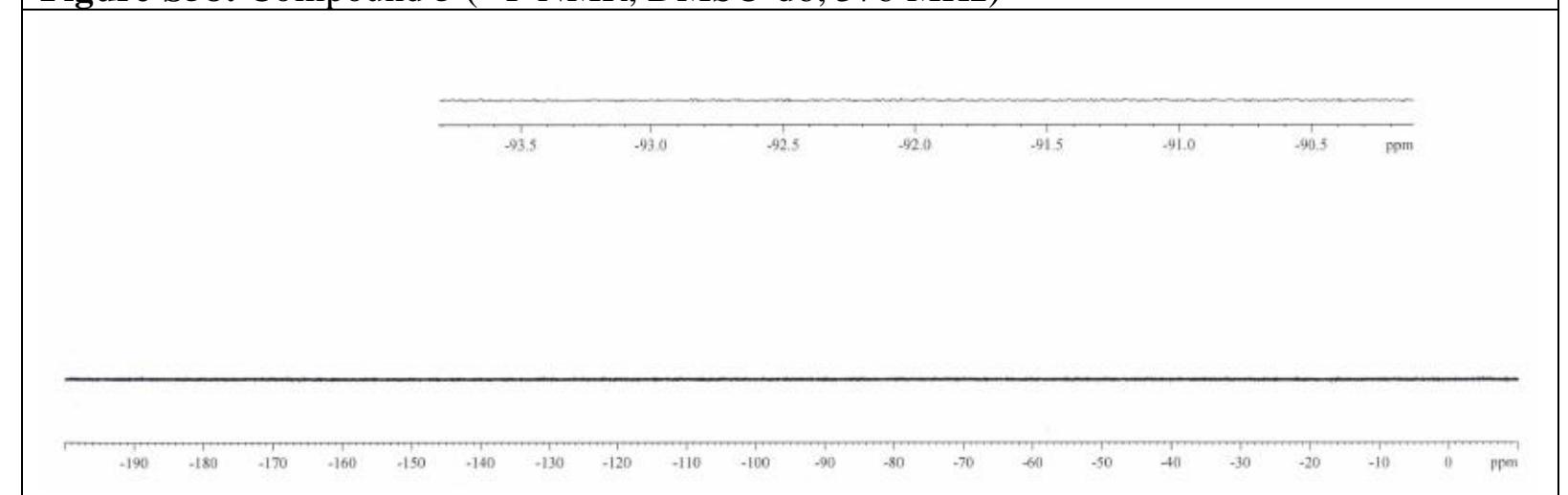


Figure S59: Compound $5\left({ }^{13} \mathrm{C}\right.$ NMR, DMSO-d6, $\left.100 \mathrm{MHz}\right)$

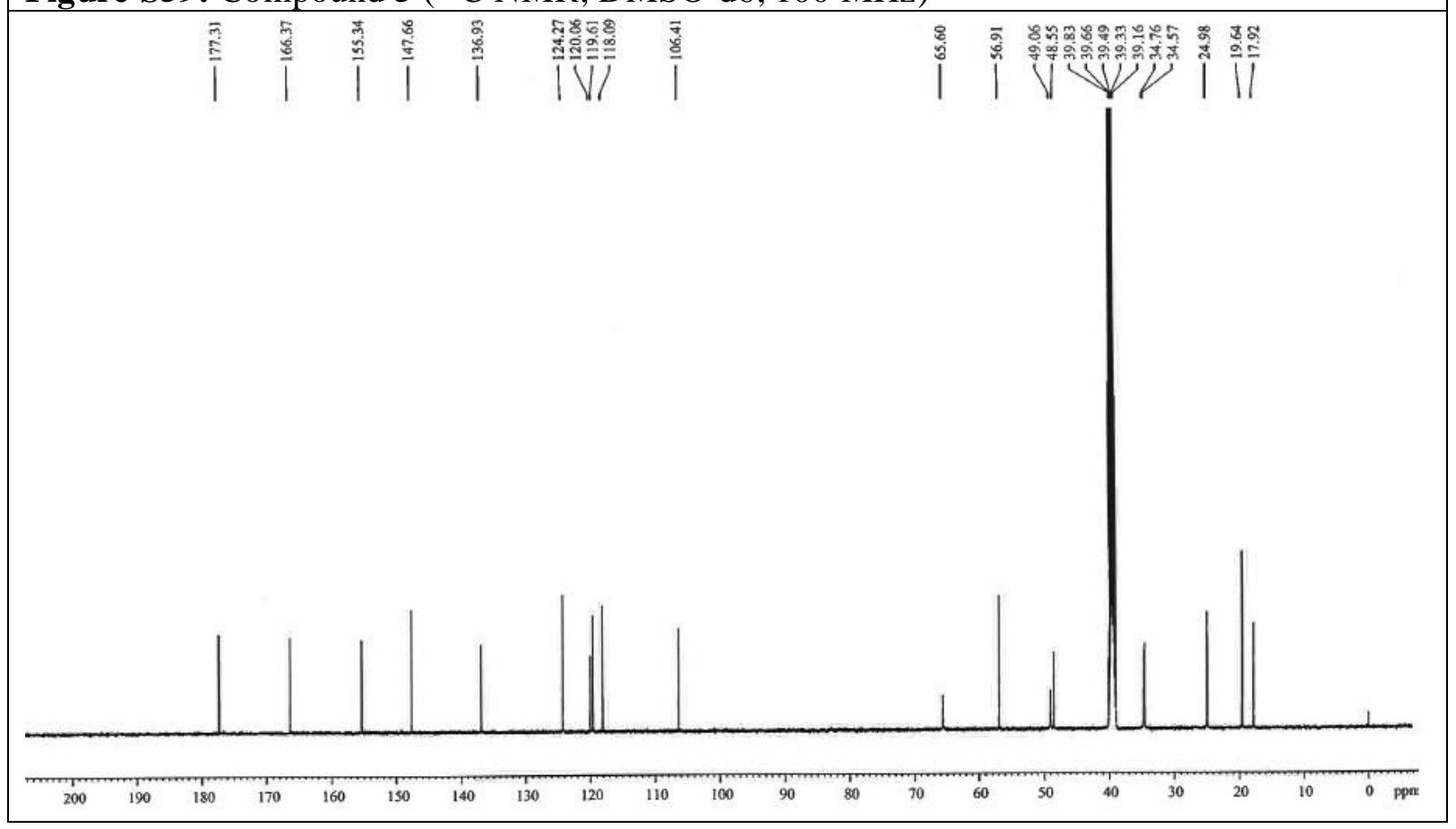

Figure S60: Compound $5\left({ }^{13} \mathrm{C}\right.$ NMR DEPT, DMSO-d6, $\left.100 \mathrm{MHz}\right)$

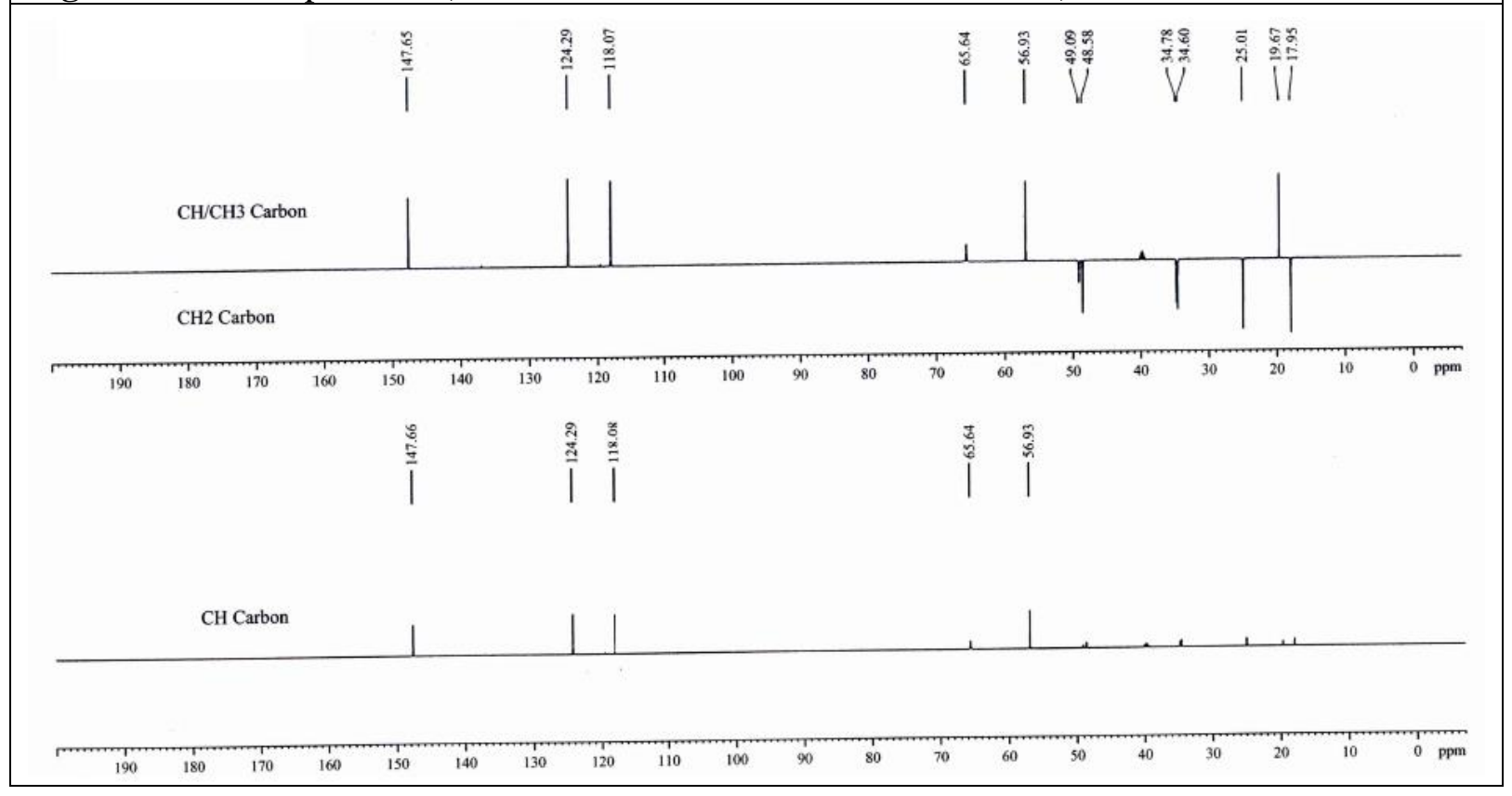




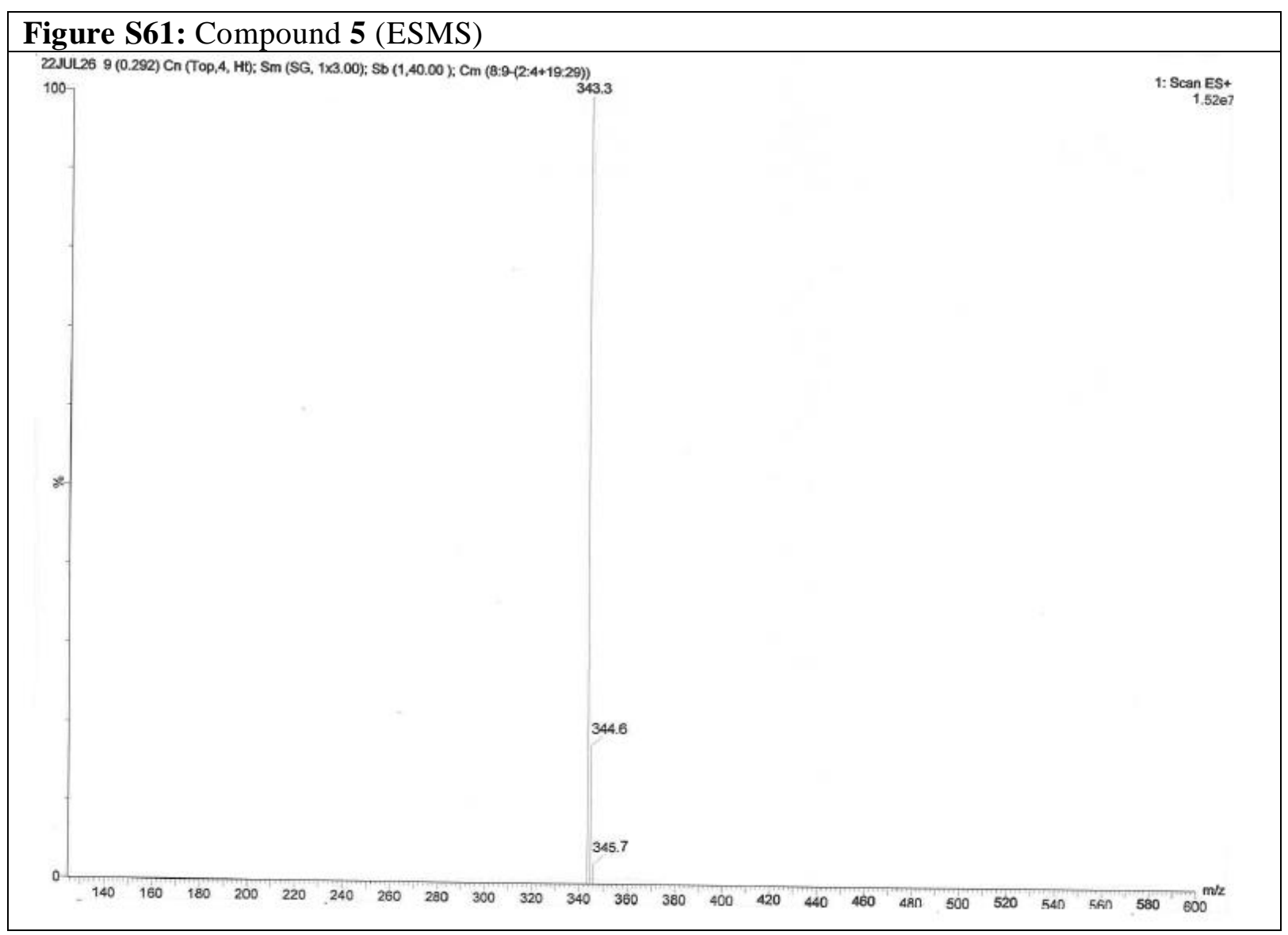

Figure S62: Compound 5 (IR)

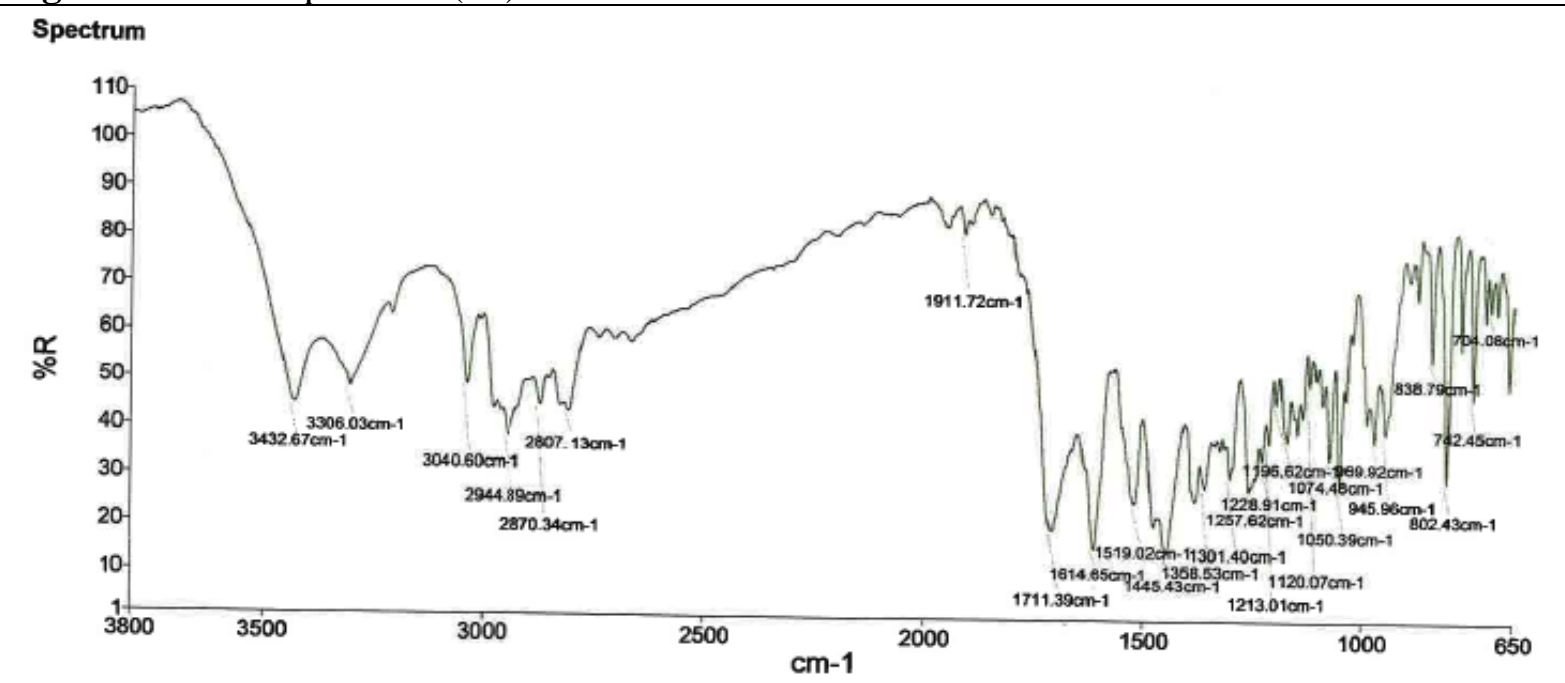




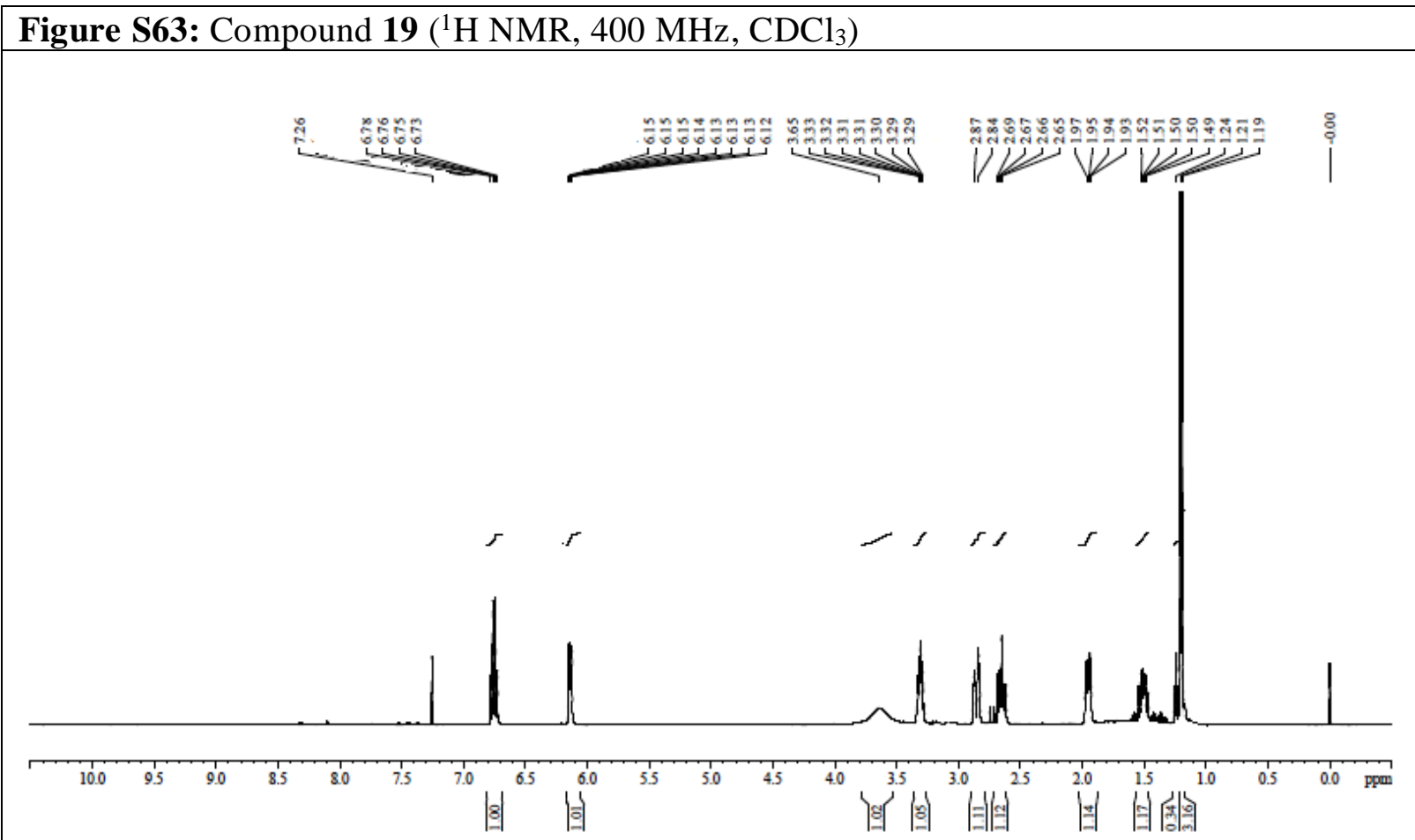

\section{Figure S64: Compound 19 (ESMS)}
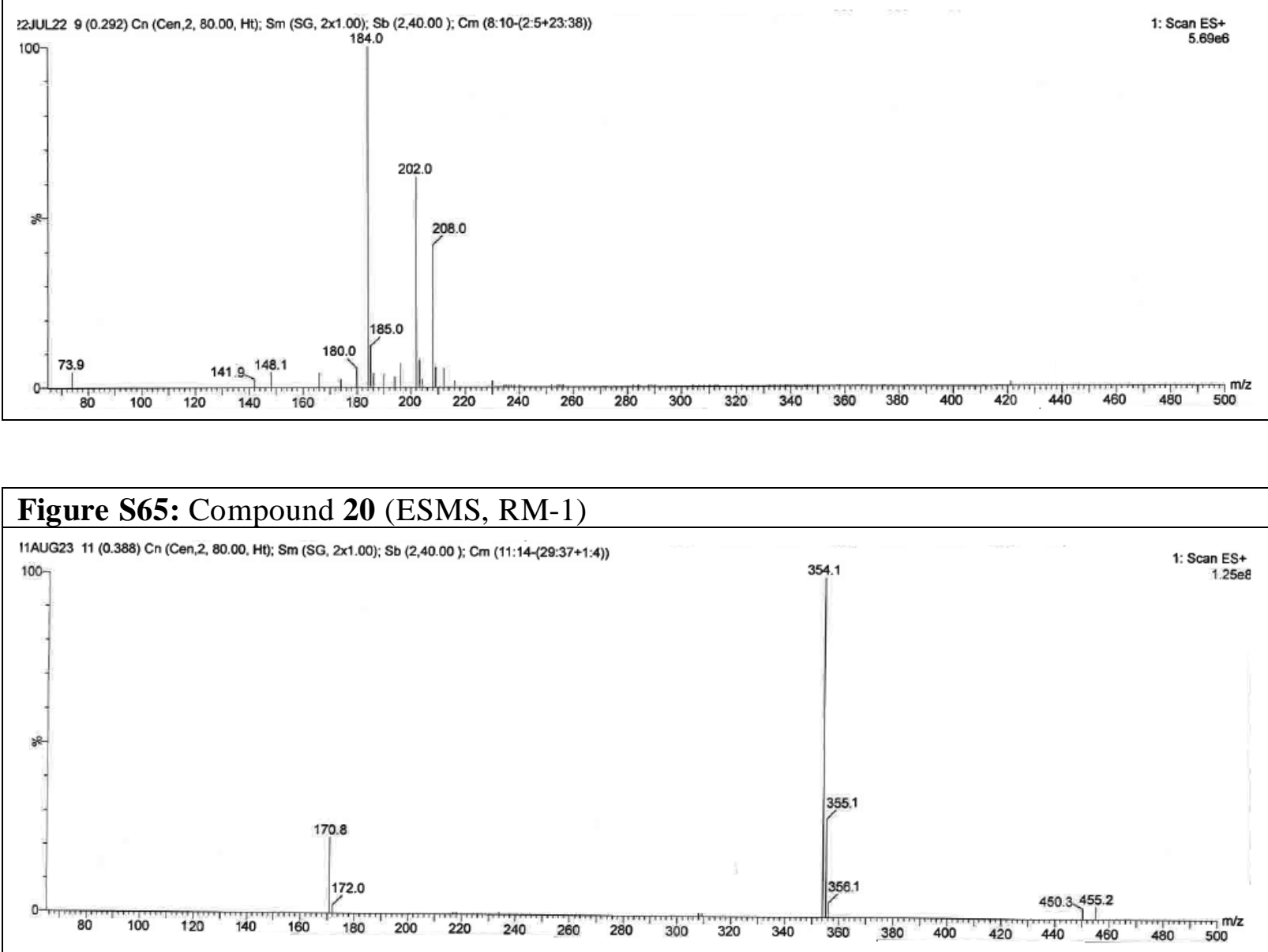


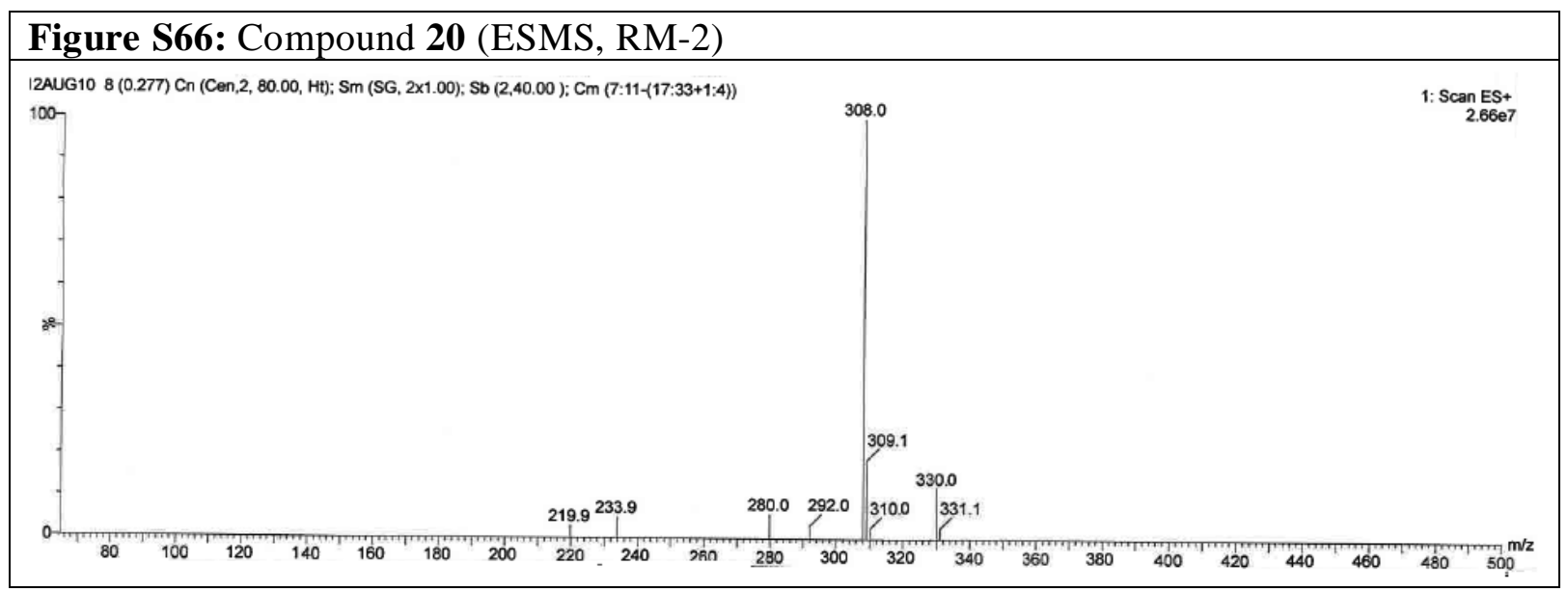

Figure S67: Compound $20\left({ }^{1} \mathrm{H} \mathrm{NMR}, 400 \mathrm{MHz}, \mathrm{CDCl}_{3}\right)$

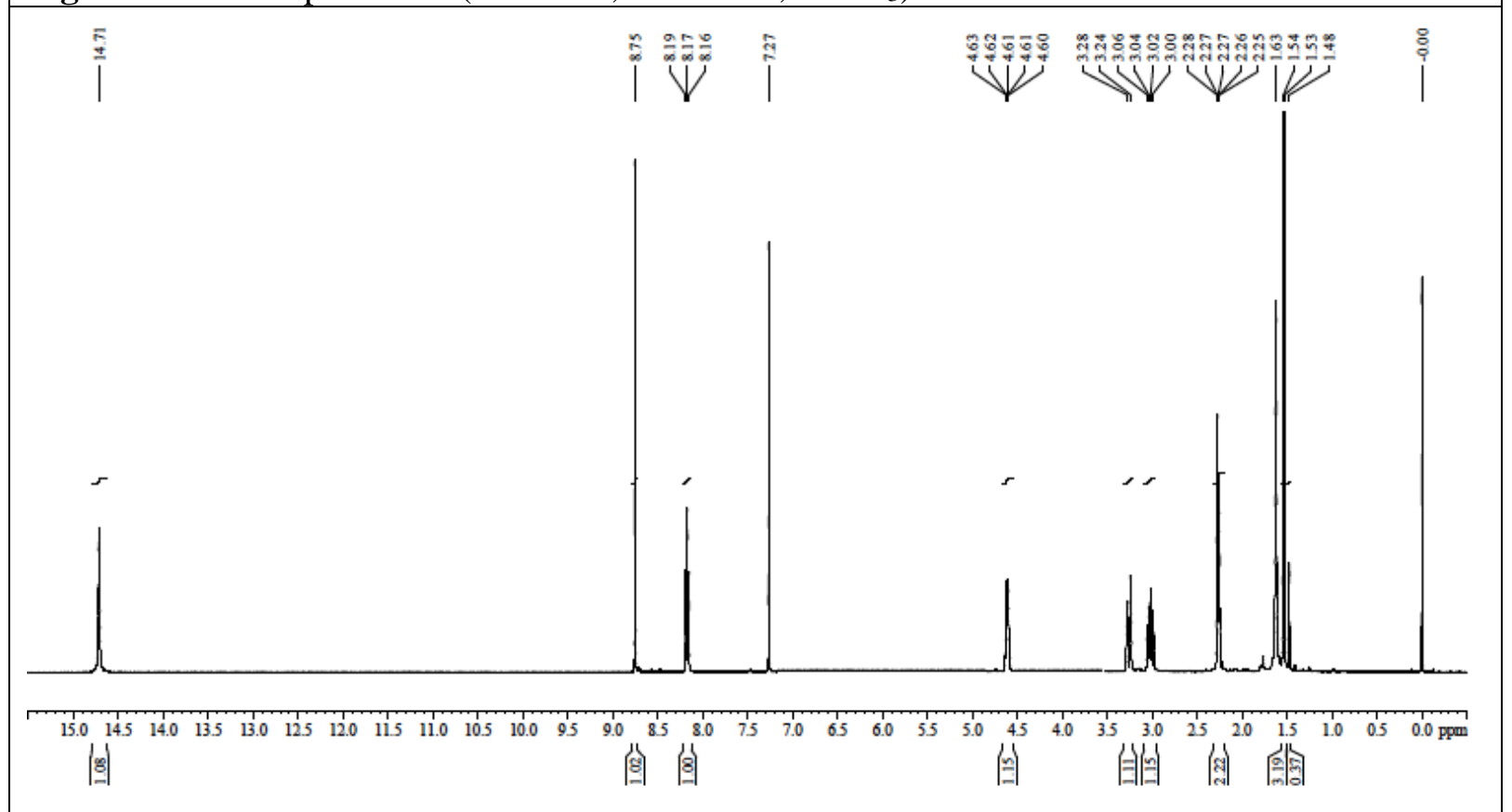




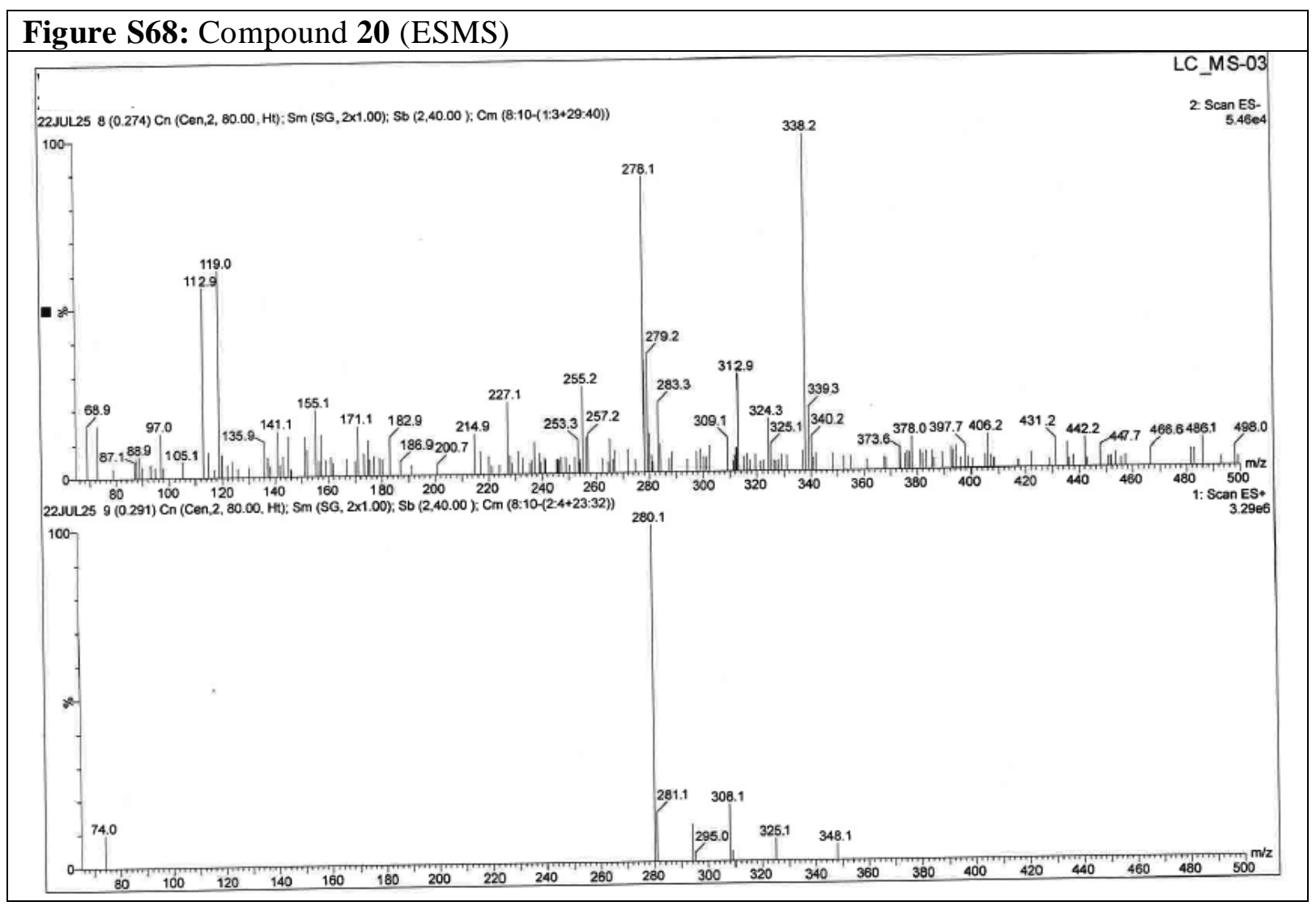

Figure S69: Compound $21\left({ }^{1} \mathrm{H}\right.$ NMR, $\left.400 \mathrm{MHz}, \mathrm{CDCl}_{3}\right)$

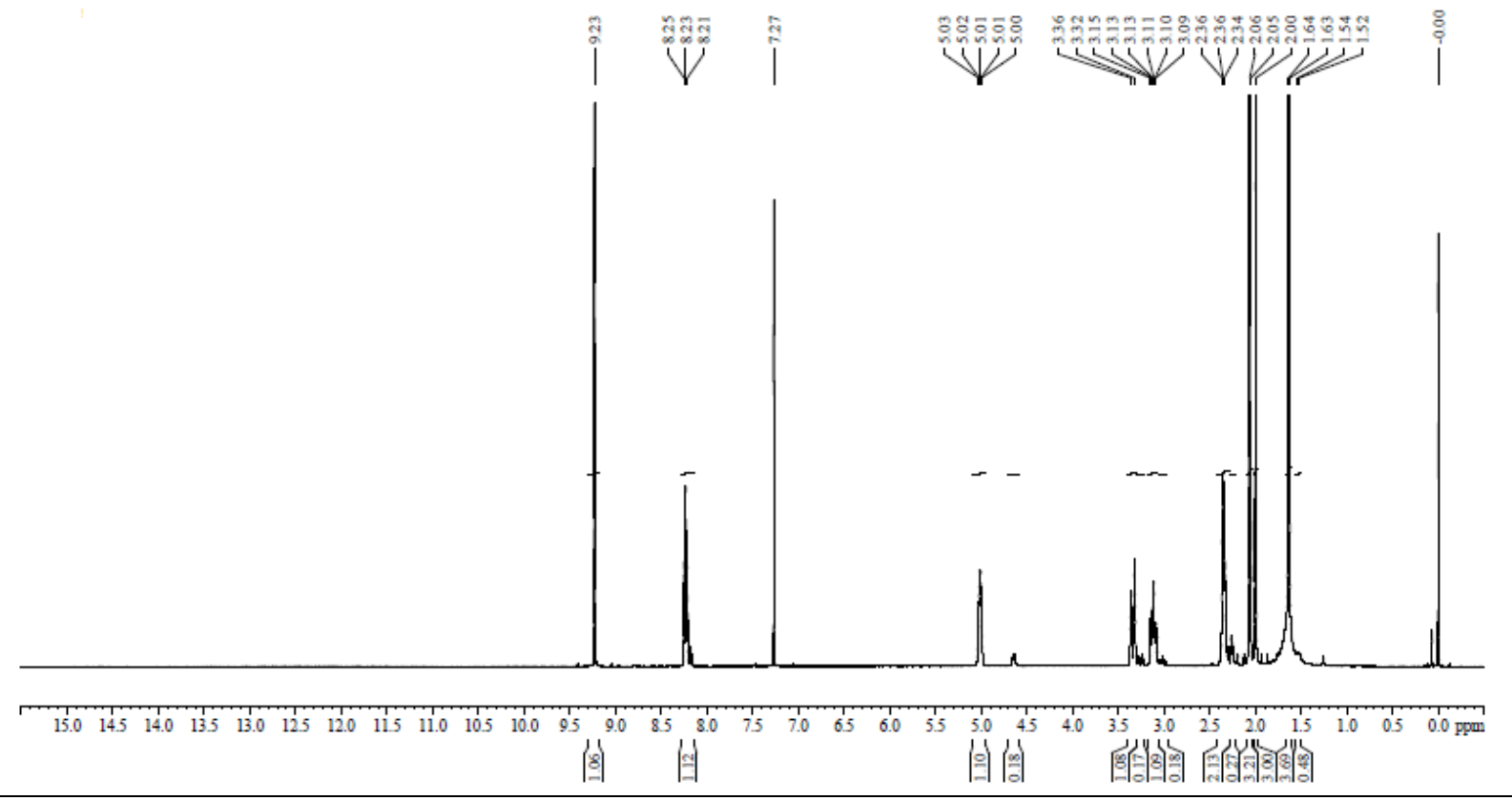




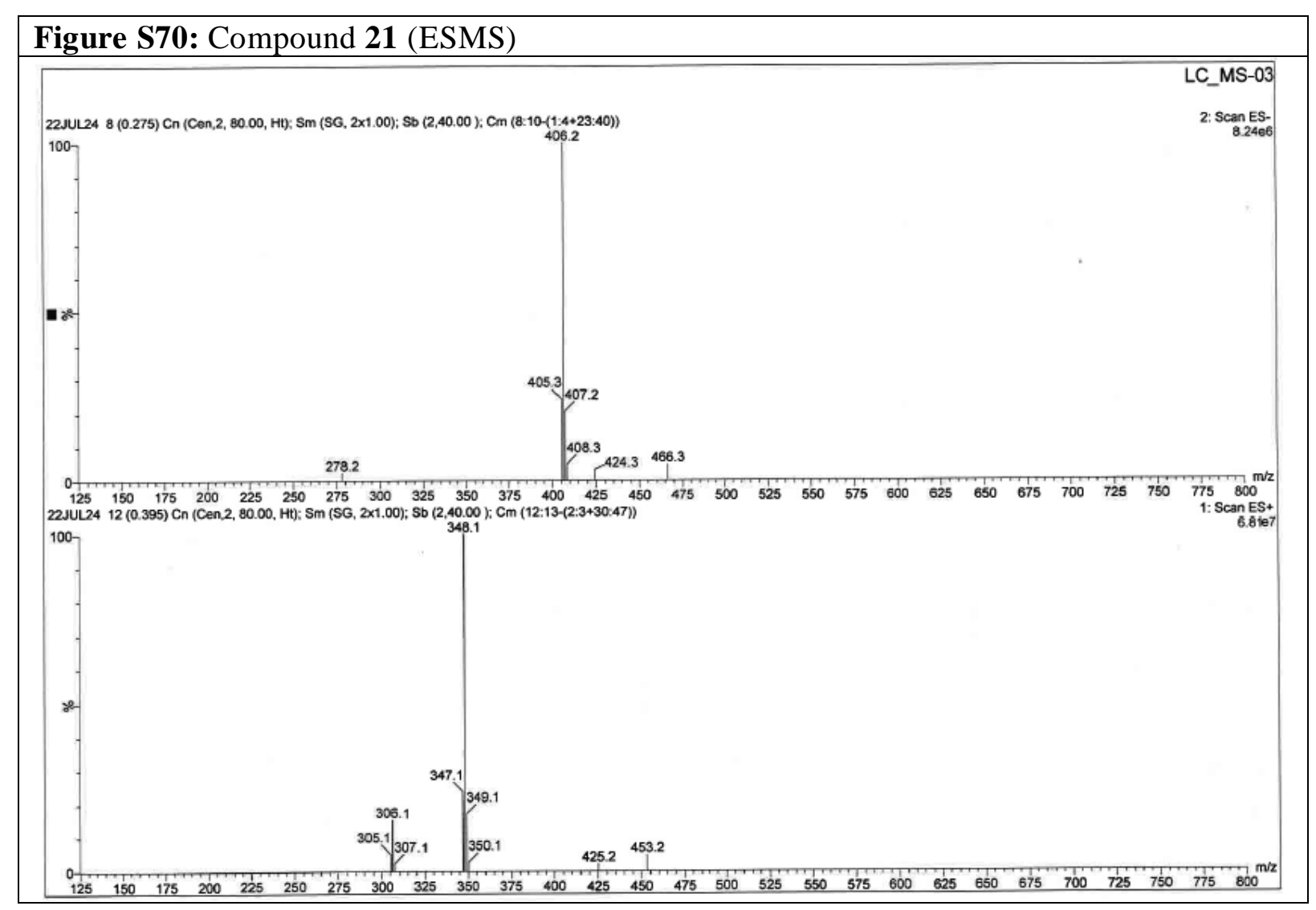

Figure S71: Compound $8\left({ }^{1} \mathrm{H}\right.$ NMR, DMSO-d6, $\left.500 \mathrm{MHz}\right)$

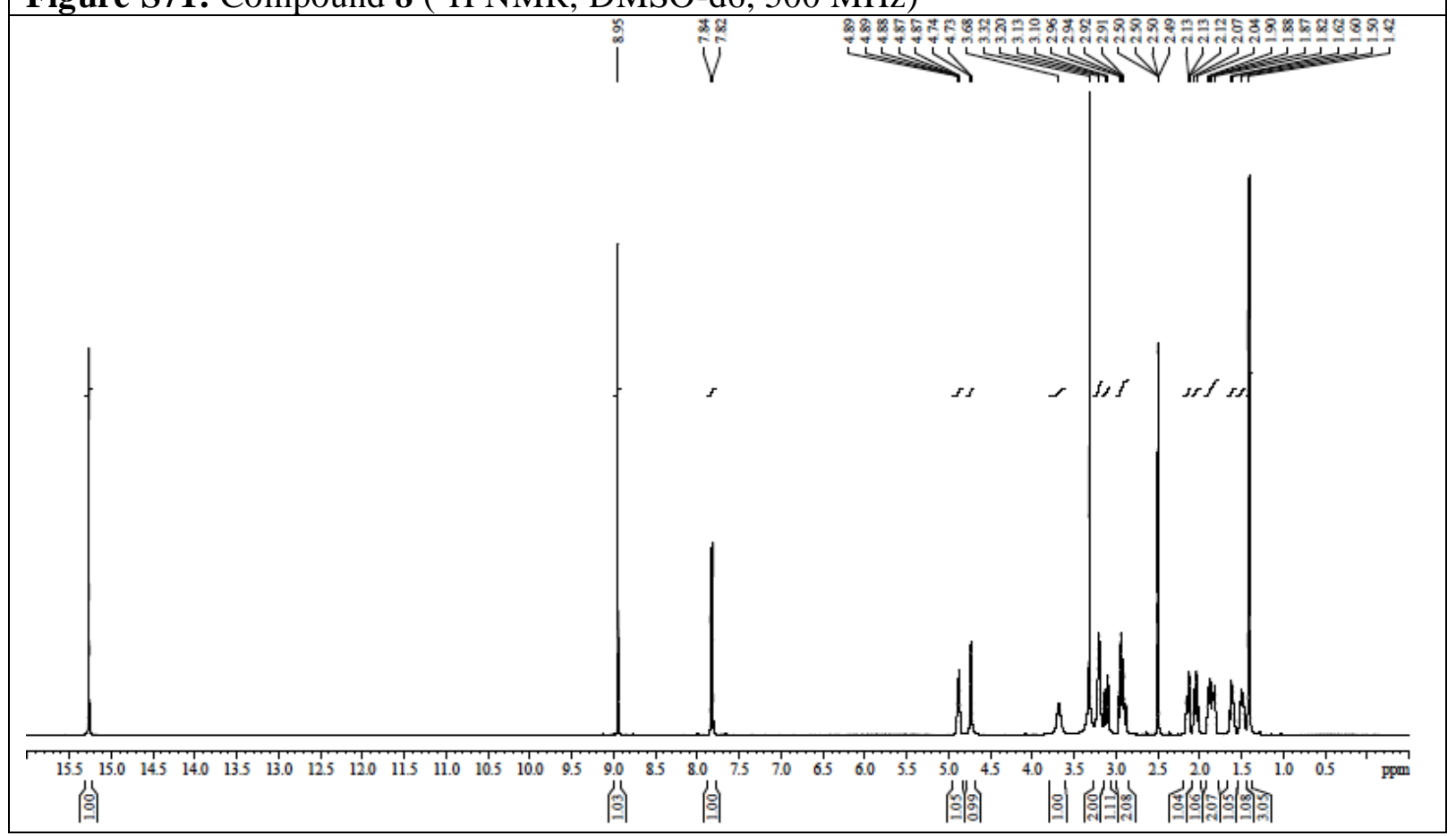


Figure S72: Compound 8 ( ${ }^{19} \mathrm{~F}$ NMR, DMSO-d6, $\left.376 \mathrm{MHz}\right)$

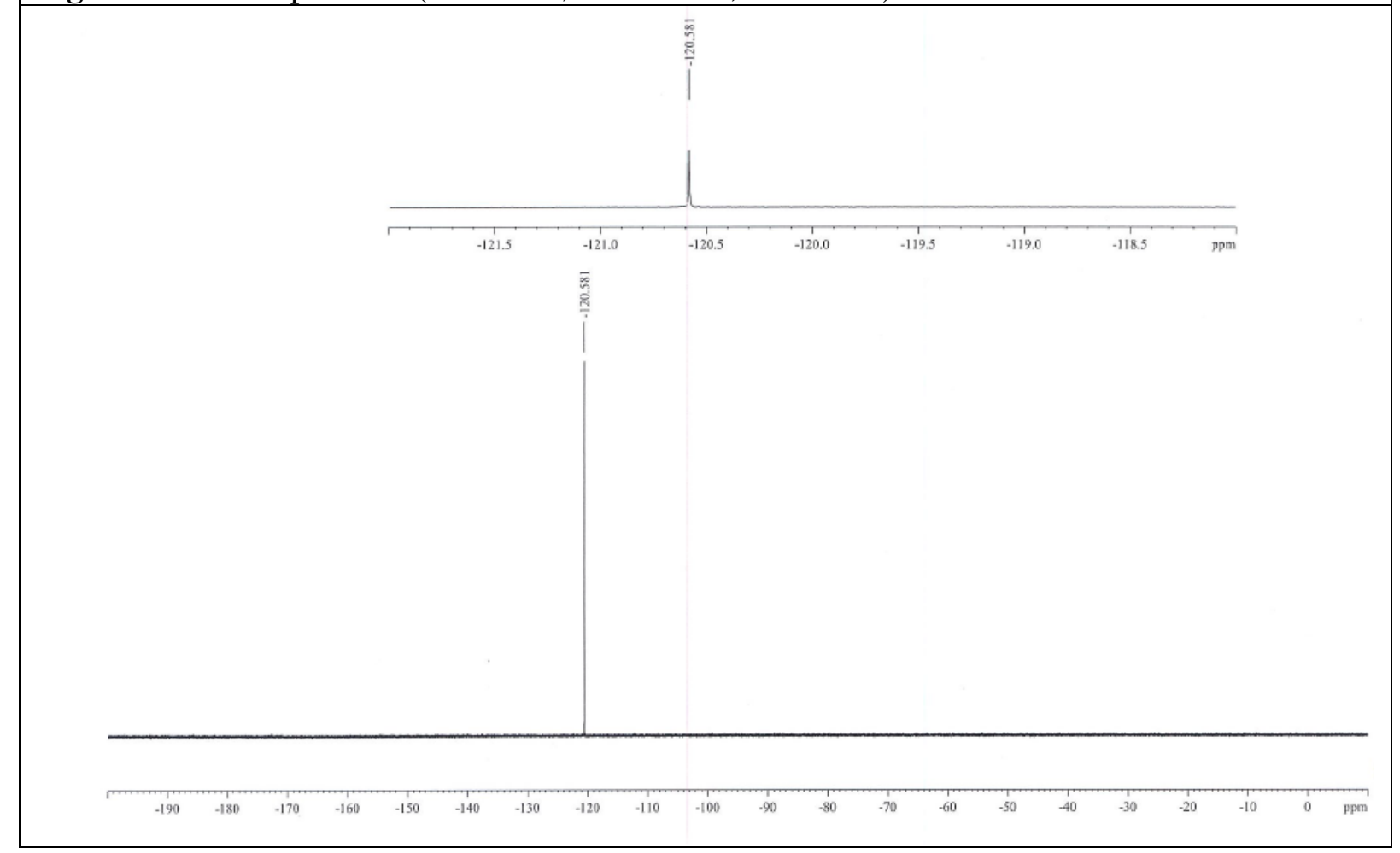

Figure S73: Compound $8\left({ }^{13} \mathrm{C}\right.$ NMR, DMSO-d6, $\left.125 \mathrm{MHz}\right)$

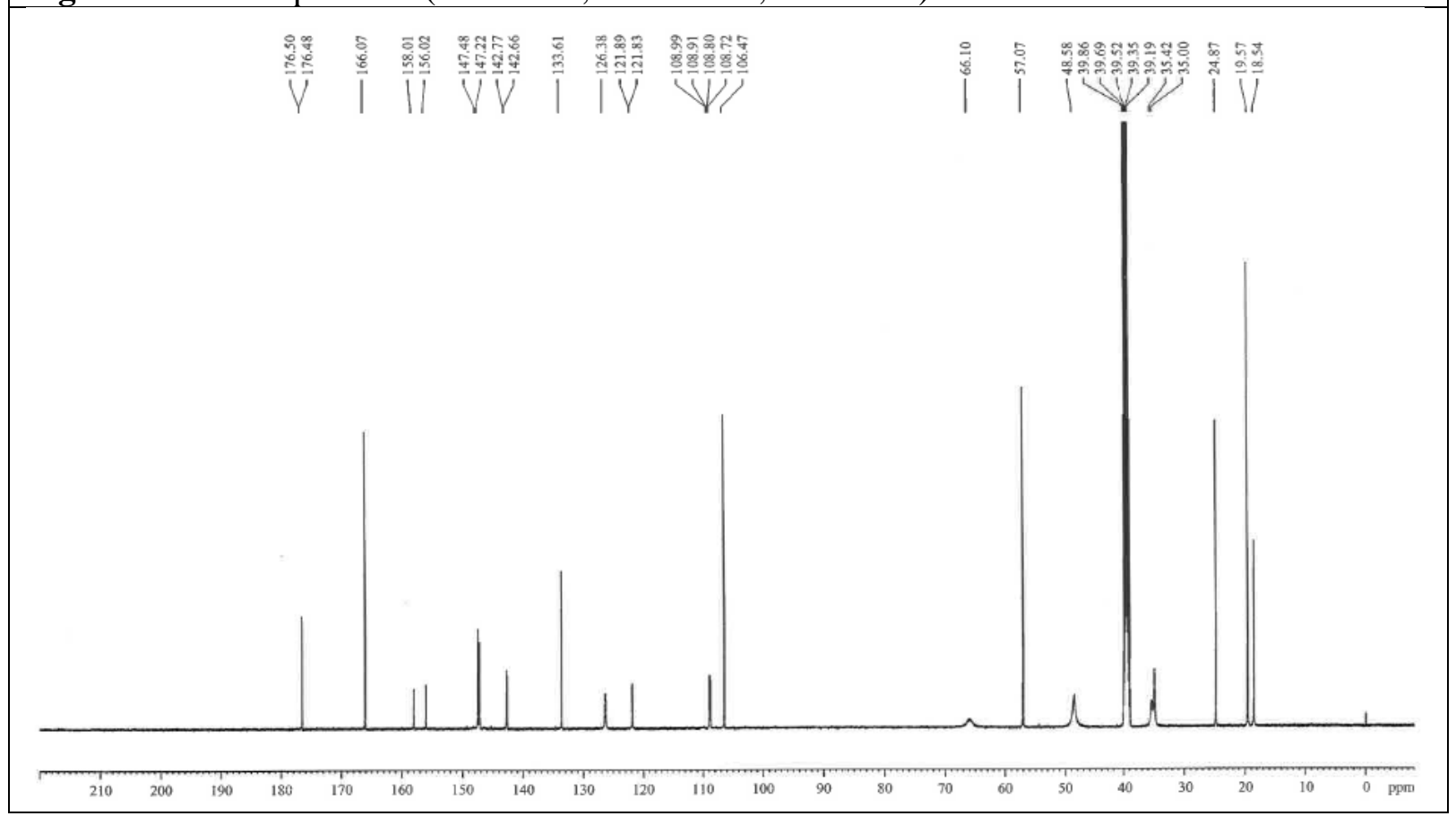



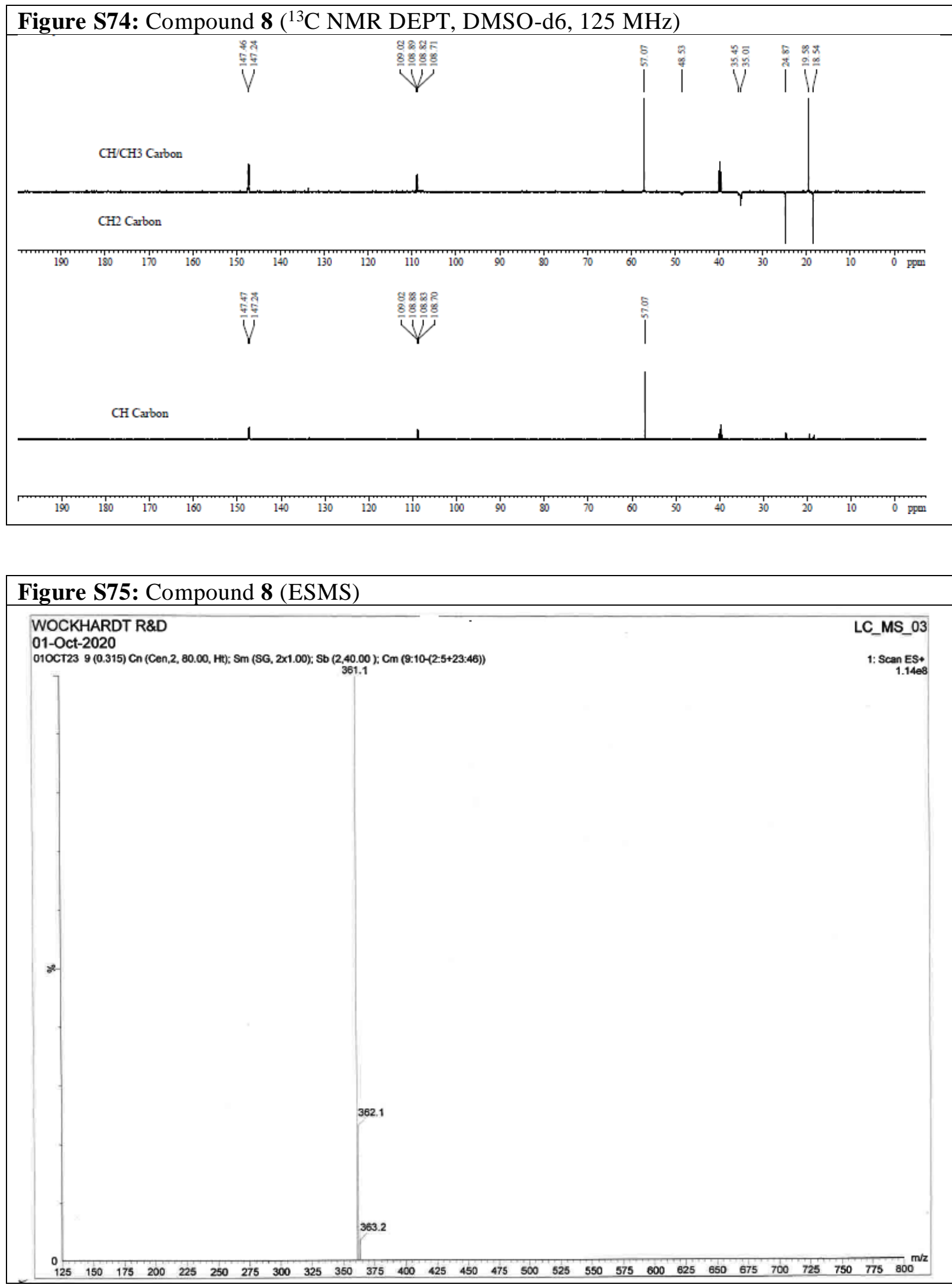

S37 


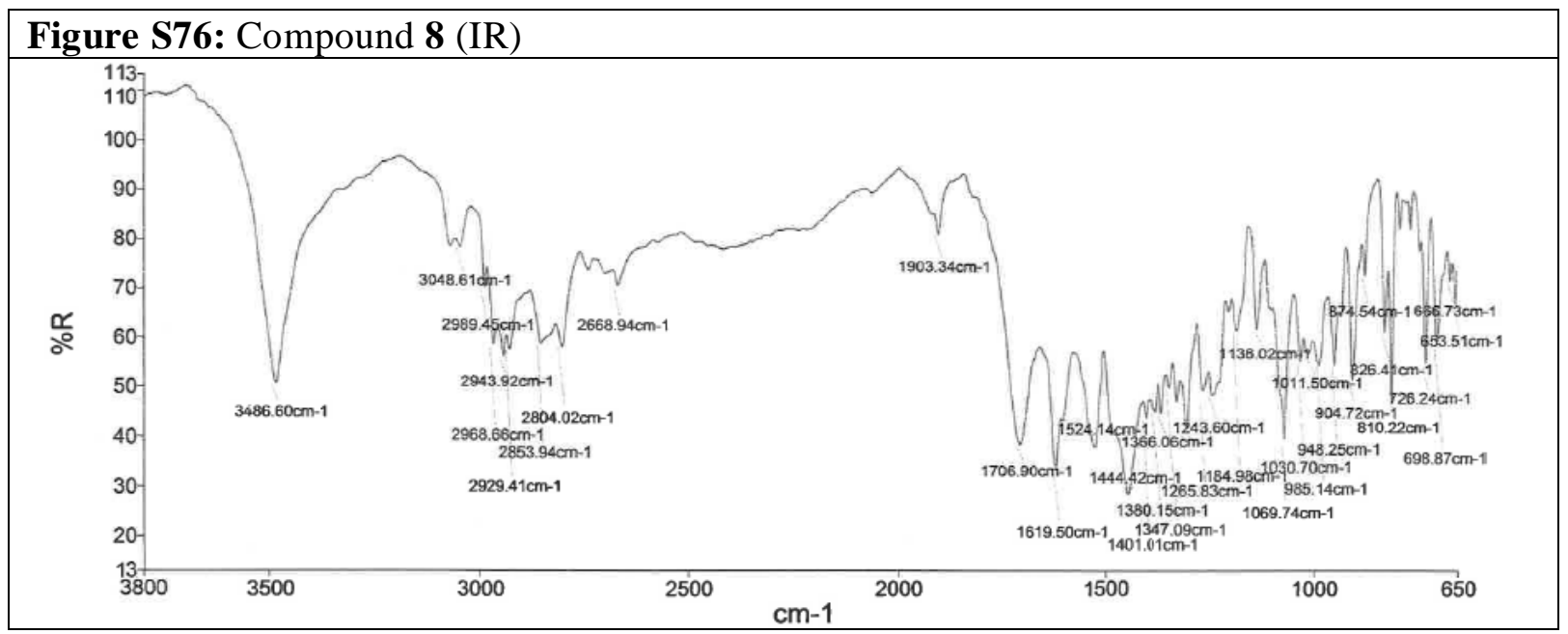




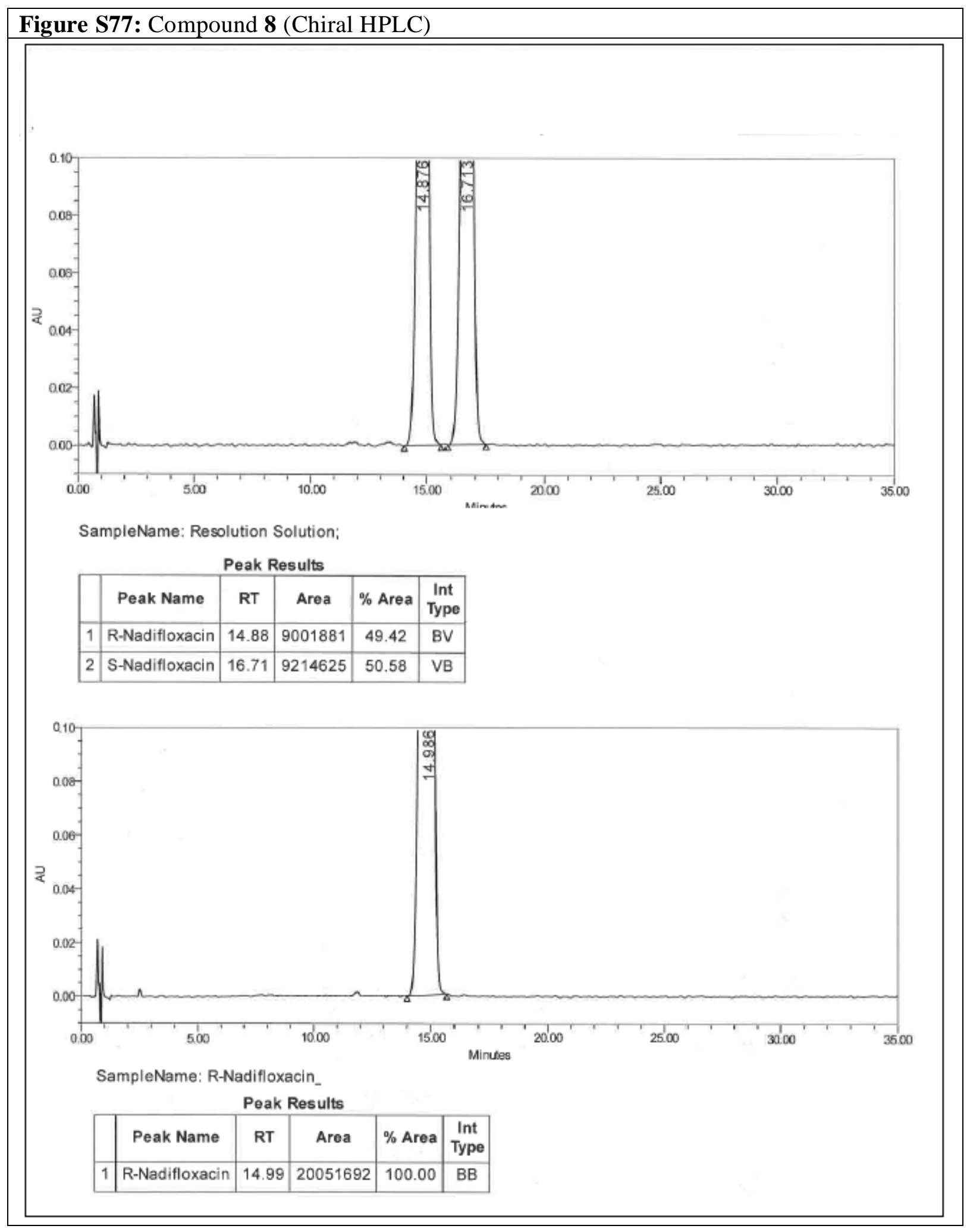

